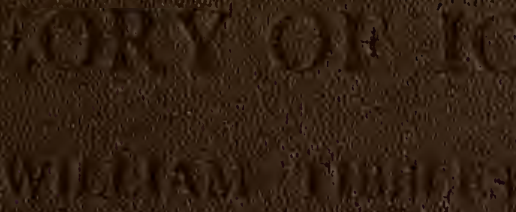



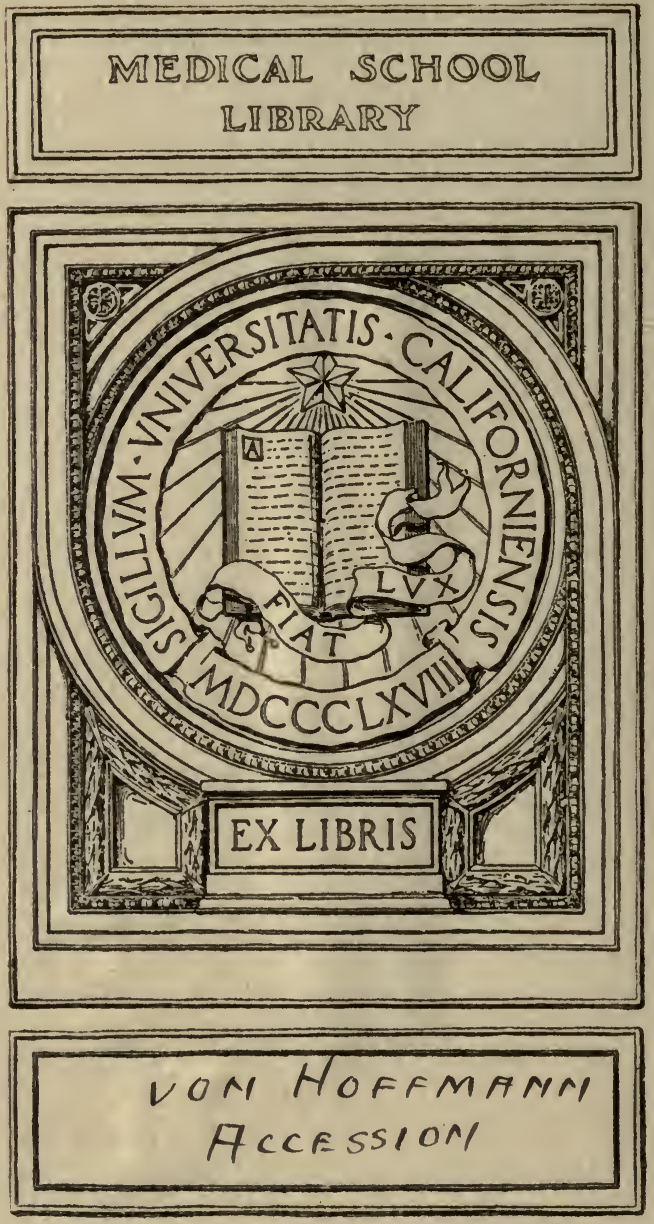

Digitized by the Internet Archive in 2007 with funding from Microsoft Corporation 


\section{THE THEORY OF IONS}





\section{TH E \\ THEORY OF IONS}

A CONSIDERATION OF ITS PLACE

IN BIOLOGY AND THERAPEUTICS

BY

WILLIAM TIBBLES

M.D. (Hon. Causâ) Chicago, LL.D., L.R.C.P.E., M.R.C S., L.S.A., ETC.

AUthor of "FoOd AND HygIENe," ETC.

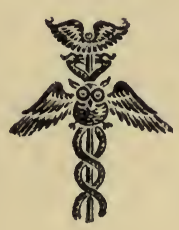

NEW YORK

REBMAN COMPANY

1123 BROADWAY 
Entered at Stationers Hall. All rights reserved by Rebman Limited, London.

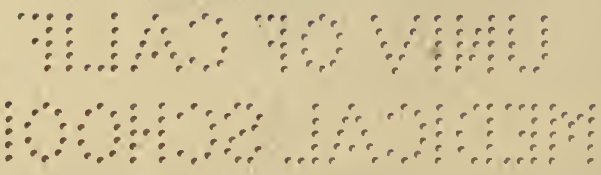




\section{PREFACE}

Time was when the earth was supposed to be fixed and have a flat surface, when the sun revolved around the earth, and the moon as a luminary shed forth its own light. Time was when dryads and fauns dwelt in our forests, when fairies tripped upon the greensward, and mermaids sang in the ocean. Time flies, customs change, and knowledge progresses. We know now that the earth is not flat, the moon is not a resplendent orb, that fairies do not dance upon our lawns. Among the many theories of the earth's origin none was so fiercely fought as the nebular hypothesis, of man's origin none caused such bitter antagonism as the evolutionary theory, but both are now accepted by the majority of men capable of considering their meaning. One of the most popular ideas, one which persists, and which our ever-increasing knowledge has not changed, is that there are only two forms of matter, inorganic and organic or dead and living matter. It is supposed that there is no condition between; a thing is either living or it is dead, it must be one or the other. In the gross this is true. There is a mighty gulf between the living and the dead. But how can we be sure that there is no intermediate condition? The question of Biogenesis 
presents many difficulties, and the way of their solution is not yet apparent. Scientific experience has been unable to establish the fact of Abiogenesis or spontaneous generation to the satisfaction of many minds. Some men of note accept Abiogenesis willingly, and claim to have proved it. Many others have sought evidence which would convince them of its possibility and probability, and would gladly be convinced, but they have failed to get the living from the dead, and have said that the doctrine of Biogenesis, or Life can only come from Life, was victorious all along the line. The passage from the inorganic to the organic world, from the dead to the living, appears to be barred. No change of substance, no chemistry, no transformation of energy, has ever yet endowed any single atom with vitality. Such is the argument. Huxley admitted that the present state of our knowledge furnishes us with no link between the living and the not-living. Bastian's experiments on the Beginning of Life have failed to satisfy the minds of most men. Is there any middle course, any other way between the theories of Biogenesis and Abiogenesis? Energy is capable of transformation from one form to another; potential energy becomes kinetic energy. Evolution is evidenced in many things which are not associated with tho development of animals. It is thought that even matter is not constant, but that developmental changes take place in it. We know that a diamond and a piece of charcoal are both composed of carbon ; the diamond must have undergone much transformation if it ever had the characteristics of charcoal. The transmutation of the metals was a desideratum 
of the Alchemists ; and such transformation is possible, even though it be not in the way they desired. May not the evolution theory be applied to matter which becomes organic ? The touch of life is necessary to give life! Life is apparently not conferred upon raw and inert matter, but upon such compounds as are prepared for it, such substances as have been evolved from the inorganic to the organic. This view is held by the author. Life is to him a gradual growth, a gradual transformation from the dead to the living by evolution, a change of character, step by step, until from the crude elements of the earth, air and water, there is evolved the motile and sentient substances which form our muscles and nerves. Natura nihil facit per saltum.

The point of view here taken necessitates the existence of intermediary substances between the living and the not-living matter-substances possessed of qualities akin to the properties of living matter. The process of ionisation appears to the author to confer some of those properties. The atoms become quick, they are no longer inert, but they are capable of forming molecular combinations ; they have movement, affinity, energy. The living materials of an organism consist of compounds of carbon, hydrogen, oxygen, and nitrogen, which have plasticity and a capacity for living. Such compounds are not drawn directly from inorganic materials, but their growth into carbohydrates, fats, and proteins is a gradual process of chemical development or evolution. The proteins are formed of compounds of amino-acids, which have been evolved from simpler bodies contain- 
ing the necessary elements. In each of these changes the substance becomes more plastic, but more unstable; more nearly living, but more easily decomposed.

In the author's view of the origin of the living from non-living substances the ionisation of materials and formation of meres takes a great part. The formation of ions is observed in many ways. It occurs both in growing and disintegrating tissues. It is observed in dead as well as in living substances. Some of the observed facts have been noted in the following pages, in which an endeavour has been made to place the theory of ions before the reader, and to show that ions occupy an important place in biological processes. The continuous adjustment of the internal relations of materials to the external relations is, in the author's view of the subject, brought about by the ionisation of matter, the transformation of energy, and the definite combination of these heterogeneous changes, both simultaneous and successive; and these "in correspondence with external coexistences and consequences" result in the development of the dead into the living, the inorganic into the organic.

W. T.

NotTinghaM. 


\section{CON'TEN'TS}

SECTION

I.-INTRODUCTION -

PAGE

II.-THE IONS -

III.-Ions IN BIOLOGY - $\quad$ - $\quad$ - 30

IV.-Evolution of ORganic Matter - - 46

V.-INFluence of Ions on the ORganisM - 80

VI.-The INFLUence OF IONS in Oxidation and

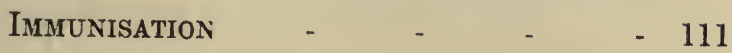





\section{THE THEORY OF IONS}

\section{I.-INTRODUCTION}

MATter is subjected to a variety of chemical and physical changes. Any change which matter undergoes without destroying its integrity is regarded as physical ; but any change which involves a structural alteration of its molecules is chemical. Matter is unstable ; change is constantly occurring. Life is the result of many changes in matter, by which it is organised, becomes motile and sentient.

According to the Atomic theory all matter consists of particles so infinitesimal as to admit of no division. These are the first principles or components of all bodies. They unite atom with atom or in proportion of some simple multiple of atoms to form molecules. Molecules are the smallest particles of matter which exist in a free and independent state ; they consist of two or more atoms of one or more kinds of matter.

Matter and force are changeable but indestructible, and there are two chief theories in respect of them. According to the kinetic theory of substance, the atoms are separate dead particles of matter which dance to and fro, and act upon other particles of 
matter at a distance; they constantly encounter and rebound from one another, some moving with a greater or less speed than others, but all having an average velocity. In these encounters there is no loss of energy so long as the temperature remains the same, for every action is balanced by an equal and contrary reaction; but any change of temperature causes a change of velocity, with increased speed there is increased heat and some of the energy then radiates into space. This vibratory motion of the smallest particles of matter is regarded by many authorities as the fundamental exhibition of the energy stored up in matter ; and attraction, gravity, chemical action, magnetism, electricity, heat and light are regarded as being modifications of the primitive inherent force.

According to the brilliant theory of J. C. Vogt, spare is filled with a fundamental force, and its activity is shown by a tendency to the condensation of matter, which produces infinitesimal centres of attraction. In this theory of condensation, however, the separate particles are credited with sensation and inclination, a will-movement of the simplest form. Centres of disturbance occur which positively exceed the mean tendency to condensation, whence are formed the ponderable matter of bodies ; centres of disturbance also occur which negatively fall below the mean power of condensation, and these form the ether or imponderable matter. Positive or ponderable matter, ever straining to complete the process of condensation, collects an enormous amount of potential energy; negative or imponderable matter (the ether) offers a perpetual 
resistance to the further increase of its strain, and thus gathers the utmost amount of actual or kinetic energy.

According to the former, the kinetic or vibration theory, the atoms of each molecule are regarded as being in a state of motion towards each other, that is in the system of the molecule; but the molecule alone, that is a whole system of atoms, performs independent movements. In the latter or condensation theory the pyknatoms, which correspond to the separate atoms of the vibration theory, are considered to have will-power and to be independent. Whichever theory we incline to, matter consists of atoms which are always associated with energy and are formed into molecules. Each atom or molecule exhibits activity towards other atoms or molecules, the general tendency of which is shown by attraction or gravity, or, according to the theory of Vogt, by condensation.

Atoms are the smallest particles of matter which can take part in a chemical action. In every chemical action there is a rearrangement of the energy as well as the matter. When water is boiled it is transformed into steam, but the molecules are not altered, when the steam is cooled it is water still. If, however, the heat is applied in a greater degree, as by passing electric sparks through the steam, there is a great change in the nature of the material, it does not condense when it is cooled, but the water is disintegrated, and in place of each molecule we have two atoms of hydrogen and one of oxygen. The nascent atoms of $\mathrm{H}$ and $\mathrm{O}$, into which the compound molecule has been 
dissociated, are charged with electricity and move about; such dissociated atoms are called ions. Whenever a change occurs in the constitution of molecules consisting of similar or diverse material such ions constitute the nascent material. They consist of one or more elements, and part at least of the associated energy is in the form of electricity. In a fluid or gas which is undergoing dissociation, the ions or dissociated particles are in a state of rapid movement, and their velocity varies more or less with the temperature and other conditions. Their movements are infinitely complicated owing to the impaction of the ions one against another, some having a velocity greater than others and consequently a higher temperature. There is however a mean velocity and temperature throughout the particles, and a mean free-path; and although the rate of velocity differs for ions of different kinds, ions of the same elements, under the same conditions, travel at the same rate.

Much as we know about matter, our knowledge is finite, and it is certain that our present knowledge is incomplete. The discovery of new elements has shown that there are forms of matter whose existence until recently was unsuspected; that matter exists from which force emanates in such a manner as to show the close relationship of matter and force. Some of these elements shed forth energy so long as they endure, and, inert as they are chemically, their radio-activity is enormous. Much speculation about the nature of radio-activity and much experimental work has not yet solved the mystery of the energy which emanates from such materials 
as radium, uranium and thorium. We know that the emanations are powerful, and that they are not of a simple character, for the "radiations" consist of separable emissions. Among these are what are known as the $a$ rays, which consist of particles of matter sent forth with an enormous velocity, highly charged with positive electricity and capable of producing the ionisation of gases. The particles of matter forming these emanations are considered by physicists to differ from the chemical atom and are called primary atoms, corpuscles, electrons and metabolons. Whatever their nature may be, they appear to be similar to the ions dissociated from matter in many ways, and they are charged with such an amount of energy as to be phosphorescent. When solid radium nitrate is brought near to a suitable screen, the latter is seen to be dotted all over with brilliant specks of light (visible through a lens) due to "the bombardment of the screen by the electrons hurled off by the radium." Among the emanations are $\beta$ rays, which also consist of matter projected with a high velocity, charged with negative electricity, and having properties similar to the cathode rays emitted from a vacuum tube. But the emissions from radio-active bodies do not all consist of matter, for there are $\gamma$ rays which consist of a wave-like motion similar to light, and are probably an exhibition of energy emitted from the material.

Experiments have shown that radio-active bodies owe their activity to atomic changes in the material, that the atoms of such materials are undergoing disintegration, that in their movements such atoms 
have their energy transformed into exhibitions of force of a very high character, and that as the atoms break up some of the matter with its accompanying kinetic energy is thrown off in the form of electrons or metabolons.

It is the "internal energy stored up in the chemical atom " which is set free during radio-activity, and it is of far greater magnitude than that exhibited during chemical changes.

The conception of an atom as a system is contrary to preconceived ideas of the nature of matter; and the idea that atoms may become disintegrated gives a new view to our conception of matter. It has hitherto been considered that an atom was the lowest stage in the composition of an element; but if the knowledge gained from radio-activity proves to be correct, we have exhibited to us the fact that the elements themselves may disintegrate. Although atoms are chemically the lowest stage of matter, yet physically such atoms undergo changes, and such changes indicate that there may be an evolution of matter, that such evolution consists in the transformation of elements of one atomic weight into elements of a different atomic weight and exhibiting different characteristics. The work of Crookes, Wendt, Preyer and others, leads to the assumption that the elements are not the simple homogeneous and unchangeable materials we previously considered them to be ; but that they are compounds of atoms whose systems consist of different numbers and various groups; that the seventy substances known and believed to be elements may be arranged into eight groups, and the arrangement of such 
groups suggests their evolution from one primitive substance, the prothyl.

The evolution of matter also includes the evolution of energy; indeed, the unity of natural forces on the basis of a common origin is accepted by most competent authorities. The transformation of energy into various exhibitions of heat, light, electricity, and other forces has long been known. It is known also that such exhibitions are accompanied by wavelike motions, which vary in their length and rapidity in accordance with the form of energy displayed. Emanations from radio-active bodies, in which the atoms are undergoing disintegration, are called electrons or metabolons, and the total energy associated with such emanations is almost incalculable. When molecules of matter disintegrate there is a similar display of energy from the disintegrated matter; the materials resulting from such disintegration are called ions, the associated energy is chiefly exhibited as heat or electricity, and in many instances the amount is ascertainable. In both instances we have matter disorganised and ready for reorganisation. In both instances we have an exhibition of the very close relationship of matter and force; evidence that matter does not exist without force. In ions and metabolons we see matter in a state intermediate between the inert substance of the earth and the living matter of an organism. As matter may undergo evolution, and the transmutation of common elements into the highly valued and rarer metals may ultimately fulfil the dreams of the alchemists; so, on the other hand, we may find that ions, which are particles of matter far more gross 
than those emitted from radio-active bodies, are so constituted as to be not only the connecting-link between the physically inert particles of a gross material and the living molecules of an organised system, but that they are materials already on their way to form new chemical substances. We may find that ions derived from chemically organic substances, hitherto classed as dead matter, already exhibit some of the characteristics of living matter. It is not considered that ions are actually living substance; but that they are in a condition in which the characteristics of vital matter may readily be developed. We may find that the process of vitalising matter is evolutionary. That life is not conferred upon gross inorganic matter, but the living matter assimilates ions of various kinds, and that ions alone constitute matter which is ready for organisation.

The only chemical compounds which are peculiar to living substance or protoplasm are the group of albuminoids ; and the only element which is capable of building up these albuminoids is carbon. All the albuminoid compounds of carbon have an intricate molecular architecture, and their structure is unstable. These compounds of carbon, nitrogen, hydrogen and oxygen, with sulphur or phosphorus, alone possess the specific fluidity and exhibit the phenomena of movement which are characteristic of living matter. When considered separately the phenomena of movement and reproduction are the only two characteristics of living matter which are peculiar to the compounds of carbon and nitrogen. Growth is in a sense exhibited by other bodies. This 
kind of growth, however, is not due to assimilation, but to chemical affinity by which the atoms of different elements select or have a preference for the atoms of other elements, in the way that one atom of nitrogen is capable of combining with three atoms of chlorine and thereby forming a molecule consisting of four atoms. Side-chains and rings are formed by materials which have a similar affinity; two molecules may be united to form a more complex molecule; by such a process growth may be said to occur. In a similar way change sometimes takes place within a molecule by a rearrangement of the atoms within it; no loss or addition occurs in such an arrangement; the same number of atoms of the same element exist in the molecule, but their position is changed, as when ammonium cyanate becomes converted into urea.

$$
\mathrm{CH}_{4} \mathrm{~N}_{2} \mathrm{O}=\mathrm{CH}_{4} \mathrm{~N}_{2} \mathrm{O} \text { i.e. } \underset{\substack{\text { Ammonium } \\ \text { cyanate }}}{\mathrm{CN} \cdot \mathrm{O} \cdot \mathrm{NH}_{4}} \text { becomes } \mathrm{CO} \cdot \underset{\text { Urea }}{\mathrm{NH}_{2}} \cdot \mathrm{NH}_{2} \text {. }
$$

The Atomic doctrine of Democritus was accepted wholly or in part by most of the philosophers of the Renaissance and their successors until Dalton formulated his law of multiple proportions, which conferred upon the theory of atoms a new significance. This doctrine still stands firm, although there have been notable secessions from it ; without this fundamental conception of matter, a theory of the material universe is almost impossible. The idea of gravitation and the polarity of magnetism has induced in the minds of some ardent thinkers and observers " the conception that atoms and molecules are endowed with attractive and repellent poles, by the play of which 
definite forms of crystallinearchitecture are produced. Thus molecular force becomes structural. It required no great boldness of thought to extend its play into organic nature, and to recognise in molecular force the agency by which both plants and animals are built up."

It may be considered proved that all the energy of this earth is derived from the sun. Growth and reproduction have, however, been supposed to be the production of a special kind of energy called vital force, under the influence of which plants and animals exhibit the special manifestations of a living organism. But within the last generation our ideas of the vital processes have become considerably changed, and few observers at the present day would argue that all the phenomena observed in an organism are the result of a single kind of energy or force. Indeed, from our knowledge of the transformation of energy, the phenomena of vitality may be considered to be due to a combination of forces acting in harmony; and, as we travel backward in our analysis, we arrive at the conclusion that the sun is the physical source of that exhibition of force which we call life. The matter in living organisms is the same as the matter of inorganic substances. No substance in an animal or vegetable differs from the same substance in the earth, air or water. Every portion of an organic being can be reduced to purely inorganic matter. Is the force which is required to form organic substance in an animal body different from the force or forces required to form the same substances outside the organism? True it is that certain protein sub- 
stances still baffle the skill of the synthetic chemist; but it is the compounding of forces belonging equally to the organic and the inorganic world which brings about the evidences of vitality. True it is that the question of identity remains unsolved. The body wastes and it is renewed; but the identity remains the same; and, with a Master in Science who gave much time to the consideration of this subject, we may say, "The matter of any period may be all changed, while consciousness exhibits no solution of continuity. Like changing sentinels the oxygen, hydrogen, and carbon that depart seem to whisper their secret to their comrades that arrive, and thus, while the Non-Ego shifts, the Ego remains the same. Constancy of form in the grouping of the molecules, and not constancy of the molecules themselves, is the correlative of this constancy of perception. Life is a wave which in no two consecutive moments of its existence is composed of the same particles." 


\section{II.-THE IONS}

The dissociation of combined elements, and the formation of ions or unattached atoms, and meres* of substances, having an electrical reaction, is brought about by various influences, the best known of which are heat, light, chemical action, electricity, Röntgen and other rays. Almost all dilute solutions contain ions derived from the substance in the solution; and gases contain some of their elements in the same condition. The dissociation of combined elements under various circumstances has long been known to scientists; and, in recent years, the theory of ions has been used to explain various phenomena, such as electrolysis. When a strip of pure zinc and a strip of platinum are dipped in acidulated water neither metal will be affected so long as they are unconnected. But if they are connected by a wire, a chemical action takes place between the zinc and acid (e.g. $\mathrm{H}_{2} \mathrm{SO}_{4}$ ), oxygen and hydrogen are disengaged and an electric current passes along the wire. The gases are disengaged at the electrodes, but not indiscriminately. $\dagger$ The dissociated gases

* Mërus, a, um: real, pure, genuine; alone, nothing else, without mixture; that with which nothing is united.

+ It is well known that this is not a simple and direct chemical action, but is a double action, which may be represented by the following equations :

$2 \mathrm{H}_{2} \mathrm{SO}_{4}=2 \mathrm{H}_{2}+2 \mathrm{SO}_{4}$ and $2 \mathrm{SO}_{4}+2 \mathrm{H}_{2} \mathrm{O}=2 \mathrm{H}_{2} \mathrm{SO}_{4}+\mathrm{O}_{2}$. 
are charged with electricity and are called ions; they travel through the water to the electrodes where they discharge their electricity ; the hydrogen conveying positive electricity to the cathode, and the oxygen conveying negative electricity to the anode, where they escape. Many substances may be dissociated into ions by electricity, e.g. hydrochloric acid, ammonia, carbonic acid, acetylene, and ozone is formed from oxygen of the air, ions being formed in each case.

All substances cannot be ionised, nor are all substances conductors of electricity. If the two poles of a battery are connected by a bar of graphite the current readily passes ; but if they are connected by sulphur no current will pass. Conductors of electricity are of two kinds; those which become heated, including all metals and some non-metals, and those which undergo a chemical change during conduction. The latter include a very large number of compound substances in a liquid state or in some solvent. Pure water is a non-conductor, and when the poles of a battery are inserted into it no current passes; but if some hydrochloric or other acid is added the solution becomes a conductor and a current passes ; at the same time hydrogen and chlorine are disengaged at the cathode and anode respectively, i.e. the acid becomes dissociated into ions charged with electricity which they convey to the electrodes -they are electrolysed and the liquid is called an electrolyte. It is the substance in the liquid which is really the electrolyte and which becomes ionised; it is usually understood to be in solution in water. Liquids are classified as follows :* Non-electrolytes

* Newth's "Inorganic Chemistry," tenth edition, p. 97. 
are liquids which do not conduct electricity or only do so with difficulty because they do not become ionised; e.g. pure water, aqueous solutions of alcohol or sugar, benzene, and a large number of organic compounds which do not fall under the head of salts, acids or bases.. Electrolytes are readily ionised and good conductors of electricity, e.g. aqueous solution of chloride of sodium or of strong acids, strong bases and nearly all salts. There are materials which stand between the two called Halfelectrolytes, including weak acids, e.g. tartaric, acetic and oxalic acids; the weak bases, e.g. ammonium hydroxide, and hydroxides of metals other than alkaline earths.

Dissociation takes place in chemicals having (a) a homogeneous system, like ammonium chloride, ammonium sulphide, mercurous chloride, phosphorous pentachloride or amylene chloride; and (b) in systems that are not homogeneous, as the hydrated salts, the carbonates of lime, magnesia and silver, the oxides of mercury and iridium, compounds of the metallic oxides and metallic hydrides.* Ions are produced in many ways, both in liquids and gases. When a gas is traversed by uranium rays ions are produced which are charged with electricity, and the same effect follows the action of cathode rays. $\dagger$ The ionisation is independent of the composition of the gas, and varies directly as the pressure and density. $t$

Some salts are more or less decomposed by water,

* Watts" "Dict. Chem." : article, "Dissociation."

† McLennan: Proc. Roy. Soc., 1900, lxvi., 375.

$\ddagger$ Ibid. 
ions being formed. Salts of a strong acid and a weak base are so decomposed, and the solution contains a free acid and a residual salt, which may be a basic or a normal salt. Mercuric sulphate is so decomposed.*

Dissociation takes place in colloidal solutions just as it does in watery solutions. Levi has shown that potassium iodide is dissociated to the same extent in solution of gelatine, agar-agar or silicic acid, as in aqueous solution. Dissociation also occurs in the salts of the blood, lymph, serum, and other animal or vegetable fluids. Dissociation is produced by heat and in some bodies by a low temperature. Nitrogen tetroxide may become completely dissociated at $27^{\circ} \mathrm{C}$. Regnault showed by experiment that some bodies which are decomposed by heat into one or more solid bodies and a gas, give off the gas more freely when in the presence of a foreign gas than when exposed to the products of their own decomposition. Chalk loses its $\mathrm{CO}_{2}$ more freely in air than in an atmosphere of $\mathrm{CO}_{2}$; and hydrated salts give off their water of hydration more freely in an atmosphere of dry air than in one of watery vapour. Similarly, venous blood gives up $\mathrm{CO}_{2}$ more freely in pure air than in an atmosphere containing much $\mathrm{CO}_{2}$, according to the laws of diffusion.

The formation of ions depends somewhat upon the constitution of the molecules, for many substances which consist mainly of polymerised molecules do not readily become ionised. In order that a substance shall possess electrolytic conductivity its

* Guinchant : Bull. de Soc. Chim., 1896, iii., 555.

$\dagger$ Gazetta, 1900, ii., 64-70. 
chemical constitution must be such that ions can be formed from it, its dielectric constant must be high, and it should not contain a large proportion of polymerised molecules.* It is also extremely probable that the degree of dissociation depends considerably upon the capacity of the ions to unite with molecules of the solvent. $\dagger$ Many substances with large dielectric constants, e.g. water, formic acid, methyl alcohol and ethylalcohol, are bad conductors of electricity because they consist largely of polymerised molecules. $\ddagger$ Other substances with large dielectric constants and small polymerisation are unsuitably constituted for electrolytic conductivity, thus : nitrobenzine, ethyl nitrate, and benzonitrate contain the groups $\mathrm{NO}_{2}, \mathrm{NO}_{3}$ and $\mathrm{CN}$, which readily form ions, but they also contain the groups $\mathrm{C}_{6} \mathrm{H}_{5}$ and $\mathrm{C}_{2} \mathrm{H}_{5}$, which have never been observed in ions.

The explanation of dissociation or the formation of ions is not yet complete. Pflaunder and Lemoine explained it by the theory of the Action of Mass, Thompson by the Vortex Atom hypothesis, and others explain it by the kinetic theory of gases and the principles of thermo-dynamics; but no explanation up to the present time has been found satisfactory to all parties.

The ions are anodic or cathodic, that is they are charged with positive or negative electricity. But their electrical reaction may change or is convertible, and the conversion is demonstrable by experiment.\|

* Abegg : Zeit. für Electro-Chem., 1899, v., 353.

$\dagger$ Ibid. $\quad$ \$ Ibid.

|| Küster : Zeit. für Electro-Chem., 1897, iv., 105. 
The ions which convey positive electricity or are positively electrified travel to the cathode or negative electrode during electrolysis, and are cations or positive ions; they include hydrogen and the metals. Ions which convey negative electricity travel to the anode or positive electrode, and are called anions; they include most of the metalloids and non-metals. Cations consist for the most part of a single element, e.g. $\mathrm{Na}, \mathrm{H}, \mathrm{K}, \mathrm{Li}, \mathrm{Pb}, \mathrm{Cu}, \mathrm{Fe}$ or $\mathrm{Bi}$. But many anions are compounds of two or more elements, e.g. $\mathrm{OH}, \mathrm{NO}_{3}, \mathrm{ClO}_{3}, \mathrm{C}_{2} \mathrm{H}_{3} \mathrm{O}_{2}$, $\mathrm{SO}_{3}, \mathrm{C}_{2} \mathrm{O}_{4}, \mathrm{PO}_{4}$.

All ions do not convey an equal amount of electricity, but their capacity varies with the valency of the atoms. A unit has been established whereby this capacity may be measured; the ions of 1 gramme-molecule of hydrogen will convey an amount of electricity which is equivalent to 96,550 coulombs; and the ions of all monovalent elements carry an equal amount of electricity, the ions of divalent elements twice that amount, and so on. The molecular conductivity of any liquid, however, depends upon the degree of dissociation, for it is the ions alone in any solution which convey electricity, the undissociated molecules being inoperative. The molecular conductivity is increased up to a certain point by dilution of the liquid, which is due partly to the greater rapidity of migration of the ions and partly to the formation of a greater number of ions in the solution. The more a fluid is diluted so much the greater is the ionisation and rate of molecular conductivity up to a certain point; when this point is reached there is no further increase in 
the ionic velocity or conductivity, for it has been shown that henceforth the ionic velocity decreases with the dilution.* Even when the conditions are the same, ions travel at different rates; but given the same concentration and electrical conditions all ions of one kind travel with a constant velocity. $\uparrow$ Thus, the cation $\mathrm{H}^{\cdot}$ travels with a velocity which is twice as great as the anion $\mathrm{OH}^{\prime}$, and five times as great as that of the cation $\mathrm{K}$. The ionic velocity is determined by conductivity experiments, and it is found to vary with the condition; by this method the velocity of ions produced by $\mathrm{X}$ rays in air, $\mathrm{O}$, $\mathrm{CO}_{2}$ and $\mathrm{H}$, has been determined. $\ddagger$ It is even influenced by the solvent, e.g. the ionic velocity of $\mathrm{Cl}^{\prime}$ in aqueous solution and in glycerol solution was found by Cattaneo $\S$ to be for sodium chloride 0.658 and 0.645 respectively, and for ammonium chloride 0.510 and 0.568 respectively. Moisture also diminishes the velocity of ions, especially negative ions; and, in general, the velocity of negative ions is greater than that of positive ions.\|

The degree of dissociation or ionisation of salts in solution is usually determined by conductivity experiments at a temperature of 18 to $25^{\circ}$. The temperature has considerable influence upon the formation of ions. Dampier and Williams 9 have shown that the degree of dissociation at 18 to $25^{\circ}$ is not comparable with that at freezing-point. They also showed that the degree of dissociation at $0^{\circ}$

* Hans Jahn : Zeit. für Physik.-Chem., 1900, xxxv., 1-10.

† Hittorf : cf. Newth's "Inorganic Chemistry."

† Zeleny: Proc. Roy. Soc., 1900, lxvi., 238-241.

$\S$ Real Acad.-Linc., 1896, v. and vi.

II Zeleny: loc. cit. T Proc. Roy. Soc., 1900, Ixvi., 192. 
varies with the concentration of the solution, and that at $0^{\circ}$ the dissociation falls less rapidly with increasing concentration than at a higher temperature.

The electro-motive force(E.M.F.)required to separate the ions from their electrical charges varies, which Hans Jahn considers is probably a cause of apparent divergences from Ostwald's law.* As the ratio of ionic concentration can be found by E.M.F. observations, so likewise, assuming Ostwald's law, can the actual concentration be determined. The ionic concentration of a dilute solution of potassium chloride was calculated from E.M.F.observations and compared with that of six other solutions of varied strength, and the value of these was found to vary from 0.001638 to 0.001642 . Similar calculations were made from solutions of sodium chloride and hydrochloric acid. By assuming the value of the most dilute solution, Hans Jahn calculated from it the ionic concentration of the stronger solutions, and he found these values agreed with those obtained by the dilution law.

The presence of ions in a solution influences the osmotic pressure. All substances in solution behave like gases, the dissolved molecules exerting pressure on the sides of the containing vessel in their effort to diffuse through space. But the osmotic pressure depends upon whether the substance in solution is an electrolyte or a non-electrolyte. The osmotic pressure of non-electrolytes in solution is proprotionate to the number of contained molecules ; but in the case of electrolytes the pressure is in propro* Loc. cit. 
tion to the molecules + ions in the solution. Sugar is a non-electrolyte, and 0.5 per cent. solution exerts exactly half the pressure of a 1 per cent. solution. But $\mathrm{NaCl}$ is an electrolyte, and a $\mathbf{0 . 5}$ per cent. solution exerts more than half the pressure of a 1 per cent. solution, because the dissociation is greater and there are relatively more ions in the weaker than in the stronger solution.

1 During diffusion, it is found that the presence of a dividing medium or septum influences the rate of diffusion and the velocity of the ions. The rate of diffusion of various gases through porous septa is nearly inversely proportional to the square root of the density of the gases ; thus $\mathrm{H}$ passes through porous septa four times as quickly as 0 , and nearly three times as quickly as steam.* Many experiments have been performed which show that septa influence the velocity of the transmission of ions. The relative velocity of cations is in all cases less when a dividing membrane is used than when no membrane is used; but the difference is greatest when the septum consists of an animal membrane, and is smaller or comparatively negligible when the septum consists of parchment paper or porous clay. $\dagger$ Bein determined the rate of transmission of ions through clay, parchment paper, gold-beater's skin, and fish-bladder of $\mathrm{H}, \mathrm{Na}, \mathrm{Li}, \mathrm{Ca}$, and $\mathrm{Cd}$ in the form of chlorides, and in every instance the rate of transmission of cations through gold-beater's skin and fish-bladder was diminished. $\ddagger$ Absorption

* Watts' "Dict. Chem."

+ Bein: Zeit. Physikal-Chem., 1899, xxviii., 439.

$\ddagger$ Loc. cit. 
through animal membranes has also been studied from the ionic standpoint by Rudolf Höber.* $\mathrm{He}$ has shown that the salts absorbed from the small intestine into the blood are hypertonic, isotonic, and hypotonic; and that isotonic salts are absorbed at different rates. He used solutions so dilute that the salts were almost completely dissociated electrolytically, and he found that they behaved differently according to the proportion of the contained ions or the ionic concentration. The cations $\mathrm{K}, \mathrm{Na}$, and $\mathrm{Li}$, were absorbed with almost equal rapidity; $\mathrm{NH}_{4}$ and urea more quickly; Ca more slowly, and $\mathrm{Mg}$ slowest of all. Of the anions, $\mathrm{Cl}$ was absorbed most rapidly, then followed in order $\mathrm{Br}, \mathrm{I}, \mathrm{NO}_{3}$ and $\mathrm{SO}_{4}$. The absorption of Ba could not be observed because of its injurious action on the mucous membrane.

Various other biological functions have also been considered from the standpoint of the ionic theory, For instance, chloride of sodium is a common and almost essential constituent of ordinary human food, and it has been asserted that its presence in food provokes or aids the secretion of hydrochloric acid in the stomach. Now, it is not proved that the stomach is impermeable to $\mathrm{Cl}^{\prime}$ ions ; but Beurath and Sachs $\uparrow$ consider they have proved that the acid secretion has no relation to the presence or absence of chloride of sodium in the food ; that the absence of $\mathrm{Cl}$ ions from the food does not prevent the formation of $\mathrm{HCl}$ in the stomach ; nor does the introduction of a chlorine-free solution into the stomach abolish the secretion, which comes from the blood.

* Pflïger's Archiv, 1898, lxx., 624.

† Ibid., 1905., cix., 466. 
The taste or flavour of substances is due to the reaction which is produced by a solution of that substance upon the nerve-endings; and the sense of taste is regarded by some authorities as being due to the dissociation which takes place in the solution, that is, to the action of ions upon the surface of the tongue or the nerve-endings. Richards* attributes the sour taste of acids to the action of $\mathrm{H}$ ions in the solution; which view he considers upheld by the fact that a solution of $\mathrm{HCl}$ of distinctly acid taste becomes tasteless when neutralised by potash. Dilutions of less ionised acids, e.g. acetic and tartaric, are not so sour to the taste as corresponding solutions of mineral acids. When a small quantity of sodium acetate is added to a dilute solution of $\mathrm{HCl}$ or acetic acid the sour taste is diminished, which is in accordance with the view that almost wholly dissociated sodium acetate is capable of destroying the freedom of $\mathrm{H}$ ions. Kalenberg, $\dagger$ on the other hand, says that the sour taste of acids and acid sodium salts is obtained at concentrations of $\mathrm{H}$ ions below the limit for acids ; hence the sour taste of acid sodium salts cannot be attributed to the $\mathrm{H}$ ions which are present, but rather that it is due to the acid ion ; and he considers this to militate against the view which explains the sense of taste by the theory of ions. Höber and Kiesson $\ddagger^{-}$also appear to consider the dissociation theory to afford an unsatisfactory explanation of the sense of taste. Richards, $\S$ however, says that

* Amer. Jour. Chem., 1898, xx., 121-126.

$\dagger$ Jour. Physiol. Chem., 1900, iv., 33-37.

$\ddagger$ Abstracts, Jour. Chem. Soc., 1899, i., 206.

$\S$ Jour. Physiol. Chem., 1900, iv., 207-211. 
the sour taste of acid salts is stronger than would be expected from the concentration of $\mathrm{H}$ ions, but he does not consider that this militates against an explanation of taste from the ionic standpoint. If the taste is due to a chemical action upon a substance on the surface of the tongue, the sensation may be accompanied by the removal of $\mathrm{H}$ ions, and further dissociation would then occur in accordance with mass-action law. Although the degree of dissociation in a liquid is correctly ascertained no quantitative connexion could be obtained from the taste. This explanation is also in agreement with paralysis of the sense of taste which follows the application of concentrated solutions to the tongue. $\mathrm{H}$ - and $\mathrm{OH}^{\prime}$ ions are those which possess the most marked taste, and are those most likely to cause reactions in the substance of the tongue, and such phenomena are not opposed to an explanation of taste by the ionic theory.

The effects of dissociated substances upon many organisms have been observed. Acid ions, even $\mathrm{CO}_{2}$, stop the contractile manifestations of protoplasm; the ions of alkalies at first increase its activity. W. E. Garrey* states that the effect of such chemicals upon flagellated infusoria is analogous to that of heat, light, galvanism, and other stimuli. Inorganic acids have equal effects upon them, if their ionic concentration is the same; but organic acids behave differently and their effect is greater than would be expected. When fungi are subjected to the action of deleterious ions they offer in general more resistance than higher organisms. Clarke $\dagger$

* Amer. Jour. Physiol., 1900, iii., 291-315.

† Jour. Physiol. Chem., 1899, iii., 263. 
found that the anion $\mathrm{OH}$ is rather more toxic to moulds than the cation $\mathrm{H}$; and the toxicity of the anions $\mathrm{Cl}, \mathrm{Br}$ and $\mathrm{I}$, increases slightly with their atomic weight. The ion of cyanogen radical is powerfully poisonous to fungi, and potassium cyanide has nine times more toxicity than that of $\mathrm{HCl}$. Mercuric chloride and silver nitrate are about equally toxic to moulds, and are followed closely by potassium dichromate, potassium chromate, and formaldehyde. In many cases the dissociation lessens the toxic effects. Out of eight acids, six were more toxic in the molecular than in the ionised form. The anions of mineral acids have a low toxic value for fungi : those of $\mathrm{HCl}, \mathrm{HNO}_{3}$, and $\mathrm{H}_{2} \mathrm{SO}_{4}$ have a toxicity of less than $\frac{1}{32}$ that of $\mathrm{H}$ ions. The undissociated $\mathrm{HCN}$ molecule has a toxicity $76 \cdot 6$ times that of $\mathrm{H}$ ions ; that of acetic acid 2.8 times that of $\mathrm{H}$ ions; but when the hydrogen in acetic acid is replaced by chlorine the toxicity increases, but the dissociation increases also and the two effects partially balance one another.*

Chloride of sodium is toxic to many low-formed organisms, and to contractile tissues generally. Thus, fundulus ova will develop in distilled water, but not in water which only contains sodium chloride; if, however, some calcium chloride also be added to the water the development proceeds normally; from which it is inferred that sodium ions are toxic, but calcium ions antitoxic. $\dagger$ Strontium ions have the same antitoxic effect as calcium ions.

What influence has ionisation upon muscular

* Clarke: loc. cit.

† Osborne: Proc. Physiol. Soc., 1905, x.-xii. 
contractility? There is abundant evidence of the splitting up of muscle constituents during activity, and some evidence of their ionisation. Living resting muscle has a neutral or alkaline reaction; but during activity the reaction becomes acid from the development of sarcolactic and carbonic acids which result from the splitting up of a more complex substance or substances about the time of contraction. We do not know exactly what occurs during contraction. "It may be that the chemical changes at the bottom of the contraction do not involve the real living material of the fibre, but some substance manufactured by the living material. It may be that when a fibre contracts it is this substance which explodes and not the fibre itself. It may be a compound of carbon and hydrogen which explodes, the products being sarcolactic and carbonic acids, but such is not yet proved."* When a muscle-nerve preparation is subjected to a shock from an induction coil a change passes along the nerve to the end-plate, where it is transmuted into a muscle impulse. This takes place in the latent period. It is evident that the electricity, whatever change it undergoes in its course through the nerves, sets up an electrolytic process or an "explosive decomposition which leads to the formation of sarcolactic acid and disengagement of $\mathrm{CO}_{2}$ and heat, accompanied by a visible wave of contraction in the muscle itself." $\dagger$ The proportion of the products bears a constant relationship to the energy and duration of the contraction, or vice versa, the energy of the contraction

* Foster's "Physiology," vol. i., p. $106 . \quad$ † Ibid., p. 125. 
bears a constant relationship to the consumption of an explosive material which results in the development of $\mathrm{CO}_{2}$ and sarcolactic acid. The nature of this chemical change is not clearly understood; but we know that the materials essential for the process must contain carbon and hydrogen, and we also know that oxygen is certainly consumed in the form of $\mathrm{O}^{\prime}$ or $\mathrm{OH}^{\prime}$. The $\mathrm{H}$ - ion may also be in use ; and sarcolactic acid is probably formed by the union of acid or $\mathrm{OH}^{\prime}$ ions with products of decomposition of the exploded molecule as a secondary reaction. Muscle substance could not exist without water ; and the explosive substance may be in solution in the water. Now ions alone can take part in the conduction of the electric current through liquids or gases; the undissociated molecules being inoperative, ergo ions convey the electricity through the muscle fibre. The ions only remain active and have an independent existence so long as they retain their electrical charges, which may be enormous. A great amount of energy is transformed into heat during muscular activity, and although we cannot tell what is the exact chemical action which takes place we may judge of its importance by analogy; e.g. when a known combination of carbon and hydrogen, such as methane, undergoes oxidation much energy is liberated in the form of heat, as shown by the following thermo-chemical equation :

$$
\mathrm{CH}_{4}+2 \mathrm{O}_{2}=\mathrm{CO}_{2}+2 \mathrm{H}_{2} \mathrm{O}+212,000 \text { calories. }
$$

Which means that when 16 grammes of methane are combined with 64 grammes of oxygen there are produced 44 grammes of carbon dioxide, 36 grammes 
of water, and 212,000 calories or units of heat; in other words, the energy of 16 grammes of methane and 64 grammes of oxygen together is more than that possessed by 44 grammes of carbon dioxide and 36 grammes of water by an amount which would produce 212,000 calories. During muscular action a similar amount of force over and above that which is necessary to produce sarcolactic acid and carbon dioxide produces the contraction and is transformed into heat.

The effects of ions on contractile tissues have been observed, and Loeb asserts that sodium chloride is a poison to them all. The well-known effects of ions on muscular tissue are masked by the presence therein of organic substances having large molecules, which is regarded as an indication of their combination.* Although the ions of sodium and lithium are very similar physically, their physiological effects are not equivalent. There is no foreign element so slow to make a noteworthy change in skeletal muscle as lithium; but when most of the normal sodium in it has been replaced by lithium, it is followed by a characteristic fall in the muscular irritability. $\dagger$ A controversy has existed for some time as to whether the action of contractile tissue is of muscular or nervous origin. The constitution of the environment, as well as that of the tissues, enters into the question ; and many of the arguments about it have been based upon the ionic theory. Loeb $\ddagger$ experimented with the medusa ;

* Stiles and Beer: Amer. Jour. Physiol., 1905, xiv., 133.

$\dagger$ Millikin and Stiles : Ibid., p. 359.

$\ddagger$ Ibid., 1900, iii., 383-396. 
and found that in the presence of calcium and potassium salts the impulses started in the margin and were therefore of nervous origin; from which he concluded that the chemical rather than the histological structure of the ganglia was important. Howell* says the normal stimulus of contraction depends upon the presence of calcium salts, but for rhythmical contraction the presence of potassium salts is also necessary. Loeb $\dagger$ also considers that calcium, potassium, or sodium salts do not form the stimulus for rhythmical contraction in cardiac and other contractile tissues, but that their presence in the tissues in a definite proportion is necessary ; if the proportion is not correct a rhythmical contraction does not take place. If the amount of sodium chloride in it is too small, it may be increased by placing the tissue in a solution of pure $\mathrm{NaCl}$, and a rhythmic action will then be brought about; if the calcium chloride is too small increasing it in the same manner will initiate contraction. $f$ All contractile tissues do not require the same chemical constitution or environment. Thus, potassium alone annihilates muscular contraction rapidly ; but ciliary activity, which is considered to be a protoplasmic action of the same order, and cell division will continue in the presence of enormous quantities of potassium salts.

A similar discussion has arisen about the action of the heart, and has partly taken place from the standpoint of ionic dissociation. Attempts, considered by many authorities to be successful, have

$$
\begin{array}{ll}
\text { * Amer. Jour. Physiol., } & 1898, \text { ii., } 47 . \\
+ \text { Loc. cit. } & \ddagger \text { Loc. cit. }
\end{array}
$$


been made to show that the heart is automatic, and that its action depends upon the constitution of the blood. Howell* says a strip of vena cava from the terrapin's heart may be kept in rhythmic action for two or more days if it is immersed in a bath containing sodium chloride and calcium or potassium chloride. This renders very improbable the statement of Kronecker that cardiac tissue only beats so long as serum albumen is supplied to it. It also makes it evident that the energy is derived from within the cardiac tissue, and that if the tissue is supplied with an adequate stimulus the beat will continue until the source of the energy is consumed. Wilson $\dagger$ also states that a strip of muscle from the apex of a terrapin's heart was kept alive by placing it in normal serum for several days ; normal serum, however, did not keep it in contraction, but a regular rhythmic contraction was induced by the addition to the serum of some calcium chloride. On the other hand, Loebł concludes that the presence of calcium and potassium chloride is not essential for the maintenance of rhythmic contraction, but that their constant presence is necessary indirectly by neutralising the toxic effect of sodium chloride, which is present in blood and sea-water, and which he asserts is toxic to all contractile tissues.

* Loc. cit. † Amer. Jour. Physiol., 1893, ii., 82-126.

‡Pflïger's Archiv, lxxx., 229-232. 


\section{III.-IONS IN BIOLOGY}

THERE is abundance of evidence that electrical changes are an important item in biological processes, that chemical substances are built up as well as broken down in living tissues, that living substances are organised and disorganised. How far the theory of ions may account for the changes that take place in living tissues and to what extent ionisation is responsible for them is at present unknown. But that ionisation takes place in living structures and the presence of ions therein influences biological processes is evident. On purely theoretical grounds Nägeli* considered that the essential substance of protoplasm, that is the living substance, must consist in its ultimate structure of ultramicroscopical solid particles or systems of such particles surrounded by material of a fluid consistence. He supposed that such particles, acting like substances known as ferments or enzymes, produced chemical changes in the materials with which they are brought in contact, without being themselves materially changed. McKendrick $\dagger$ of Glasgow said in a lecture : "When cells were examined by the highest microscopical powers they did not seem to have advanced far towards an explana-

* Quain's "Anatomy," vol. i., part ii., "Histology."

† Brit. Med. Jour., 1901, ii., 817. 
tion of the ultimate phenomena of life ; and there was the same feeling when the cell was attacked from the chemical side. It would appear that the phenomena of life depended on changes occurring in the interaction of particles of matter far too small to be seen by the microscope. The physicist and chemist explained many phenomena by recourse to the conception of molecules and atoms and by the dynamical laws which regulated their movements. The conception of the existence of molecules in living matter had not escaped many physicists. Probably the germinal vesicle of an ovum contained millions of organic molecules. The conception of physicists was that molecules were more or less in a state of movement; and the most advanced thinkers were striving towards a kinetic theory of molecules and atoms which would be as fruitful as the kinetic theory of gases. It was conceivable that vital activities might also be determined by the kind of motion that took place in the molecules of living matter. It might be different in kind from that known to physicists. But it was probable that life might be the transmission to dead matter, the particles of which already had a special kind of motion, of a form of motion sui generis." The process of ionisation appears to confer upon matter a movement and a power which does not belong to inert material; for we find that in electrical conduction it is only the ions which are operative, and the undissociated molecules are inoperative.

The protoplasm of all animal and vegetable cells is probably of a similar constitution. Water enters largely into its composition. The imbibition of 
water, up to a certain point, accelerates its activity; beyond this point it is destructive. Desiccation even to a slight degree will destroy the vitality of the protoplasm of all cells in the higher animals or plants ; but this does not hold good for certain lowformed organisms. We also know that certain salts are as essential to protoplasm as the water which acts as their solvent. But their action shows that an excess of any chemical in a molecular form is deleterious to protoplasm; and their freedom from injury depends upon their presence in the form of a dilute solution. Plants absorb chemical substances through their root-hairs by osmosis, each ingredient in the moisture around the roots tending to become as abundant inside as outside the root-hair. Absorption by osmosis only takes place when the solution outside is richer than the cell-sap in the absorbed material. But in any case the solution must be dilute, because strong solutions would kill the plant.

The evidence that salts are largely absorbed in the form of ions is increasing. It is also known that the proportion of ions in the moisture surrounding the roots influences the osmotic pressure, and consequently the rate of absorption. It has been stated, vide ante, that the osmotic pressure of electrolytes is equal to the proportion of the contained molecules + ions, that the weaker the solution the greater is the ionic concentration, therefore the pressure is higher and the absorption more rapid in consequence.

The roots of a plant excrete certain acid excretions which render soluble some of the otherwise insoluble mineral constituents of the soil, and thereby produce 
the ions which are so much more readily absorbed than the molecules.

All the food required by plants must be in solution, excepting carbon and oxygen, and, excepting the latter, they are all absorbed by the roots. They are absorbed chiefly as sulphates, phosphates and nitrates. That they are injurious to plants if absorbed in a high state of concentration is known; on the other hand, their absorption at all by osmosis necessitates that the degree of concentration in the solution outside shall be higher than that of the interior of the plant; whereas the more dilute the solution the greater is its ionic concentration and velocity, and consequently the greater the osmotic pressure and rapidity of absorption.

Among the mineral substances, calcium appears to be essential to the life and functions of all protoplasm, yet it is unknown in what way it is combined with the essential basis of life. Another important element, especially of plant life, is potassium ; like calcium, it is obtained from the soil ; without it the absorption of $\mathrm{CO}_{2}$ and assimilation of carbon does not go on, and the plant does not increase in weight. All plants which are rich in starch or sugar contain an abundance of potash salts ; and it appears that chlorophyll is unable to take up $\mathrm{CO}_{2}$ and fix the carbon, except in the presence of potassium. Chlorophyll is only formed by the leaves of plants when iron is being absorbed from the soil ; and it is the combination of a ferric or ferrous ion with the chloroplastid which enables the plant to utilise the $\mathrm{CO}_{2}$ absorbed by the leaves. Under the influence of the sun's rays $\mathrm{CO}_{2}$ absorbed from the air and $\mathrm{H}_{2} \mathrm{O}$ 
absorbed by the roots are dissociated into ions which are united in the chloroplastid to form a carbohydrate molecule, thus : $\mathrm{CO}_{2}+\mathrm{H}_{2} \mathrm{O}=\mathrm{CH}_{2} \mathrm{O}+\mathrm{O}_{2}$. This is the first stage in the formation of starch and sugar, and it is never performed except by plants containing chlorophyll and in the presence of potash salts. Potassium takes no direct part in the process, but it has a well-marked, indirect effect, and the process is a more intricate one than is indicated by the equation. $\mathrm{CH}_{2} \mathrm{O}$ may be formed by a combination of $\mathrm{CO}$ and $\mathrm{H}$ ions ; but peroxide of hydrogen is produced from water by the sun's rays, therefore hydroxyl or $\mathrm{OH}$ ions may take a part in the process. Such constructive work cannot be done without energy; and the plant avails itself of the kinetic energy of the sun's rays, which is the force dissociating $\mathrm{CO}_{2}$ and $\mathrm{H}_{2} \mathrm{O}$ into ions. Plants without light and protoplasm without chlorophyll are unable to construct starch or sugar from these materials ; and animals or parts of plants which do not contain chlorophyll must derive their carbon for constructive purposes from more complex compounds or already organised material. Out of the simple plastic molecule containing $\mathrm{C}, \mathrm{H}$, and $\mathrm{O}$ more complex substances are formed by polymerisation and condensation of the simple molecules; and the process by which these compounds are united is a complex one, which results in the formation of starch, sugar, cellulose or fat.

Starch is an insoluble material which is formed in the leaves of plants and deposited therein. When it is carried from place to place for nutrition, growth or storage, it is converted under the influence of an 
enzyme into soluble carbohydrates-glucose, lævulose, or maltose; the route is determined by the demand for them, and the mode of distribution is by diffusion. Where a tuber begins to sprout the starch is drawn upon for constructive purposes, and, being converted to sugar, travels to the growing points of the young shoots, and supplies a large portion of the plastic material necessary for growth.

Sugar is formed by the hydrolysis of carbohydrates by acids or alkalies. Hydrolysis by alkalies is due to the presence and influence of $\mathrm{OH}$ ions ; hydrolysis by acids to free $\mathrm{H}$ ions ; the former is a slow, the latter a comparatively rapid process.* In the conversion of starch to sugar by ptyalin, or other cellular enzyme, the hydrolysis is probably performed by ionisation in a similar manner. Inulin is not converted to sugar by enzymes such as ptyalin or amylopsin, and, when consumed by animals, its conversion takes place in the stomach by aid of the acid ions. $\dagger$ Many changes are produced in the salts contained by the sap of plants; during these changes free $\mathrm{CO}, \mathrm{OH}, \mathrm{H}, \mathrm{O}, \mathrm{CO}_{3}, \mathrm{NO}_{3}, \mathrm{SO}_{4}, \mathrm{PO}_{4}, \mathrm{C}_{2} \mathrm{O}_{4}$, $\mathrm{C}_{2} \mathrm{H}_{3} \mathrm{O}_{2}$, and other ions are constantly present from the breaking down of organic or inorganic substances, and the free ions assist in the transformation of carbohydrates from one form to another. Fatty bodies are abundant in many cells, especially in animal fat, vegetables, seeds and fruit. They are formed by the union of a fatty acid, such as oleic or palmitic acid with glycerine, during which combination the fatty acid replaces three hydroxyl ions split off from the

* Abstracts, Jour. Chem. Soc., 1898, 714.

† Wróblewski : Zeit. für Physiol. Chem., 1898, xxiv., 73. 
glycerine. In the digestion of fat by animals, the fats are split up into a glyceryl radical and a fatty acid radical; the glyceryl radical is joined by $\mathrm{OH}$ ions and forms glycerine; the fatty acid radical unites with ions of $\mathrm{Na}, \mathrm{K}$, or $\mathrm{Mg}$, and forms stearate, oleate or palmitate of those elements, in which condition they are absorbed. After their diffusion into the blood-stream or while in the interior of cells forming a part of the alimentary system, the glycerine and soap are again dissociated and their radicals reunite to form fat.

In biological processes heat is disengaged during chemical action just as it is observed to be in non-biological processes. Metabolism consists of anabolic and catabolic changes in which the heat disengaged is measurable in calories or heat units. The consumption and oxidation of proteid, fat, and carbohydrate results in the liberation of known quantities of heat. Other chemical processes in an organism also result in the liberation or consumption of heat and energy which is not always considered in problems of metabolism. The neutralisation of an alkali, the conversion of organic acids to alkaline carbonates, the reduction of proteids to urea or other waste products, of fat to carbonic acid and water, are all attended by the disengagement or absorption of heat. This is in accordance with the physical law that matter and energy are indestructible. When a chemical action takes place between two substances the total quantity of matter and energy remains the same. The equation $\mathrm{C}+\mathrm{O}_{2}=$ $\mathrm{CO}_{2}$ shows only the rearrangement of the atoms, i.e. that when 12 grammes of carbon are united 
with 32 grammes of oxygen they form 44 grammes of carbon dioxide. But just as there is a rearrangement of the matter so is there a rearrangement of the energy. Clerk Maxwell in his book on "Matter and Motion" says: "The total energy in any material system is a quantity which can neither be increased nor diminished by any action between the parts of the system, although it may be transformed into any of the forms of which energy is susceptible." Thus, in electrical conductivity the potential energy of the molecules becomes kinetic, the molecules are split into ions, and the energy takes a new form, which is positive or negative electricity. Again, during the formation of carbon dioxide from carbon and oxygen, 12 grammes of carbon require 32 grammes of oxygen for the formation of 44 grammes of $\mathrm{CO}_{2}$; but the potential energy of these amounts of carbon and oxygen is more than is retained by the carbon dioxide, and the excess is transformed into 97,000 calories or units of heat; therefore $\mathrm{C}+\mathrm{O}_{2}=\mathrm{CO}_{2}+97,000$ calories. The heat disengaged during the combination of two or more elements is sometimes called the heat of formation; and many other instances can be given of the transformation of energy into heat during chemical action. A familiar instance in biology is the transformation of organic acids to alkalies or alkaline carbonates. In this process ions are dissociated, e.g. acetates contain the ion acetoxyl $\mathrm{C}_{2} \mathrm{H}_{3} \mathrm{O}_{2}{ }^{\prime}$. During the union of acids and alkalies energy is liberated which is transformed into heat; from the ionic standpoint the heat arises from the formation of water by the union of $\mathrm{H}^{\cdot}$ and $\mathrm{OH}^{\prime}$ ions. The liberated energy is 
ascertainable, and is called the heat of neutralisation, as in the following thermo-chemical equation.

$$
\mathrm{HCl}+\mathrm{NaHO}=\mathrm{NaCl}+\mathrm{H}_{2} \mathrm{O}+13736 \text { or } 13 \cdot 736 \text { calories. }
$$

When glycero-phosphoric acid is neutralised by sodium hydroxide there is developed $+\mathbf{1 4 . 9 5}$ calories for the first equvialent, +13.75 for the second, and +0.1 for the third equivalent; when potassium hydroxide is substituted the values are $+15.9,+13.9$ and +0.4 calories for the same equivalents; and when phosphoric acid is used the caloric equivalents are practically the same.*

In all biological processes heat is developed in a similar manner, that is by the transformation of the energy possessed by ions in excess of that retained by the combined molecules. When 1 gramme of fat is oxidised to $\mathrm{CO}_{2}$ and water, the potential energy of the fat is transformed into kinetic energy, and is equivalent to the chemical force necessary to form $\mathrm{CO}_{2}$ and water $+9,300$ or 9.3 calories or units of heat. Proteid and carbohydrate are not directly reduced to the low stage of chemical constitution in which they leave an organism; but the amount of energy lost in the form of heat is the same as if they were directly transformed.

Under the influence of living matter, substances more complex than sugar or starch are formed. Organic compounds arise which contain $\mathrm{N}, \mathrm{S}, \mathrm{P}$, and other elements in more and more complex combination, until finally protoplasm is formed. But the formation of nitrogen compounds can only

* Imbert and Belugon : Compt. Rendus, 1897, exxv., 1040. 
take place when nitrogen is being taken up by the organism. The mystery of their formation is by no means elucidated yet, although many workers are endeavouring to throw light on the subject by organic analysis and synthesis. In plants, nitrogen is taken up as nitrates and compounds of ammonia.* When sulphate of ammonia is used as a manure it is reduced to nitrate before it is absorbed. The nitro-bacteria of the soil transform ammonia compounds first to nitrites and then nitrates. Most plants are unable to assimilate uncombined nitrogen. But peas and beans will flourish in a soil which is quite free from nitrogen compounds; their roots and tubercles contain nitrifying bacteria which, in the presence of a non-nitrogenous substance like glucose, can form nitrogenous compounds from the nitrogen of the air; and such nitrogenous substance will be absorbed. $\dagger$ The plants, however, only absorb nitrogen in the form of ammonia and nitrates in a very dilute solution, which contains molecules and ions from which the plants construct nitrogenous substances under the influence of the protoplasm or enzymes of the cells.

The first organic nitrogenous substances produced are amino-acids, and these are the basis of the whole series of protein substances. Proteins consist of molecules of enormous complexity, or long chains of

* $\mathrm{NO}^{\prime}$ ions from certain nitrates joined with $\mathrm{H}$ * ions form hydroxylamine, which is a base and may be regarded as ammonia in which one of its hydrogen atoms has been replaced by an $\mathrm{OH}$ ion, the formula being $\mathrm{NH}_{2}(\mathrm{OH})$. Salts are formed from it by direct union with acids, without elimination of water. This is an example of the formation of simple nitrogen compounds in plants.

† Vine's "Botany." 
relatively simple molecules, which can be split by hydrolysis, resulting in the production of amino-acids. During recent years Fischer, Siegfried and others have been able to unite synthetically the aminoacids into longer or shorter chains, that is of transforming them or constructing amide-like anhydrides with the formation of peptides and polypeptides having the same properties and reactions as the natural peptones.* The synthesis of peptones and albumoses in the laboratory may therefore be looked for, and this will probably throw light upon the mode of proteid construction in the living organism. The whole series of proteins appears to consist of amino-acids, but these are grouped into chains which vary both quantitatively and qualitatively. The importance of the amino-acids is very great; some of the acids being present in all and others in most proteins.

If little is known of the formation of protein bodies in living organisms there is evidence to show that the assimilation of nitrates, sulphates and phosphates containing the necessary elements for protein formation can only take place in plants in the presence of light; and that the first stage in proteinformation by plants is the production of the comparatively simple amino-acids, leucin and asparagin. The next step is the formation of the protein molecule, in the construction of which the amino-acids occupy such an important place. It is conceivable that, besides the amide-like chains, other modes of union of the elements of the protein-molecule occur,

* Prof. Barker's address at British Medical Association meeting, Toronto, 1906. 
as piperazin rings and ester or ether groups, resulting from the formation of intra-molecular anhydrides dependent upon the presence in the oxy-aminoacids of hydroxyls $\left(\mathrm{OH}^{\prime}\right.$ ions).* The formation of protein is a complicated process, probably consisting of a series of assimilatory additions to the molecule, whereby the amino-acids form the peculiar complexes under construction. "In the architecture of the protein-molecule and its derivatives Nature has attained her highest chemical performances."

Where and how the formation of protein from amino-acids takes place is not known exactly, but there is evidence in vascular plants that it takes place in the leaves. Emmerling $\dagger$ favours the theory that in plants the amino-acids are formed from the simple inorganic nitrogen compounds which are absorbed by the roots. The formation of asparagin, leucin, and other amino-acids takes place chiefly in the leaves. They are used in the synthesis of albumin and other proteins; but as time goes on the amount produced is in excess of that required for leaf-production, and is used up in the development of seeds. In plants nitrogenous substances travel in the form of amino-acids and amides from one part to another. In their construction or transformation from one grade to another ions are doubtless formed and utilised for chaining groups together. Ions are the vehicles of energy, whether it be of the nature of electricity, chemical energy, or a more subtle vital force, and their presence most

* Prof. Barker's address at British Medical Association meeting, Toronto, 1906.

$\dagger$ Lander. Versuchs.-Stat., 1900, liv., 215. 
decidedly exercises a beneficent influence upon the process of construction, which apparently has its ne plus ultra in the production of cellular protoplasm endowed with powers of reproduction, and those higher functions which are the characteristics of brain and mind.

Animals are quite unable to assimilate unorganised nitrogen; and we do not know exactly how they assimilate or construct out of organised nitrogenous material the proteins of the body. We know, however, that each animal has its own specific proteins; and that the protein molecules of its food, including edestin, gliadin, hordeolin, zein, legumin, hæmatin, globulin, casein, egg-albumin and serum-albumin, are not assimilated in these forms, but are foreign to the organisation of the consumer and could not be directly used for cell metabolism. The proteins in the composition of each animal maintain a constancy of constitution and composition, no matter what kind of protein is consumed. If serum-protein of one animal were injected into the blood of another animal it would lead to the formation of precipitines, and would not amalgamate directly with the serum of the animal into which it was injected.* Digestion is necessary therefore not merely to render protein absorbable, but to break down the foreign protein brought to the organism as food, during which process a number of amino-acids appear. The proteins of each animal and tissue are peculiar to it ; there must therefore be some means by which the organism is rendered independent of the kind of protein supplied. A child fed on milk constructs

* Barker's address : Brit. Med. Jour., 1906, ii., 1093-1110. 
out of it all the proteins of its body. The blood contains a constant amount of serum-albumin and serum-globulin just as it contains a constant amount of sugar; and these are constructed from the free amino-acids resulting from the hydrolysis of protein in the food. It is not possible to detect the presence of free amino-acids, albumoses or peptones in normal blood; but the foreign proteins are broken down to these forms by digestion and are reconstructed apparently by the cells of the alimentary canal into cellular proteins, and from this source a supply of the specific proteins of the blood is kept up, no matter how foreign in nature is the protein substance consumed as food.

In a similar manner the individual cells of the tissues also probably build up their specific proteins. Barker* says there is much evidence of a local hydrolysis in the cellular tissues, by which means the proteins of the serum are in turn broken down to amino-acids which are transformed into the special amino-acids required for constructing proteins according to their own pattern. How this is done is not exactly known. It is said that all protoplasmic cells contain enzymes by which the catalytic process is performed. But granting that cellular enzymes break down the protein molecules in contact with them into fragments or "building-stones," as the amino-acids have been called, how from such fragments do the cells make up the arginin required to build histone for the thymus, glycocoll to build up elastin, leucin and glutaminic acid for serumalbumin, aspartic acid for keratin, etc? What is

* Barker's address : Brit. Med. Jour., 1906, ii., 1093-1110. 
the influence which produces these architectural changes? Is it a chemical action resulting from the splitting of molecules into ions ? We have been informed that substances consisting of a high proportion of polymerised molecules cannot readily form ions, and that other substances with large dielectric constants but small polymerisation are unsuitably constituted for ionisation in the ordinary way.* Nevertheless, as all constructive processes depend upon the formation of molecules or atoms of matter in an active condition (ions being matter in an active form), the fragments of protein which are split up must remain in an active condition, otherwise reconstruction would not take place. Highly polymerised molecules are split up by ferments or enzymes, which sometimes take part in their reconstruction. It is thus that emulsin and myrosin act in the formation of prussic acid and volatile oil of mustard. Emulsin splits the glucoside amygdalin into ions or other fragments, which reunite to form the essential oil of almonds, free prussic acid, formic acid and glucose. All cellular substances are believed to contain such enzymes; by their aid serum-proteins are split into amino-acids, and active ions such as $\mathrm{CO}, \mathrm{OH}, \mathrm{H}, \mathrm{NH}_{2}$ and others link them together and form new complexes in which the enzyme itself very likely forms a central figure. All the amino-acids contain one or more asymmetrical atoms of carbon, and nearly all such acids have been manufactured in the laboratory. The same kinds of amino-acids are present in nearly all animal and vegetable proteins, but as their * Abegg: loc. cit. 
proportion varies so does the composition and character of the proteins; and the proportion of amino-acids which can be obtained from proteins affords no clue to the mode of their arrangement in the protein molecule.* Albumoses and peptones are units in the protein molecule of much higher chemical constitution than the amino-acids from which they are derived, indeed their constitution is nearly as obscure and complex as that of protein itself. Recently Fischer has, by chemical action, chained together the amino-acids into substances called peptides and polypeptides which give the biuret reaction like true or natural peptones. A coritinuance of such synthetic processes will probably throw light on the mode of protein-formation in the living organism.

* Barker : loc. cit. 


\section{IV.-EVOLUTION OF ORGANIC MATTER}

ThE vortex-atom theory assumes that the universe consists of a uniform primary substance; and that what we call matter consists of portions of this substance which have become animated with vortex motion. This is the theory of Helmholtz, and it receives the support of Kelvin, Tait and other eminent physicists. The atoms are supposed or believed to be in the form of vortex rings, each of which is distinct in mass, form and motion, and is indestructible. The rings of smoke formed by tobacco-smokers have often been used as illustrating such vortex action; the particles of such rings are revolving in small circles at right angles to the axis or circumference of the larger circle or ring. Such rings have stability, although they bend, recede, enlarge, and are capable of intussusception, as they are moulded by the movements of the air or other such rings which come into contact with them. They ultimately burst because they meet with resistance from the circulating air. If they were free from all friction, such rings would be indivisible and indestructible. Such is supposed to be the nature of atoms and their movements. The atoms form molecules, and although the molecules are diversified, all the forms of matter are simply combinations of 
so many vortex rings, distinct and indestructible in form and motion.

Since the discovery of radio-activity physicists, led by Larmor, now conceive that each atom, like the ring of smoke, consists of still smaller particles, electrons or metabolons, with which the energy is associated. These smaller particles convey the energy and are the source of the electrical condition of the atom. What they are is still unknown. Their close association with force, and the origin of matter from one primal substance, favours the idea that they are the same as the ether. The atomic constitution of the ether has been admitted, and it is by many authorities considered to be the primal substance, or at any rate to form the substratum of matter. It is also thought that it is the electrons which cause the wave-movements in ether which we recognise as heat and light. Further, the atomic weight of the elements varies with the number of electrons in an atom; an atom of hydrogen is said to contain 1,000, while that of mercury consists of 100,000 electrons.

Atoms are endowed with polarity, which, being aided by affinity, quantivalence, atomicity and isomerism, gives a clue to the construction of inorganic and organic matter which is built up by polar forces. Polarity is a term used to express briefly the generally observed fact, called the principle of polarity, that when energy changes from the passive to the active form, from potential to kinetic, it develops opposite and conflicting forces. There is no action without a contrary and equal reaction, no attraction without repulsion, no positive 
without a negative. The simplest example of polarity is seen in the magnet. It pervades the material and immaterial universe.

The elements exhibit this polarity in different ways. It may be like that of a magnet, in which there are two poles and two only. Thus, oxygen is bipolar and capable of attracting to itself two ions of hydrogen to form a molecule of water. Hydrogen on the other hand is unipolar, and the ion only attracts and holds a single ion of chlorine to form a molecule of $\mathrm{HCl}$. Chlorine is also unipolar. The $\mathrm{H}$ ion is positive, the $\mathrm{Cl}$ ion carries a negative electrical charge. An element having a single pole must create the opposite pole by induction in another body. The analogy between atomic or electrical and magnetic polarity can be rendered evident by pith-balls. If a pith-ball charged with positive electricity is brought near to a negatively charged one, they mutually attract one another, and each becomes the pole of the other. Separated to a distance each carries its own charge, and they no longer influence each other; but each draws an opposite electrical charge from the nearest conductor, and thus creates for itself the opposite pole. Similarly, when a glass rod is rubbed with silk, it becomes positively electrified, and induces the opposite kind of electricity in the silk. Polarity involves the opposition of two relations or poles which attract each other; this is an indispensable condition. Electrical polarity differs from magnetic polarity in the fact that in magnetic polarity both poles are in one body, in electric polarity they are in separate bodies. 
This exhibition of polarity by the elements is called their valency or chemical affinity; and the elements are unipolar, bipolar, or multipolar, according as each atom has the power of attracting or combining with one or more atoms. It is as though each atom were a magnet, with one or more poles by which other atoms are attracted or attached to it. These valencies or poles have a strong craving for satisfaction, called saturation; so great is their attraction that they seize upon their own kind when no other element is free, or they will displace atoms from some other combination to form molecules.

The valency of the ions may therefore be represented as the poles of attraction, and each ion is a monad, dyad, triad, tetrad, or pentad, according to the number of poles of attraction, valencies, or affinities it exhibits. Arranged in this manner the ions can be classified according to the following examples :

\section{A.-Cations.}

1. Monads : Monovalent or unipolar ions-e.g., $\mathrm{H}$ (in acids), $\mathrm{NH}_{4}, \mathrm{~K}, \mathrm{Na}, \mathrm{Li}$, $\mathrm{Ag}$, also $\mathrm{Hg}$ (mercurous) and $\mathrm{Cu}$ (cuprous).

2. Dyads : Divalent or bipolar ions, as $\mathrm{Mg}, \mathrm{Ca}$, $\mathrm{Fe}$ (ferrous), $\mathrm{Ba}, \mathrm{Sr}, \mathrm{S}, \mathrm{Zn}, \mathrm{Pb}$, also $\mathrm{Cu}$ (cupric) and $\mathrm{Hg}$ (mercuric).

3. TRIADS: Trivalent or tripolar ions, as Fe (ferric), Al, Bi, Sb. 
B.-Anions.

1. Monads: $\mathrm{OH}, \mathrm{F}, \mathrm{Cl}, \mathrm{Br}, \mathrm{I}, \mathrm{NO}_{3}, \mathrm{ClO}_{3}$, $\mathrm{C}_{2} \mathrm{H}_{3} \mathrm{O}_{2}$ and the anions or radicals of all monobasic acids.

2. Dyads: $\mathrm{SO}_{4}, \mathrm{SO}_{3}, \mathrm{~S}_{2} \mathrm{O}_{3}, \mathrm{CO}_{3}, \mathrm{~S}$ (sulphide), $\mathrm{C}_{2} \mathrm{O}_{4}$, and all anions of dibasic acids.

3. TrIaDs : $\mathrm{PO}_{4}$, and anions of all tribasic acids.

The amount of the electrical charge carried by the ions varies with the valency of the element or elements, as before stated. Thus, 1 grammemolecule of $\mathrm{H}$ ions carries a charge of positive electricity estimated as 96,550 coulombs. This is the standard of the capacity of ions for carrying electricity. All monovalent ions or monads carries the same in proportion to their atomic weight. Divalent ions or dyads carry twice as much, therefore a gramme-molecule of calcium ions carry $2 \times 96,550$ coulombs of positive electricity, and each ion would require two ions of negatively charged chlorine to satisfy its valency. Similarly, the trivalent nitrogen ion would require three ions of hydrogen to satisfy its valency or neutralise its electricity ; and a gramme-molecule of $\mathrm{N}$ ions would carry $3 \times 96,550$ coulombs.

It is to be observed that the valency of some ions may be changed. Carbon may be either dyad or tetrad ; sulphur, a dyad, tetrad, or hexad ; nitrogen, a triad or pentad; phosphorus, a triad or pentad; and chlorine may be monad, triad, pentad, or heptad. This changeable character is, however, only shown towards bodiles that wre more electro-negative than 
themselves. Towards electro-positive bodies their polarity or valency is invariable. Hydrogen is always a monad; $\mathrm{Cl}$ uniting with one ion-atom of $\mathrm{H}, \mathrm{S}$ with two, $\mathrm{N}$ with three, $\mathrm{C}$ with four, providing that only one ion-atom of these elements enters into the combination.

The bond between two different ions is not always a stable one. $\mathrm{HCl}$ is formed by the union of two monovalent ions, of which $\mathrm{H}$ is positive and $\mathrm{Cl}$ strongly negative. But the $\mathrm{H}$ is easily displaced by any other positive ion for which the $\mathrm{Cl}$ ion has a greater affinity, as the dyad calcium, or the triad iron. Such displacement may be due to the attacking ion carrying a greater charge of electricity. The same displacement is observed in many organic and inorganic molecules. The substitution of other ions for $\mathrm{H}$ or $\mathrm{OH}$ ions takes place with ease and rapidity, and $\mathrm{OH}$ ions are themselves greatly provocative of such changes, whereby the character of the molecule may be very greatly altered.

This linking together of atoms or ions by polar attraction and according to their valency has given rise to what is known as the chain theory of molecular constitution. In the hydrocarbons, for instance, methane, $\mathrm{CH}_{4}$, is a complete molecule; but it may be robbed of an atom of $\mathrm{H}$ by a wandering $\mathrm{OH}$ ion, leaving methyl, $\mathrm{CH}_{3}$, which is a monad, a rest, radical, or link, having one unsatisfied valency. $\mathrm{CH}_{4}$ might be robbed of two $\mathrm{H}$ atoms, leaving the rest, $\mathrm{CH}_{2}$, and a divalent ion. Such rests or links do not exist in a free state, they are ions demanding companionship. They attract other ions, rests or links, or even displace an atom or a link from some other molecule 
and join it to form a chain. These are straight or open chains and cylo or closed chains or rings, of which examples are here given. If $\mathrm{H}$ atoms are removed from the ends of the straight chain, and the free.valencies of the carbon are not satisfied by union with another ion, they bend over until they meet and form a ring. Side chains are formed by another radical or rest dislodging one or more $\mathrm{H}$ atoms from such a ring. $\mathrm{H}$ is represented by the open circle and $\mathrm{C}$ by the closed one.

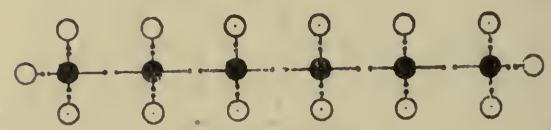

Hexane, $\mathrm{C}_{6} \mathrm{H}_{14}$

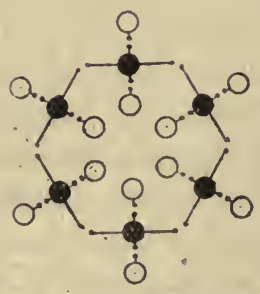

Benzene-hexahydride, $\mathrm{C}_{6} \mathrm{H}_{12}$

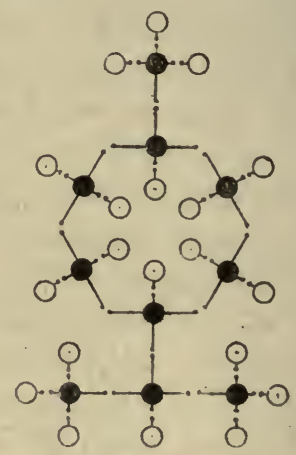

Cymene-hexahydride, $\mathrm{C}_{10} \mathrm{H}_{20}$

The importance of ions in the physiological economy of plants and animals is strikingly evident. Animals are dependent, herbivora directly and carnivora indirectly, upon plant life for the chief elements of their sustenance, viz., proteins, carbohydrates and 
fats. It is therefore to the plants that we should look for their formation. These bodies take their rise from a few simple combinations of ions dissociated from $\mathrm{CO}_{2}$ and water; from which, together with ions from ammonia compounds, nitrates, and a few other salts, the plant builds up the complicated substances of its organism. An endeavour is here made to give an idea of their evolution or development.

The synthetic processes are started from the dissociation of carbonic dioxide and water by the energy of sunlight into $\mathrm{CO}, \mathrm{OH}, \mathrm{H}$, and $\mathrm{O}$ ions. The equation $\mathrm{CO}_{2}+\mathrm{H}_{2} \mathrm{O}=\mathrm{CH}_{2} \mathrm{O}+\mathrm{O}_{2}$ represents in gross what takes place in the leaves of the plant. But the intermediate stages are not represented and the knowledge of them is not quite so clear. Under the influence of the sun's rays hydrogen peroxide, $\mathrm{H}_{2} \mathrm{O}_{2}$, is formed, which may split into $\mathrm{OH}$ ions ; or water may be directly split into $\mathrm{H}$ and $\mathrm{OH}$ ions. Again an $\mathrm{O}$ ion may be split off from $\mathrm{CO}_{2}$, leaving the $\mathrm{CO}$ ion or carbonyl. Now $\mathrm{CO}+\mathrm{OH}=\mathrm{CO} \cdot \mathrm{OH}$ or carboxyl, which is an anion, and an acid radical formed in the construction of the molecules of all organic acids.

$$
\mathrm{CO} \cdot \mathrm{OH}+\mathrm{OH}=\mathrm{CH}(\mathrm{OH})+\mathrm{O}_{2} \text { or } \mathrm{CH}_{2} \mathrm{O}+\mathrm{O}_{2} \text {. }
$$

The $\mathrm{O}$ atom in the carbonyl ion $\mathrm{CO}$ may be displaced by an $\mathrm{OH}$ ion, thereby forming $\mathrm{CHO}$, which is the aldehyde index represented by

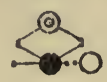

the oxygen being shown as a double circle. The tetrad earbon joins by two of its poles or valencies 
to the dyad or bipolar oxygen, while one pole is occupied by the $\mathrm{H}$ atom, and the fourth valency remains free and demands satisfaction. $\mathrm{CHO}$ is therefore a monad or monovalent ion. Where this is satisfied by an $\mathrm{H}$ ion directly, or indirectly through displacement of the $\mathrm{O}$ by an $\mathrm{OH}$ ion, we have the molecule $\mathrm{CH}_{2} \mathrm{O}$, which is methyl aldehyde. This has a strong tendency to polymerise ; in fact, polymerisation is a great characteristic of the aldehydes as a group. Thus when two molecules are linked together they form glycollic aldehyde, $\mathrm{C}_{2} \mathrm{H}_{4} \mathrm{O}_{2}$; when three molecules are linked together they form Trioses, $\mathrm{C}_{3} \mathrm{H}_{6} \mathrm{O}_{3}$, e.g. glycerose; four molecules form Tetroses, $\mathrm{C}_{4} \mathrm{H}_{8} \mathrm{O}_{4}$, e.g. erythose ; five molecules form Pentoses, $\mathrm{C}_{5} \mathrm{H}_{10} \mathrm{O}_{5}$, e.g. arabinose or xylose ; and by linking together six molecules we have formed the Hexoses or Glucoses, $\mathrm{C}_{6} \mathrm{H}_{12} \mathrm{O}_{6}$, including dextrose, lævulose, galactose, mannose, acrose, etc. Singly linked compounds of carbon containing hydroxyls, besides the aldehyde nucleus, are termed Aldols (contracted from alcoholic aldehyde), and when each carbon atom except the aldehyde nucleus is linked with one hydroxyl $(\mathrm{OH})$ it is called a carbohydrate.* Thus :

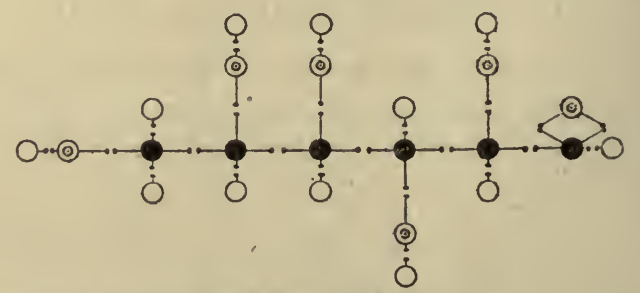

Dextrose, $\mathrm{C}_{6} \mathrm{H}_{12} \mathrm{O}_{6}$

* Möller's "Chemistry," p. 155. 
The mono-saccharides are aldehydes or ketones of polyhydric alcohols. The first are aldoses, e.g. dextrose, $\mathrm{C}_{6} \mathrm{H}_{12} \mathrm{O}_{6}$, and the second are ketoses, e.g. lævulose, which is also $\mathrm{C}_{6} \mathrm{H}_{12} \mathrm{O}_{6}$. The difference between them is shown by the ionic linking or structural formula.

Dextrose $=$

$\mathrm{CH}_{2}(\mathrm{OH}) \cdot \mathrm{CH}(\mathrm{OH}) \cdot \mathrm{CH}(\mathrm{OH}) \cdot \mathrm{CH}(\mathrm{OH}) \cdot \mathrm{CH}(\mathrm{OH}) \cdot \mathrm{CHO}$

Lævilose =

$\mathrm{CH}_{2}(\mathrm{OH}) \cdot \mathrm{CH}(\mathrm{OH}) \cdot \mathrm{CH}(\mathrm{OH}) \cdot \mathrm{CH}(\mathrm{OH}) \cdot \mathrm{CO} \cdot \mathrm{CH}_{2}(\mathrm{OH})$.

The mono-saccharides are convertible into corresponding alcohols by nascent hydrogen, i.e. by $\mathrm{H}$ ions; thus dextrose and lævulose become sorbite, mannite, and dulcite : $\mathrm{C}_{6} \mathrm{H}_{14} \mathrm{O}_{6}$. Inversely the corresponding sugars may be derived from the alcohols through oxidation by $\mathrm{OH}$ ions.* The pentoses, $\mathrm{C}_{5} \mathrm{H}_{10} \mathrm{O}_{5}$, are formed from more complex carbohydrates by hydrolytic splitting to form pentosanes. These are of great importance in the vegetable kingdom as building material, and consequently as food for the herbivorous animals. The chief pentoses are arabinose and xylose, the latter of which is widely distributed throughout the vegetable kingdom.

One of the derivatives of the glucoses (dextrose or mannose) is glucosamine, $\mathrm{C}_{6} \mathrm{H}_{13} \mathrm{NO}_{5}$ or $\mathrm{CH}_{2}(\mathrm{OH})$. $\mathrm{CH}(\mathrm{OH}) \cdot \mathrm{CH}(\mathrm{OH}) \cdot \mathrm{CH}(\mathrm{OH}) \cdot \mathrm{CH}\left(\mathrm{NH}_{2}\right) \cdot \mathrm{CHO}$. This is an intermediary member between the carbohydrates (hexoses) and the amino-acids obtainable from proteids, and is therefore to be regarded as a bridge between the carbohydrates and the proteids. $\dagger$

* Hammarten's "Physiological Chemistry," p. 85.

† Ibid., p. 98. 
The di-saccharides or Cane-sugar group are products of an aldose or alcoholic aldehyde and a ketose in such a way that there is a loss of a molecule of water. Thus :

$$
\left.\underset{\text { Dextrose }}{\left(\mathrm{C}_{6} \mathrm{H}_{12} \mathrm{O}_{6}-\mathrm{H}\right)}+\underset{\text { Lævulose }}{\left(\mathrm{C}_{6} \mathrm{H}_{12} \mathrm{O}_{6}\right.}-\mathrm{OH}\right)=\underset{\text { Cane-sugar }}{\mathrm{C}_{12} \mathrm{H}_{22} \mathrm{O}_{11}}+\underset{\mathrm{H}_{2} \mathrm{O} .}{\mathrm{H}_{2}}
$$

Maltose consists of two molecules of dextrose linked together, with loss of water ; and lactose of a molecule of dextrose and a molecule of galactose, also linked together with loss of $(\mathrm{H}+\mathrm{OH})$ a molecule of water.

The poly-saccharides, amyloses, or cellulose group are likewise formed by linking together more than three molecules of hexoses or glucoses in the sugarcane fashion.

Glucosides are formed from dextrose or other glucoses and a phenol, by junction of their alcoholic hydroxyls in regular ether-fashion; that is, by one of the molecules dropping an $\mathrm{H}$ and the other an $\mathrm{OH}$ to form a molecule of water. They can also be split into their components by enzymes or by dilute alkalies and acids.

Combinations of $\mathrm{C}$ and $\mathrm{H}$ alone are called hydrocarbons. The simplest compound is that in which each of the four valencies or poles of the carbon atom is joined to a hydrogen atom. It is marsh gas or methane, $\mathrm{CH}_{4}$. The organic world is constructed out of this combination by repeatedly removing one or more atoms of hydrogen, and placing some equivalent in their stead. This is done by substitution or replacement. The carbon atom may drop one 
or more atoms of $\mathrm{H}$ for something for which it has a greater affinity; or some other ion more strongly negative may be able to displace the $\mathrm{H}$ and occupy its place ; thus the $\mathrm{OH}$ ion carries a stronger electronegative charge than $\mathrm{H}$.* Indeed, $\mathrm{OH}$ ions play a very active part in the molecular changes of an enormous number of organic compounds, for by $\mathrm{OH}$ displacing any $\mathrm{H}$ the compound is indirectly oxidised.

If the methane molecule is robbed of one of its $\mathrm{H}$ atoms by a migrating $\mathrm{OH}$ ion or any other ion having that power, it leaves the combination with a free valency which demands satisfaction. What is left is methyl, $\mathrm{CH}_{3}$, a monovalent ion, which will seize upon the free valency of similar molecules. Ethane is formed by union of two such ions, thus :

$$
\mathrm{CH}_{3} \cdot \mathrm{CH}_{3} \text { or } 2 \mathrm{CH}_{4}-2 \mathrm{H}+2 \mathrm{OH}=2 \mathrm{H}_{2} \mathrm{O}+\mathrm{C}_{2} \mathrm{H}_{6} \text {. }
$$

But methane may be stripped of two hydrogen atoms, leaving $\mathrm{CH}_{2}$, a rest or divalent ion with two unsatisfied valencies. These also may be saturated. by joining ions. Such molecules form open chains, and may be composed of a number of ions or links of a like character. In this manner series of compounds are formed of which the following are examples :

Ethane, $\mathrm{C}_{2} \mathrm{H}_{6}=\mathrm{CH}_{3} \cdot \mathrm{CH}_{3} \cdot$
Propane, $\mathrm{C}_{3} \mathrm{H}_{8}=\mathrm{CH}_{3} \cdot \mathrm{CH}_{2} \cdot \mathrm{CH}_{3} \cdot$
Butane, $\mathrm{C}_{4} \mathrm{H}_{10}=\mathrm{CH}_{3} \cdot \mathrm{CH}_{2} \cdot \mathrm{CH}_{2} \cdot \mathrm{CH}_{3} \cdot$
Pentane, $\mathrm{C}_{5} \mathrm{H}_{12}=\mathrm{CH}_{3} \cdot \mathrm{CH}_{2} \cdot \mathrm{CH}_{2} \cdot \mathrm{CH}_{2} \cdot \mathrm{CH}_{3}$.
Hexane, $\mathrm{C}_{6} \mathrm{H}_{14}=\mathrm{CH}_{3} \cdot \mathrm{CH}_{2} \cdot \mathrm{CH}_{2} \cdot \mathrm{CH}_{2} \cdot \mathrm{CH}_{2} \cdot \mathrm{CH}_{3}$.

* $\mathrm{H}$ is positive; but some ions may have their electrical reaction changed from negative to positive or vice versa. The acid anions are all negative whether they contain $\mathrm{H}$ or not. 
The Fats are derivatives of the hydrocarbons, whence they are called the Aliphatic or fatty series. The alcohols are also derived from them by one or more $\mathrm{OH}$ ions displacing or being substituted in the link for the same number of $H$ atoms, and the molecule is oxidised. Thus :

Methane, $\mathrm{CH}_{4}+\mathrm{OH}=\mathrm{H}+\mathrm{CH}_{4} \mathrm{O}$, Methyl alcohol. Ethane, $\mathrm{C}_{2} \mathrm{H}_{6}+\mathrm{OH}=\mathrm{H}+\mathrm{C}_{2} \mathrm{H}_{6} \mathrm{O}$, Ethyl alcohol. $\mathrm{C}_{2} \mathrm{H}_{6}+2 \mathrm{OH}=\mathrm{H}_{2}+\mathrm{C}_{2} \mathrm{H}_{6} \mathrm{O}_{2}$, Ethylene alcohol or Glycol.

Propane, $\mathrm{C}_{3} \mathrm{H}_{8}+3 \mathrm{OH}=3 \mathrm{H}+\mathrm{C}_{3} \mathrm{H}_{8} \mathrm{O}_{3}$, Glycerine or triacid alcohol.

Butane, $\mathrm{C}_{4} \mathrm{H}_{10}+4 \mathrm{OH}=2 \mathrm{H}_{2}+\mathrm{C}_{4} \mathrm{H}_{10} \mathrm{O}_{4}$, Butyl alcohol.

Hexane, $\mathrm{C}_{6} \mathrm{H}_{14}+6 \mathrm{OH}=3 \mathrm{H}_{2}+\mathrm{C}_{6} \mathrm{H}_{14} \mathrm{O}_{6}$, Mannite.

Alcohol, radicals are formed by removing one $\mathrm{OH}$ from each carbon atom in the structure; such radicals are monad, dyad or triad ions according to the number of valencies thus liberated. They do not exist in a free state, but migrate to join other compounds by dehydrating them, when free $\mathrm{OH}$ ions do not exist to satisfy their craving. It is in this manner that ethers are formed from two molecules of alcohol, the one losing $\mathrm{OH}$ and the other $\mathrm{H}$ to form a molecule of water. Monovalent alcoholradicals are called alkyls, and divalent ones alkylenes. Although the hydrocarbon is oxidised by the $\mathrm{OH}$ ion to alcohol, the influence of $\mathrm{OH}$ ions upon the molecule is not ended; it can abstract more $\mathrm{H}$ atoms from it. If the action of the $\mathrm{OH}$ ion be upon a primary alcohol the result is the formation of an aldehyde. 
Ethyl alcohol, $\mathrm{C}_{2} \mathrm{H}_{6} \mathrm{O}+2 \mathrm{OH}=2 \mathrm{H}_{2} \mathrm{O}+\mathrm{C}_{2} \mathrm{H}_{4} \mathrm{O}$, or Ethylic aldehyde.

If the action be upon a secondary alcohol, e.g. secondary propyl-alcohol, the result is a ketone, di-methyl-ketone, or acetone-

$$
\mathrm{C}_{3} \mathrm{H}_{8} \mathrm{O}+2 \mathrm{OH}=\mathrm{C}_{3} \mathrm{H}_{6} \mathrm{O}+2 \mathrm{H}_{2} \mathrm{O} \text {. }
$$

The aldehydes and ketones may be still further attacked by $\mathrm{OH}$ ions, which, being oxidised thereby, are transformed into acids. In the case of aldehydes, the $\mathrm{H}$ belonging to the carbonyl group is displaced by the hydroxyl ; e.g.

Methyl-aldehyde, $\mathrm{CH}_{2} \mathrm{O}+2 \mathrm{OH}=\mathrm{H}_{2} \mathrm{O}+\mathrm{CH}_{2} \mathrm{O}_{2}$ or Formic acid.

Ethyl-aldehyde, $\mathrm{C}_{2} \mathrm{H}_{4} \mathrm{O}+2 \mathrm{OH}=\mathrm{H}_{2} \mathrm{O}+\mathrm{C}_{2} \mathrm{H}_{4} \mathrm{O}_{2}$ or Acetic acid.

Propyl-aldehyde, $\mathrm{C}_{3} \mathrm{H}_{6} \mathrm{O}+2 \mathrm{OH}=\mathrm{H}_{2} \mathrm{O}+\mathrm{C}_{3} \mathrm{H}_{6} \mathrm{O}_{2}$ or Proprionic acid.

Butyl-aldehyde, $\mathrm{C}_{4} \mathrm{H}_{8} \mathrm{O}+2 \mathrm{OH}=\mathrm{H}_{2} \mathrm{O}+\mathrm{C}_{4} \mathrm{H}_{8} \mathrm{O}_{2}$ or Butyric acid.

In a similar way Caproic acid, $\mathrm{C}_{6} \mathrm{H}_{12} \mathrm{O}_{2}$, is formed from Hexane or normal hexyl-alcohol. Capric, caprylic, lauric, myristic, palmitic, stearic, and oleic fatty acids are the higher homologues of Caproic acid.

The Fats are neutral compound ethers or esters of the poly-acid alcohol, glycerine, $\mathrm{C}_{3} \mathrm{H}_{8} \mathrm{O}_{3}$ or $\mathrm{C}_{3} \mathrm{H}_{5}\left\{\begin{array}{l}\mathrm{OH} \\ \mathrm{OH} \text {. } \\ \mathrm{OH}\end{array}\right.$

These esters are tri-glycerides, that is, the $\mathrm{H}$ atoms of the three hydroxyls are replaced by fatty acid- 
radicals.* Fundamental dibasic acids have two carboxyl groups in the chain, and are formed by removing hydroxyls from these groups. In this manner oxalic acid is derived from acetic acid, and succinic acid from propionic. When succinic acid is oxidised by an $\mathrm{OH}$ ion displacing and taking the place of an $\mathrm{H}$ atom we get malic acid; by hydroxyls

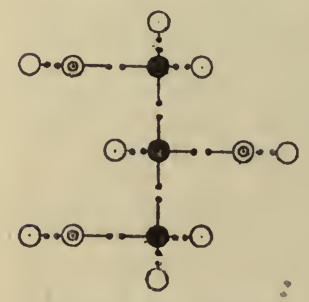

Glycerine $\mathrm{C}_{3} \mathrm{H}_{8} \mathrm{O}_{3}$

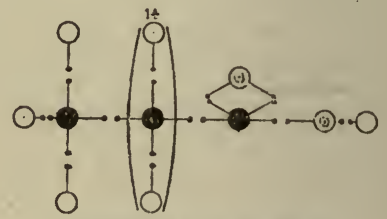

Palmitic Acid $\mathrm{C}_{16} \mathrm{H}_{32} \mathrm{O}_{2}$

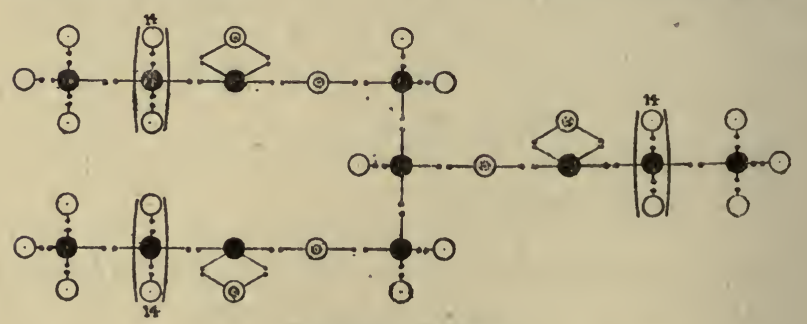

Palmitin $\mathrm{C}_{61} \mathrm{H}_{98} \mathrm{O}_{6}$

replacing two $\mathrm{H}$ atoms from succinic acid or one from malic acid we get tartaric acid. Glycollic acid in unripe fruit is also formed by the oxidation of acetic acid through the action of the $\mathrm{OH}$ ion. Lactic acid is formed by oxidation of propionic acid in this way, and other organic acids are formed in a similar manner.

* Diagrams from Möller's "Chemistry." 
Other elements may take part in the construction of molecules from ions consisting of radicals or rests. Among the most important substances absorbed by the roots of plants are phosphates, sulphates, chlorides, and nitrates. These salts exist in the sap of plants chiefly in the form of ions ; e.g. the phosphoric acid of the phosphates of potash ammonia or soda absorbed is in the form of a trivalent anion, $\mathrm{PO}_{4}$. An important organic compound is glycero-phosphoric acid, $\mathrm{C}_{3} \mathrm{H}_{9} \mathrm{PO}_{6}$, formed by the acid ion joining to the tri-acid-alcohol called glycerine in ether fashion, i.e. by the acid ion displacing one $\mathrm{OH}$ from the glycerine molecule. Lecithin, another important organic phosphorus compound, is formed from glycero-phosphoric acid by fatty acids replacing the other two hydroxyls in the glycerine of the compound. The fatty acids may be stearic, palmitic, or oleic, one or two kinds. Lecithin originates in plants ; enters the animal organism, and is found in nearly all cellular structures, being the chief link between inorganic and organised phosphorus in the living body. Phosphorus is pentad or pentavalent; phosphoric acid is trivalent. It forms three kinds of salts, thus: normal sodium phosphate, which is $\mathrm{Na}_{3} \mathrm{PO}_{4}$, may have one of its $\mathrm{Na}$ atoms replaced by $\mathrm{H}$ as in hydrogen-disodium phosphate, $\mathrm{HNa}_{2} \mathrm{PO}_{4}$, or by $2 \mathrm{H}$ as in $\mathrm{H}_{2} \mathrm{NaPO}_{4}$. Again, one hydrogen atom may be displaced by another ion as $\mathrm{NH}_{4}$ in hydrogensodium-ammonium phosphate, $\mathrm{HNa}\left(\mathrm{NH}_{4}\right) \mathrm{PO}_{4}$; and the other $\mathrm{Na}$ atom may be displaced by another metallic ion, e.g. $\mathrm{Mg}$, in the compound ammoniummagnesium-phosphate, $\left(\mathrm{NH}_{4}\right) \mathrm{MgPO}_{4}$.

The halogens $\mathrm{Cl}, \mathrm{Br}$ and $\mathrm{I}$, form monovalent ions 
which can displace hydrogen from very many of its combinations and occupy the same position in the molecule. A large number of halogen compounds derived from the hydrocarbons are known to pharmacology. Thus $\mathrm{CH}_{4}$ by displacement of $\mathrm{H}$ may become successively methyl-chloride, $\mathrm{CH}_{3} \mathrm{Cl}$, methylene chloride, $\mathrm{CH}_{2} \mathrm{Cl}_{2}$, and chloroform, $\mathrm{CHCl}_{3}$. Other alcohol radicals may likewise have their hydrogen displaced, thus $\mathrm{C}_{2} \mathrm{H}_{6}$ becomes Ethyl bromide, $\mathrm{C}_{2} \mathrm{H}_{5} \mathrm{Br}$, and Ethylene Iodide, $\mathrm{C}_{2} \mathrm{H}_{4} \mathrm{I}_{2}$. The hydrogen may likewise be displaced by a halogencompound; thus $\mathrm{C}_{2} \mathrm{H}_{6}$ may become $\mathrm{C}_{2} \mathrm{H}_{5} \mathrm{HgCl}$, or Mercury-ethyl-chloride. Aldehydes and acids also may have their hydrogen displaced by $\mathrm{Cl}$ ions, thus :

Acetic aldehyde, $\mathrm{C}_{2} \mathrm{H}_{4} \mathrm{O}+3 \mathrm{Cl}=3 \mathrm{H}+\mathrm{C}_{2} \mathrm{HCl}_{3} \mathrm{O}$, or chloral.

Acetic acid, $\mathrm{C}_{2} \mathrm{H}_{4} \mathrm{O}_{2}+3 \mathrm{Cl}=3 \mathrm{H}+\mathrm{C}_{2} \mathrm{HCl}_{3} \mathrm{O}_{2}$, or Tri-chlor-acetic acid.

Sulphur, like chlorine and phosphorus, enters the organism in the form of an ion derived from organic or inorganic compounds. The salts of the soil enter the root-hairs of plants chiefly as ions in the dilute solution which surrounds them, and they exist mainly in form of ions in the circulating fluids of the plants.

Sulphur behaves towards other elements differently from $\mathrm{C}, \mathrm{H}$, and $\mathrm{O}$. The latter have a certain number of poles or valencies, no more nor less. Such valencies represent the demand or craving for union with other atoms. Atoms are active ions until each valency is satisfied; and the body is not at rest or the compound in a stable form until such poles are 
joined to other poles of attraction. Thus $\mathrm{H}$ is a monad ion in all circumstances; oxygen is always a dyad; and carbon is a tetrad in all its relations to hydrogen. The halogens, however, are only monads in their combinations with ions more electro-positive or electro-negative than themselves. Towards $\mathrm{O}$ ions they may present one, three, five, or even seven valencies or poles of attraction, according to the circumstances under which they combine. Sulphur is similar to them. It is a divalent ion or dyad towards electro-positive ions, but a tetrad or even hexad in the presence of electro-negative ions.

In its electro-negative character, therefore, sulphur is a dyad. It resembles oxygen in its chemical behaviour and can replace it in its many compounds. Thus $\mathrm{H}_{2} \mathrm{O}$ becomes $\mathrm{H}_{2} \mathrm{~S}$ or sulphuretted hydrogen. All the compounds in which $\mathrm{O}$ is replaced by $\mathrm{S}$ are called thio-compounds. They are numerous, and include thio-alcohols, thio-ethers, thio-aldehydes, and thio-acids ; and in each case the oxygen is replaced by sulphur by the action of its ions. Thus $\mathrm{C}_{2} \mathrm{H}_{6} \mathrm{O}+\mathrm{H}_{2} \mathrm{~S}=\mathrm{H}_{2} \mathrm{O}+\mathrm{C}_{2} \mathrm{H}_{6} \mathrm{~S}$ or ethyl-hydrosulphide, a substance which causes the peculiar smell in the urine after eating asparagus; and $\mathrm{CH}_{4} \mathrm{O}+\mathrm{H}_{2} \mathrm{~S}=$ ' $\mathrm{H}_{2} \mathrm{O}+\mathrm{CH}_{4} \mathrm{~S}$ or methyl-hydrosulphide, one of the intestinal gases.

As a tetrad sulphur can unite with oxygen by two valencies forming SO or oxy-sulphine, a dyad or divalent ion. One valency of this ion may unite with $\mathrm{C}$ and the other with an $\mathrm{OH}$ ion, and from such a combination many salts and compound ethers are derived.

As a hexad, sulphur unites with two atoms of 
oxygen to form sulphone, $\mathrm{SO}_{2}$. This is a divalent ion; when each of its free valencies is united to a carbon atom sulphones are formed; with a carbon atom to one valency and an $\mathrm{OH}$ ion to the other we get sulphonic acid; with $\mathrm{H}$ to one valency and $\mathrm{OH}$ to the other we get sulphurous acid; and with an $\mathrm{OH}$ to each valency we get sulphuric acid.

Sulphonal is an alcohol-derivative of sulphone; when one of its methyl-radicals is displaced by an ethyl-radical we have trional. Other therapeutic compounds are derived from alcohol, benzene or naphthaline radicals by sulphone or sulphonic acid joining their free valencies, and hydroxyl or $\mathrm{OH}$ ions again come into action in some of these replacements.

Nitrogen, like sulphur, has a variable number of valencies. It can replace the carbon atoms in a closed chain. Among its most important combinations are those including oxygen and hydrogen.

Two atoms of $\mathrm{N}$ may unite with two $\mathrm{OH}$ ions to form hypo-nitrous acid, $\mathrm{N}_{2} \mathrm{O}_{2} \mathrm{H}_{2}$. This is capable of forming salts and ethers. When joining to other - compounds, which have only one free valency, it splits into hydroximide, NOH, which is a divalent ion. This again may be robbed of the $\mathrm{H}$ atom and remain as Nitrosyl or the $\mathrm{NO}$ ion. When two valencies of a carbon atom are available they may be seized by hydroximide or $\mathrm{NOH}$ ions. Nitrosyl or NO ions are also capable of entering into direct union with the carbon atom in various compounds.

One nitrogen atom may also unite with an $\mathrm{O}$ and an $\mathrm{OH}$ ion to form nitrous acid, $\mathrm{HNO}_{2}$ or $\mathrm{NO} \cdot \mathrm{OH}$. 
Salts are formed from this acid by removing the $\mathrm{H}$ of $\mathrm{OH}$ in the usual way, e.g. by the alkali metals. The radical Nitroysl, NO, is also formed by removing the $\mathrm{OH}$, and the radical hydroximide by removing the $\mathrm{O}$ from nitrous acid. These radicals form many organic compounds, as in the following equation, where, however, the by-play of the radicals is not represented.

$$
\mathrm{C}_{2} \mathrm{H}_{6} \mathrm{O}+\mathrm{HNO}_{2}=\mathrm{H}_{2} \mathrm{O}+\mathrm{C}_{2} \mathrm{H}_{5} \mathrm{NO}_{2} \text {. }
$$

That is to say ethyl-alcohol plus nitrous acid forms ethyl-nitrite or sweet spirit of nitre and water.

When nitrogen is pentavalent it may unite with three atoms of oxygen, one of which is an $\mathrm{OH}$, and thereby form nitric acid, $\mathrm{HNO}_{3}$ or $\mathrm{NO}_{2} \cdot \mathrm{OH}$. This acid also forms many salts, as many metals are able to replace the $\mathrm{H}$ in the molecule. Aromatic compounds are also able to replace the $H$, and in this manner the nitro-group assists in the formation of various essences. The carbon atom can also unite with the nitro-group, not merely by replacing the $\mathrm{H}$ in the molecule, but by displacing the $\mathrm{OH}$.

As a triad, nitrogen combines with hydrogen to form Ammonia, $\mathrm{NH}_{3}$, which is an exceedingly important body in the organic world. Two or more valencies of the $\mathrm{N}$ in $\mathrm{NH}_{3}$ come into play when it is approached by an electro-negative group, e.g. $\mathrm{OH}$, $\mathrm{Cl}, \mathrm{Br}, \mathrm{I}$, acid radicals, etc. Thus $\mathrm{NH}_{3}+2 \mathrm{OH}=$ $\mathrm{O}+\mathrm{NH}_{5} \mathrm{O}$ or ammonium hydroxide. This body, however, has not been isolated, any more than ammonium, $\mathrm{N}_{2} \mathrm{H}_{8}$, which is admitted, on all hands to exist, and probably consists of two $\mathrm{NH}_{4}$ or ammonium radicals joined. 
When ammonia is approached by a hydrocarbon radical we get an amido-compound :

$\mathrm{NH}_{3}+\mathrm{CH}_{3}=\mathrm{H}+\mathrm{CH}_{5} \mathrm{~N}$ or methylamine.

If another $\mathrm{H}$ is removed from the ammonia we shall have $\mathrm{NH}_{2}$, which is an ammonia-rest, the amidogroup, a monovalent ion. Primary, sccondary, tertiary, and quaternary compounds of this group are called Amines, or combinations of ammonia with hydrocarbons.

Mono-amines, primary ammonia bases or amidobases, contain one molecule of $\mathrm{NH}_{3}$ in which one $\mathrm{H}$ is replaced by an alcohol-radical, e.g. methylamine, ethylamine, propylamine, and benzylamine. In the secondary bases two $\mathrm{H}$ atoms are replaced by two hydrocarbon radicals; in tertiary bases all three $\mathrm{H}$ atoms are replaced by hydrocarbon radicals ; and in quaternary bases the triad nitrogen of the ammonia turns into a pentad.

Di-amines contain two molecules of ammonia, in which the hydrogen atoms may be similarly displaced by hydrocarbons. Poly-amines contain three or more ammonia or amido-groups, in which the $\mathrm{H}$ atoms of the group have been replaced by a similar number of hydrocarbon radicals.

Nitrogen becomes a pentad when joined to $\mathrm{OH}$ or other electro-negative ions if there is an electropositive ion at hand to take up the fifth valeney. If there is not, the ammonia gives up one of its $\mathrm{H}$ atoms to a hydroxyl ion to form water, and the result is hydroxyl-amine, $\mathrm{NH}_{3} \mathrm{O}$ or $\mathrm{NH}_{2} \cdot \mathrm{OH}$.

$$
\mathrm{NH}_{3}+2 \mathrm{OH}=\mathrm{NH}_{3} \mathrm{O}+\mathrm{H}_{2} \mathrm{O} \text {. }
$$


This is a basic ion which is capable of forming many compounds, with alcohols, phenols, aldehydes or acids. It would take us much too far to enter into all these. It must suffice to indicate a few of ammonia's compounds with acids, and especially such as are of biological or physiological importance.

AMIDO-ACIDS are formed by an organic acid radical attaching itself by its alkyl-part to the amido-group. Thus we have--

1. Carbamic acid, $\mathrm{CH}_{3} \mathrm{NO}_{2}$, or amido-formic acid from ammonia and formic acid.

2. Glycocoll or glycocine, $\mathrm{C}_{2} \mathrm{H}_{5} \mathrm{NO}_{2}$, or amidoacetic acid from acetic acid. Sarcosine, $\mathrm{C}_{3} \mathrm{H}_{7} \mathrm{NO}_{2}$, is methyl-glycocoll, formed by the introduction of a methyl radical into the amido-group of glycocoll.

3. Alanine, $\mathrm{C}_{3} \mathrm{H}_{7} \mathrm{NO}_{2}$, or amido-propionic acid from propionic acid. Cystein is formed from alanine by the radical $\mathrm{SH}$ displacing one $\mathrm{H}$ from the carbon.

4. Leucine, $\mathrm{C}_{6} \mathrm{H}_{13} \mathrm{NO}_{2}$, or amido-caproic acid from caproic acid.

5. Aspartic acid, $\mathrm{C}_{4} \mathrm{H}_{7} \mathrm{NO}_{4}$, or amido-succinic acid from succinic acid.

6. Glutaminic acid, $\mathrm{C}_{5} \mathrm{H}_{9} \mathrm{NO}_{4}$, or amido-glutaric acid from glutaric acid.

7. Tyrosine, $\mathrm{C}_{9} \mathrm{H}_{11} \mathrm{NO}_{3}$, may be looked upon as a combination of alanine and phenol ; it is hydroxylphenyl-amido-propionic acid.

8. Taurine, $\mathrm{C}_{2} \mathrm{H}_{7} \mathrm{NSO}_{3}$, is amido-ethane-sulphonic acid.

The amido-acids are peculiar compounds, and very important constituents of proteins. It has been suggested that all proteins arise from aspartic alde- 
hyde, $\mathrm{C}_{4} \mathrm{H}_{7} \mathrm{NO}_{2}$, by condensation. When in a free state these acids have a neutral reaction. They can form combinations with other acids, and also by their carboxyl-end with bases.

Amides, Acid-amines, or Aminic-acids. An amido-acid can form other compounds with ammonia, by substituting a radical in place of a hydroxyl. The amides or aminic-acids are formed by fixing ammonia to an acid at its carboxyl-end. A molecule of water is eliminated by loss of $\mathrm{H}$ from ammonia and $\mathrm{OH}$ from the carboxyl-group. Thus Formic acid and ammonia $=$ Formamide and water; or Acetic acid and ammonia=Acetamide and water. Carbamic acid and ammonia = Urea and water, thus :

$$
\begin{aligned}
\mathrm{CH}_{3} \mathrm{NO}_{2}+\mathrm{NH}_{3} & =\mathrm{CH}_{4} \mathrm{~N}_{2} \mathrm{O}+\mathrm{H}_{2} \mathrm{O} \\
\text { or } \mathrm{CO} \cdot \mathrm{NH}_{2} \cdot \mathrm{OH}+\mathrm{NH}_{3} & =\mathrm{CO} \cdot \mathrm{NH}_{2} \cdot \mathrm{NH}_{2}+\mathrm{H}_{2} \mathrm{O} .
\end{aligned}
$$

Carbamic acid does not exist in a free state, and unless it meets with other bodies to form carbamides it splits into $\mathrm{CO}_{2}$ and $\mathrm{NH}_{3}$. The acid may however join any base, alcohol or another amide-group, by displacing a hydroxyl; it thus forms a salt, an ether or an amide. Urea or carbamide is so formed as the final decomposition product of the oxidation of nitrogenous compounds such as albumin.

If aspartic or amido-succinic acid be used the ammonia ion displaces one of the hydroxyls, and the resulting amide is Asparagine. If Benzoic acid is used we get Benzamide; and by joining the alkylpart of this to acetic acid we get Hippuric acid, $\mathrm{C}_{9} \mathrm{H}_{9} \mathrm{NO}_{3}$, or Benzamide-acetic acid, which is looked upon as benzoyl and glycocoll linked together. 


\section{NITROGEN COMPOUNDS}

IMIDES. Indol and skatol, products of pancreatic digestion, are derivatives of secondary ammonia bases. If two $\mathrm{H}$ atoms of $\mathrm{NH}_{3}$ are displaced the ammonia-rest or $\mathrm{NH}$ is designated an imido-group. This displacement may occur through the influence of $\mathrm{OH}$ ions or hydrocarbon-radicals. If the amidobase $\mathrm{NH}_{2}$ displaces one $\mathrm{H}$ atom from a benzene ring it forms amido-benzene or Aniline. If another $\mathrm{H}$ atom is displaced from the amido-group of aniline by an ethyl-radical it forms Ethyl-aniline. This may be still further attacked by $\mathrm{OH}$ ions, thereby abstracting another $\mathrm{H}$ from the benzene-ring and three $H$ atoms from the ethyl-end, to form water; that which is left will form an interlocked molecular ring, Indol, $\mathrm{C}_{8} \mathrm{H}_{7} \mathrm{~N}$; Skatol is methyl-indol, $\mathrm{C}_{9} \mathrm{H}_{9} \mathrm{~N}$.

Cholin is a decomposition product of lecithin, in the animal organism. It is a derivative from a quaternary ammonium base, and is really hydroxyethyl - trimethyl - ammonium - hydroxide. Now in tetra-methyl - ammonium - hydroxide four methylradicals are joined to the ammonium-hydroxide, $\mathrm{NOH}$, thus $4 \mathrm{CH}_{3}+\mathrm{NOH}=\mathrm{C}_{4} \mathrm{H}_{13} \mathrm{NO}$. If one of these methyl-radicals is replaced by a hydroxy-ethyl radical, $\mathrm{C}_{2} \mathrm{H}_{5} \mathrm{O}$, we have cholin, $\mathrm{C}_{5} \mathrm{H}_{15} \mathrm{NO}_{2}$. If a molecule of water is split off from cholin we have Neurin, $\mathrm{C}_{5} \mathrm{H}_{13} \mathrm{NO}$. Both these substances arise from lecithin, probably as a result of hydrolysis by the action of bacterial enzymes. By exposing cholin to the action of oxidising agents such as $\mathrm{OH}$ ions, it loses two atoms of $\mathrm{H}$ and becomes muscarine, $\mathrm{C}_{5} \mathrm{H}_{13} \mathrm{NO}_{2}$; the two $\mathrm{H}$ atoms abstracted by two $\mathrm{OH}$ ions may form water of crystallisation, and muscarine 
is then $\mathrm{C}_{5} \mathrm{H}_{15} \mathrm{NO}_{3}$. Cholin may be robbed of four atoms of $\mathrm{H}$ by $\mathrm{OH}$ ions or other oxidising agents, such as an aldehyde and an acid. The result is Betaïne, $\mathrm{C}_{5} \mathrm{H}_{11} \mathrm{NO}_{2}$, a non-poisonous substance found in beetroot, other plants, and in mollusca. Betaine is also an amido-acid, tri-methyl-glycocoll or oxyneurin, and is derivable from hydroxy-ammoniumalcohol. If the carboxyl-group of alanine or amidopropionic acid is displaced by sulphonyl it forms Taurine, $\mathrm{C}_{2} \mathrm{H}_{7} \mathrm{NSO}_{3}$. Taurine and cholin occur in the bile as taurocholic and glycocholic acids. All these are products of catabolic processes in the organism.

The mode of formation of all the urea in the organism is not positively known; but that some of it is formed from ammonia in the liver is proved beyond a doubt, and it is considered to be formed partly from ammonium carbonate and partly from carbamic acid or other amino-acids (leucin, glycocoll or asparagine) or extractives (creatin, creatinine), with carbamic acid as" an intermediate product. Carbamic acid is not known in a free state, but only in combination as salts. We have seen how it may arise from formic acid, $\mathrm{CH}_{2} \mathrm{O}_{2}$, by the $\mathrm{NH}_{2}$ ion displacing an $\mathrm{H}$ atom and joining the carboxyl, $\mathrm{CH}_{2} \mathrm{O}_{2}$ $+\mathrm{NH}_{2}=\mathrm{H}+\mathrm{CH}_{3} \mathrm{NO}_{2}$ or $\mathrm{COOH} \cdot \mathrm{NH}_{2}$. It may also be formed from carbonic acid, $\mathrm{CH}_{2} \mathrm{O}_{3}$, by $\mathrm{NH}_{2}$ displacing a hydroxyl. Carbonic acid is dibasic, and may have one or both its hydroxyls displaced by an amido-group, forming amides or aminic acids. When both of the $\mathrm{OH}$ ions are displaced by ammonia-radicals it forms urea. 
Formic acid

Carbamic acid

1. $\mathrm{CH}_{2} \mathrm{O}_{2}$

( $\mathrm{H} \cdot \mathrm{CO} \cdot \mathrm{OH}$ )

Carbonic acid or $\mathrm{CH}_{2} \mathrm{O}_{3}$

(OH.CO.OH)

Carbamic acid
2. $\mathrm{CH}_{3} \mathrm{NO}_{2}$ $\left(\mathrm{NH}_{2} \cdot \mathrm{CO} \cdot \mathrm{OH}\right)$

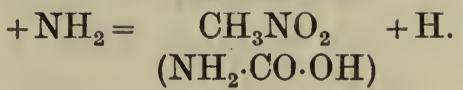

Carbamic acid

$$
+\mathrm{NH}_{2}=\cdot \mathrm{CH}_{3} \mathrm{NO}_{2}+\mathrm{OH} \text {. }
$$

$\left(\mathrm{NH}_{2} \cdot \mathrm{CO} \cdot \mathrm{OH}\right)$

\section{Urea}

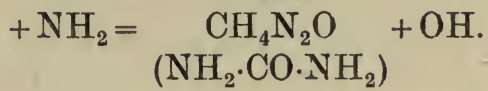

Other substances may be formed from urea by still further substitution. Thus, if the oxygen of urea is replaced by an imido-group, $\mathrm{NH}$, it will form guanidine, $\mathrm{CH}_{5} \mathrm{~N}_{3}$.

The xanthin compounds are closely related to urea. Many if not all of them actually arise from the decomposition of nucleo-proteids, which are combinations of nucleic acid with true proteids. The nucleic acids are not all of the same composition, although they generally contain four atoms of phosphorus. They also yield different products, but these always include one or more of the purinbases, which are derived from purin, $\mathrm{C}_{5} \mathrm{H}_{4} \mathrm{~N}_{4}$, and the most important of which are the following :

Hypoxanthin or oxy-purin, $\mathrm{C}_{5} \mathrm{H}_{4} \mathrm{~N}_{4} \mathrm{O}$.

Xanthin or di-oxypurin, $\mathrm{C}_{5} \mathrm{H}_{4} \mathrm{~N}_{4} \mathrm{O}_{2}$.

Uric acid or tri-oxypurin, $\mathrm{C}_{5} \mathrm{H}_{4} \mathrm{~N}_{4} \mathrm{O}_{3}$.

Adenine or amino-purin, $\mathrm{C}_{5} \mathrm{H}_{5} \mathrm{~N}_{5}$.

Guanine or amino-oxypurin, $\mathrm{C}_{5} \mathrm{H}_{5} \mathrm{~N}_{5} \mathrm{O}$.

Theobromine or dimethylxanthin, $\mathrm{C}_{7} \mathrm{H}_{8} \mathrm{~N}_{4} \mathrm{O}_{2}$.

Caffeine or tri-methylxanthin, $\mathrm{C}_{8} \mathrm{H}_{10} \mathrm{~N}_{4} \mathrm{O}_{2}$.

Carnine, $\mathrm{C}_{7} \mathrm{H}_{8} \mathrm{~N}_{4} \mathrm{O}_{5}$. 
Uric acid is the representative of the class. Its origin in the animal organism, like that of urea, is not settled beyond dispute. The urinary purins find their origin in the decomposition of cell nucleins and the free purin bases introduced in the food. Knieriem* observed an increase in the excretion of uric acid after administering amino-acids, e.g. leucin, glycocoll, aspartic acid. Other authorities agree that this may be one mode of origin. Whether the amino-acids are decomposed by splitting off the ammonia is unknown, but is considered very probable. Minkowski found a large amount of lactic acid in the urine of birds after extirpation of the liver; and considered that, at least in birds, the uric acid is formed in the liver from lactic acid and ammonia. Kowchski and Salaskin $\dagger$ also consider they have proved that to be its origin, by administering lactate of ammonium to birds. Lactic acid, $\mathrm{C}_{3} \mathrm{H}_{6} \mathrm{O}_{3}$, is hydroxy-acrylic acid or $\beta$-hydroxy-propionic acid. It is one of the products of muscular activity, and may arise from the decomposition of amino-acids and members of the aliphatic series. Uric acid is decomposable into urea and alloxan.

When two molecules of urea are united by the chain of an acid we have a diureidde. Alloxan is such a body, and is derived from urea and mesoxalic acid. But mesoxalic acid only forms this link by losing three atoms of oxygen (e.g. by $\mathrm{OH}$ ions acting on it), whereby it becomes acrylic acid, one of the aliphatic series, closely related to propionic acid. Uric acid may therefore be regarded as com- 
posed of two molecules of urea and one of acrylic acid united with loss of three $\mathrm{H}$ atoms and a molecule of water. Xanthin by connecting two molecules of urea by an acrylic acid link, with loss of hydrogen and water. Hypoxanthin only differs from the latter in having an atom of oxygen less; and adenine is the imide of hypoxanthin. If two methyls replace two hydrogen atoms in the imidogroup of xanthin it is converted into theobromine ; and if three methyls replace three hydrogen atoms of the same group it will form caffeine.

The true Proteids or the albuminous substances exist in a living and a non-living form. Our knowledge of the former, the most important and interesting substances, is practically nil. They consist of complex compound molecules, extremely unstable, and in a constant state of change-that is, of being constantly pulled down and rebuilt by the processes of metabolism. The complexity of such molecules is seen from the formula $\mathrm{C}_{636} \mathrm{H}_{1025} \mathrm{~N}_{164} \mathrm{FeS}_{3} \mathrm{O}_{181}$ which is given as the smallest possible empirical formula for hæmoglobin. Under the microscope, living proteids have been observed to possess a reducing power not shown by dead proteid. "This and other considerations have led to the hypothesis that living proteids partake more of the character of aldehydes, while the dead ones are ketonic in nature. Some authorities are of opinion that proteids are formed from ammonia and formic aldehyde, as constituents of aspartic aldehyde, $4 \mathrm{CHOH}+\mathrm{NH}_{3}=\mathrm{C}_{4} \mathrm{H}_{7} \mathrm{NO}_{2}+$ $2 \mathrm{H}_{2} \mathrm{O}$; and that by polymerisation, in the presence of sulphuretted hydrogen, we arrive at one of the proposed formulæ for albumin, $\mathrm{C}_{72} \mathrm{H}_{112} \mathrm{~N}_{18} \mathrm{SO}_{22}$. 
Others consider that living proteids consist of chains of cyanhydrines connected with benzene nuclei. All this is, however, mere paper speculation with but a very slender basis of facts."*

At the moment of death the proteids become changed in character; they are more stable, and capable of being subjected to chemical investigation. As the result of such research Fischer, Siegfried, Curtius, and others, have been able to show that the dead proteins consist of a mixture of amidoor amino-acids, and can be broken down to these by hydrolytic cleavage. The amido-acids are, as we have seen, ammonium salts of the fatty acids. But how these acids are linked together to form the molecule of living proteid, how they are influenced by the introduction or abstraction of $\mathrm{H}, \mathrm{OH}, \mathrm{NH}_{2}$ and $\mathrm{CH}_{2}$ or other ions, is not exactly known. That the proteid molecules are so influenced we know; changes are produced by oxidation, hydration, and dehydration which completely alter their character.

The proteins are formed exclusively by plants, so far as we know. Chlorophyll, as we have seen, forms aldehydes out of the ions arising from the cleavage of $\mathrm{CO}_{2}$ and water. Successive changes lead to the formation of aspartic aldehyde and aspartic acid. The latter is amido-succinic acid, and when ammonia displaces one of its hydroxyls it forms asparagine, which is also one of the amido- or amino-acids.

$$
\mathrm{C}_{4} \mathrm{H}_{7} \mathrm{NO}_{4}+\mathrm{NH}_{3}=\mathrm{C}_{4} \mathrm{H}_{8} \mathrm{~N}_{2} \mathrm{O}_{3}+\mathrm{H}_{2} \mathrm{O} \text {. }
$$

Leucine $\left(\mathrm{C}_{6} \mathrm{H}_{13} \mathrm{NO}_{2}\right)$ is amido-iso-caproic acid formed by ammonia attaching itself to iso-butyl-

$$
\text { * Möller, ibid., p. } 431 .
$$


acetic acid or to normal caproic acid; and so the aliphatic or fatty-acid series comes into the construction of the amino-acids and proteins. The importance of these amino-acids in the construction of protein is evident, for asparagine and phenylalanine occur in most animal and vegetable proteids; tyrosin and prolin in all animal proteids; glycocoll forms 25 per cent. of elastin and 1 of edestin; leucine forms 10 per cent. of casein, 20 of serumalbumin, 15 of fibrin, 21 of elastin, and 29 of hæmoglobin; and glutaminic acid forms 30 per cent. of gliadin, 8 of egg-albumin, 10 of casein, and 8 of serum-globulin.

The occurrence of protein substances which contain a carbohydrate group has been known for some time. It is always an amino-sugar, and usually glucosamine, united to the protein in a glucoside-like combination. It has also been shown by Pavy and others that true proteids yield a carbohydrate on hydrolytic cleavage. A small amount of such carbohydrate has been separated from yolk-proteids, ovoglobulin, serum-globulin, paraglobulin, fibrin, serumalbumin, and albumin of the Graminaceæ. All proteids do not contain a carbohydrate group, for none has been obtained from casein, myosin, fibrinogen, ovo-vitellin, and some vegetable proteids. It is also at present undecided as to whether the carbohydrate group positively belongs to the proteid molecule or is to be regarded as an impurity.*

The albumins are very sparingly present in vegetables, but globulins are very common. They contain vegetable-myosin, which is believed to be the

* Hammarsten's " Physiological Chemistry," p. 23. 
precursor of gluten-fibrin. The latter being coagulated forms gluten, from which again phyto-albumose (gliadin or mucedin) can be separated, leaving the insoluble gluten-fibrin. Aleuron consists of an accumulation of such globulins and albumoses about a crystal or crystals of double phosphate of lime and magnesia; it is in fact a mixture of homologous proteins, beginning with hetero-albumose and ending with globulins and albumin. An aleuron granule may probably be correctly considered a very coarse representation of the finer proteid molecule of animal structures.

The proteins of animal structures are derived from those of vegetable origin. Being consumed, they are broken down by digestion, that is, they are depolymerised and transformed from colloids to crystalloids. Having entered the organism such crystalloid substances are again polymerised to form colloids such as the globulins and albumins of the blood and tissues.

Proteid-like substances have been prepared synthetically by Curtius, Fischer, Siegfried, and others. They have succeeded in linking together two or more amino-acids; e.g. glycyl-glycyl and glycyl-alanin anhydride, which are dipeptides ; also polypeptides, containing three or four glycin molecules linked together, have been formed. They are esters, but give the biuret reaction, and are considered to be the beginning of a proteid synthesis. Proteoses and peptones have not yet been formed ; they are probably mixtures of various proteins.

The instability of the molecules of living proteids or biogens, as they are called by Verworn, is due to 
the interaction of the colloidal material with various elements, notably oxygen. Under favourable conditions dead albumin remains intact for an indefinite time. But living albumin decomposes readily under the influence of external excitement. The cause of this instability is due to intra-molecular changes, mainly produced by oxygen, by which the molecule undergoes cleavage and new groups are formed. Pflüger believes that the characteristic peculiarity of proteids and the real cause of the instabilty of living proteids is due to the presence of a cyanogen radical in the molecule.

We have seen carbon and nitrogen joined together by one or two valencies. They may also be joined together by three valencies, forming thereby cyanogen, $\mathrm{CN}$, in which the nitrogen is a triad and one valency of the carbon remains free. They may also be joined together by four valencies, as in isocyanogen, in which case the nitrogen is a pentad occupying the four valencies of the carbon atom and leaving one of its own valencies free.

When nascent hydrogen, the $\mathrm{H}$ ion, is joined to the $\mathrm{CN}$ group it forms hydrocyanic acid, $\mathrm{HCN}$, which occurs in amygdalin and other vegetable compounds. This acid will combine with iron, potassium, etc. The cyanogen radical or $\mathrm{CN}$ ion may also combine with alcohols by displacing one atom of hydrogen, as in the case of cyanhydrine, $\mathrm{C}_{3} \mathrm{H}_{5} \mathrm{NO}$ or $\mathrm{C}_{2} \mathrm{H}_{5} \mathrm{O} \cdot \mathrm{CN}$. The cyanhydrines are regarded as important substances in biological construction.

The cyanogen radical may also join in different ways with $\mathrm{OH}$ ions. One of these combinations is cyanic acid, $\mathrm{CN} \cdot \mathrm{OH}$, which forms salts with various 
bases, e.g. ammonium cyanate. The latter is isomeric with urea and can be transformed into it by intramolecular changes. Cyanic acid also combines with alcohols to form ethers; and with sulphur to form thio-cyanic acid, various combinations of which are to be found in the aromatic oils, e.g. in mustard.

It is believed by Pflüger and others that it is cyanogen which gives to protoplasm its characteristic vital properties. This idea is supported by analogies existing between the cyanide compounds, especially cyanic acid, and living albumin. Both are fluid and transparent at ordinary temperatures, and set or undergo gelation at a higher temperature; both break into $\mathrm{NH}_{4}$ and $\mathrm{CO}_{2}$ in the presence of water ; both produce urea by dissociation; both grow by concatenation of atoms, i.e. by homogeneous groups of atoms joining together chain-wise into large molecules. So that cyanogen and alcohol aldehyde, or the cyanhydrines formed from them, follow out their tendency to form polymeria or chains of radicals ; and the co-operation of oxygen, and afterwards of water and salts, to form the self-decomposable albumin of living matter is the belief of Pflüger and his followers. The non-nitrogenous products of dead and living matter agree in the main ; but the nitrogenous products of dead and living matter are totally different. Urea, uric acid, creatine, guanine, etc., the products of living tissues, all contain the cyanogen radical; from which it is inferred that living albumin always contains the cyanogen radical, but dead albumin does not. Therefore the cyanogen radical is believed to be the real cause of the instability of living substance. Max Verworn 


\section{PFLÜGER'S THEORY}

attributes a great value to the cyanogen theory, and agrees that all the decomposition products of living albumin contain the cyanogen radical; and that some of them, e.g. urea, can be synthetised from cyanogen compounds. He says in his "General Physiology": "I would say that the first albumin to be formed was living matter, endued with the property in all its radicals of attracting homogeneous parts with great force and preference, in order to build them chemically into molecules, and so grow indefinitely. On this view living albumin would not have a constant molecular weight, because it is a huge molecule in an increasing process of formation and decomposition, probably acting upon ordinary chemical molecules as the sun does upon small meteors." 


\section{V.-INFLUENCE OF IONS ON THE ORGANISM}

ALL living substances consist of erystalloidal and colloidal material. The colloids are compounds based upon a nucleus of carbon, "the asymmetrical carbon atom," which, from its having four poles of attraction or valencies, is eminently qualified to form the inner skeleton of complex combinations.

The crystalloidal substances are well known to chemistry. They obey the ordinary laws of the science; and their absorption and excretion by living organisms is governed by the laws of osmosis and diffusion. They are divisible into the two groups of electrolytes and non-electrolytes; the former consisting of the salts, acids, and bases ; the latter mostly of organic substances such as sugar and urea. Their molecular weight is low, they have a great affinity for water, and readily pass through animal membranes. They perform important duties in the organism by their physico-mechanical and physico-chemical properties. They influence many of the organic processes, impart a stimulus to various functions, and take an active share in metabolism. However, "it is not the salts, but the ions of the salts, which are essential to the organism."* There

* Pauli's "Physical Chemistry in the Service of Medicine," p. 16. 
exists no life process that is not accompanied by changes in the crystalloidal and colloidal substances of the cells and tissues. The physico-chemical laws which govern changes in crystalloids and colloids in vitro may be taken in general as governing the changes which take place in the same substances in living matter.

The biological significance of the crystalloids is however not yet fully understood, and is one of the chief objects of research in bio-chemistry. Experiment has shown that there are physiological effects solely attributable to the ions. "The vital property of the ions to keep in solution the widely distributed globulins cannot be replaced by any other kind of dissolved crystalloid."* It is also known that differences in the concentration of the ions are the source of differences in the electrical potential ; $\uparrow$ and the mineral constituents of the human body are, in the concentration in which they are present, almost completely dissociated. This is equally true of metallic or alkaloidal salts introduced into the body for therapeutical purposes. Loeb was the first who recognised the importance of ions in the electrical changes of organisms, and that changes in the ionic constitution were the causes of the majority of electrical phenomena observed in animal organs. In every dilute solution the salts are almost completely dissociated into ions, and the remaining or undissociated molecules are neutral electrically; therefore the effect of such a solution p. 42.

* Pauli's "Physical Chemistry in the Service of Medicine," † Loc. cit. 
must be due to the ions. A pure ion effect parallels the ionic concentration, and not the concentration of the salt in the solution. Cations and anions in many instances antagonise one another; and the effect of a salt upon various substances, e.g. protein, -is the sum of the effects of different ions.

We are far from a satisfactory insight into the nature of the effect of ions, which may be chiefly electrical in character and brought about by the polarity of matter. Nevertheless examples of such ion effects are to be found in pharmacology of the iodides, cocaine and other drugs, in the absorption of water by muscle, in the sense of taste, changes in the state of the proteins, etc. In the living organism we have to deal with complex mixtures of crystalloids and colloids, between which there exist relations so intimate and varied that some of them are still incapable of elucidation. "Connected with the uninterrupted vital activity of the cell, the anabolism and catabolism of its substance, is the conversion of crystalloids into colloids, and colloids into crystalloids; and this at present unexplained transformation serves at one time to protect a substance from oxidation, as in the conversion of crystalloidal sugar into colloidal glycogen; at another time it protects the protoplasm against the poisons of its own products."* These changes are brought about by the addition or abstraction of ions from the molecule, by addition or subtraction of side-chains, and by intra-molecular changes dependent upon the electrical condition of the

* Pauli's "Physical Chemistry in the Service of Medicine," p. 43 . 
elements. Absorption, secretion, growth, pharmacological and perhaps pathological processes as well as immunity, are connected with such changes in state, a discovery of the nature of which is the raison d'être of bio-chemistry.

The colloidal constitution of living matter is also connected with the problems of bio-chemistry, and especially the electrical and chemical reactions which occur in protoplasm. Colloids exist in two forms : a liquid form called by Graham the sols, and a solid or jelly-like form or gels. The colloids consist of proteioidal and lipoidal materials. They possess a high molecular weight, they do not pass through animal membranes, and their osmotic pressure is so low that they diffuse only with the greatest difficulty. Neither do they possess electrical conductivity, although they for the most part move through an electric current and have an electrical reaction.

A colloid consists of very fine particles of matter in a state of suspension. These particles vary-in number, size and electrical charge; and, like the very minutest particles of atmospheric dust, appear to be unaffected by gravity. They are, however, rendered visible by illumination; and they remain suspended owing to the development in them of an electro-statical condition induced by friction of their surfaces against each other in their molecular movements. Colloids may be organic or inorganic. An illustration may throw some light upon their constitution. If a clean metal plate is put into water it assumes a weak negative electric charge, while the surrounding liquid becomes electro-positive. Traces of the metal gradually drop off the plate 
into the liquid, and it is these particles or metallic ions in the fluid which contain the positive electric charge. If wo imagine the metal plate to be divided under the water into very fine particles of metallic dust, they will, by virtue of their minuteness and the electro-static condition induced in them, remain suspended for an indefinite length of time. Such is a colloidal solution. It is a suspension of electrically charged particles, each of which is an electrode. It is an example of colloids in general. The chief laws and the differences between colloids are all referable to the number, size and electrical charge of the particles. Although such particles appear to be unaffected by gravity, they are affected by electrical changes, and clumping or precipitation can be produced.

It is to such particles in particular that I have ventured to apply the name of Meres. They are not exactly inert particles; they possess energy, part of which is potential, and part is already kinetic as shown by their electrical charge, by their chemical combinations, and in other ways. In colloidal bodies such combinations appear to be always between ions and meres, and the influence exerted by one upon the other is among the facts demonstrated by a study of the chemistry of the colloids ; and it is to such combinations that many physiological processes are due.

The chemistry of the colloids is therefore exceedingly important both for biology and therapeutics, for "there exists no life process that is not accompanied by changes in the colloidal and crystalloidal substances." Some of the laws of general physiology 
can only be clearly understood through a knowledge of these substances; while the pharmacological action of substances and the process of immunisation will only become enlightened by a clear apprehension of the mode of action of colloid upon colloid and the interaction of crystalloid and colloid. The chemistry of the colloids is only in its infancy, but good work has been done by Graham, Butschli, Pauli, Fischer, Bernstein, Billitzer, and others, which has done something to disperse the mists by which the subject is obscured.

Living cells consist of a complex mixture of colloids and crystalloids whose relations are ever varied; and the colloids are chiefly proteioidal and lipoidal substances, and the changes in the structure of living matter consist largely of changes in the colloids. "Connected with the uninterrupted vital activity of the cell, the anabolism and catabolism of its structure, is the conversion of crystalloids into colloids and colloids into crystalloids,"* which is constantly going on. The reaction of living matter may therefore be elucidated by a study of the changes in state ex corpore of colloids and particularly of those called proteins.

Protoplasm possesses characteristics of both solid and liquid substances. The ability to stand alone agrees with the properties of solids, and this is seen in the independence of cells. An argument for the fluidity of protoplasm is however found in the condition that chemical reactions take place in the cell p. 43.

* Pauli's "Physical Chemistry in the Service of Medicine," 
with marvellous rapidity. Changes of shape and the internal structure of protoplasm also have analogies in the variations visible in dead colloids. But that all living substance is liquid meets with greater difficulties than the assumption of a solid state. Thus, for instance, an inner stabile differentiation in a liquid is impossible, whereas the proteins are stabile. While every part of an amœba is equally capable of the functions of assimilation, stimulation and movement, every element in the mass may become a surface element, or conversely. Nevertheless "there exist peculiarities in unicellular organisms, and in the individual cells of higher animals, which can scarcely be interpreted otherwise than as expressions of polarity.* Under this heading belong "the fact that absorption and secretion take place predominantly in certain directions, the dependence of muscular stimulation upon the angle of the current and the direction of the muscular fibril, and the polarity of the phenomena of degeneration in plants and animals. These phenomena indicate a persistent inner differentiation which can scarcely be explained without the assumption of a solid orientation of the particles of living matter." $f$ Pauli considers that many of the phenomena of living tissues are to be understood through a study of the non-living colloids. The gels or solid colloids such as agar-agar and gelatine show some of the characteristics of living tissues. Such a jelly does not take up any other colloid brought into contact

* Pauli's "Physical Chemistry in the Service of Medicine," p. 29.

+ Loc. cit. 
with it, which is comparable with the differentiation of cells. A foreign colloid may be thrust into it, but it shows no tendency to diffuse, just as in intracellular structures. Delicately shaded changes in state are to be observed in these colloids, just as in living matter, through the action of substances within them. Thus, they become more solid or more fluid, without change in their bulk, by the action of crystalloids or enzymes ; the latter producing partial or complete peptonisation. They also manifest the phenomena of adsorption and a great degree of selection with regard to the substances absorbed. Living colloids are such as can take up substances soluble in water or in ether. The latter are called lipoids, e.g. cholesterin and lecithin. It is not known how these lipoids are held by the protoplasm ; but it is probably governed by some property of their own, such as solution affinity. According to Overton the ability of many substances insoluble in water to enter the cells is entirely due to their solubility in the lipoids of the protoplasm; other substances also enter the cells more readily, because of their solubility in the lipoids, than their near relations which are soluble in water. The effects of narcotics, for instance, depend upon the distribution coefficient, that is upon the rapidity and ease of their distribution between two media, such as the blood-plasma and the cell-contents. The absorption of substances insoluble in water from the intestine belongs to the same heading. The similarity between the physicochemical properties of non-living gels and those in living matter is therefore extensive, and this renders them suitable for an investigation into the 
colloids of the living body and the action of crystalloids upon them. The gels in living organisms are proteins.

The sols or liquid colloids play an important part in the biological processes. Plants are able to derive nourishment from absolutely pure crystalloidal solutions. In contrast to them, animals are dependent upon liquid colloidal food. The process of digestion serves to prepare such nutrient sols for absorption, and being absorbed they are mechanically moved about and distributed through the organism to the nourishing fluids. The globulins are such sols : they are colloids held in solution by the interaction of the colloid and a crystalloid. The sols possess properties common to all suspensions of very fine particles. The enormous surface tension or free surface-energy of these particles and their osmotic pressure bear a relationship to each other in the cell which is reciprocal. The enzymes also have a colloidal constitution; and Bredig explains their effects by the enormous surface tension of the particles. Such ferment-like action is possessed even by the metallic surfaces of the particles in an inorganic colloidal solution.* The metabolic changes for ever going on in the living organism compel us to study them as a dynamic process ; and to find the right connexion between metabolic physiology and physical chemistry is an important problem.

The laws of colloidal chemistry govern the changes that go on in living cells; and, although these laws may be modified by metabolism, the parallelism

* Pauli's "Physical Chemistry in the Service of Medicine," p. 34 . 
between the changes which go on in colloids outside the body and the changes that go on inside the body is a condition which cannot be denied. Many of such changes are brought about by the interaction of ions of substances upon the meres or particles of the colloidal bodies. The reactions observable between ions and proteins (the chief colloidal substances of living organisms) become therefore of importance in the investigations of bio-chemistry. A glance at some of the results obtained by Pauli, Hoffmeister and others, as given in Pauli's admirable work called "Physical Chemistry in the Service of Medicine," may therefore be useful.

All crystalloids modify the gelation of colloids, but only the electrolytes or ionisable substances have the power of precipitating them. The non-electrolytes have no power to precipitate them in any concentration ; but they can influence the property of gelation just as the electrolytes and they act in both directions : urea inhibits while sugar favours gelation.

The precipitating power of the electrolytes also varies. A table given by Pauli* shows that the cations $\mathrm{Mg}, \mathrm{NH}_{4}, \mathrm{~K}, \mathrm{Na}$ and $\mathrm{Li}$ increase in power of precipitation in the order given; but the anionssulphate, phosphate, citrate, tartrate, chloride, bromide, iodide and sulphocyanate-inhibit the action of the metallic ions, and the power to prevent the precipitation of proteins also increases in the order given. Thus the sulphates increase in precipitating power from $\mathrm{Mg}$ to $\mathrm{Li}$; and, on the other hand, the

* Pauli's "Physical Chemistry in the Service of Medicine," p. 73. 
sodium salts decrease in precipitating power from sulphate to sulphocyanate in the order given. It is therefore the metallic ion which precipitates, while the anion inhibits or prevents that action, the ions being antagonistic. Sodium acetate will precipitate protein because the $\mathrm{Na}$ ion is too powerful to be inhibited by the acid ion; but ammonium acetate will not precipitate because the acid ion is more powerful than the metallic ion.

The effect of the salt is therefore made up of two parts, a cation and an anion effect, and the result is the algebraical sum of the effect of the ions. While bringing about a physical change in the state of the colloid the ions antagonise one another; one ion has a precipitant, the other a solvent effect, and according as one or the other predominates the colloid is either precipitated or dissolved (or remains in solution) ; and this is called an additive ion-effect.* It is the protein constituent of protoplasm which constitutes the chief point of attack, or which is most readily affected by ions in the organism. It is well known that, in a living organism, the salts are held fast and with great force; and this affinity is an analogue of the affinity exhibited between the salts and the proteins. There can be little doubt that ion-protein compounds are ever present in the animal organism ; in fact, Pauli states that there is reason to believe that all the protein constituents of the protoplasm enter into the composition of this substance only in combination with ions. $f$ The additive ion effects of the salts show a dependence upon certain quantitative relations. This may be 


\section{IONS, NOT THE SALTS, OF IMPORTANCE 91}

due to the affinity between the salt and the protein, and is of such "a character that the metallic ion and the acid ion of a salt may unite with different asymmetric parts of the protein molecule."* Thus the solubility of egg-globulin depends upon the presence of ionisable compounds, for egg-globulin is precipitated by solutions which do not ionise as sugar and urea, just as they are by non-ionised water. All the globulins are kept in solution by such combinations. These facts throw a new light upon the importance of the mineral constituents of the organism. "The ion-protein compounds are of importance in the animal body through their ability to decrease the sensitiveness to change," especially to changes in concentration, alkalinity, and temperature. $\dagger$

When proteins are subjected to heat they undergo a change in state called coagulation. The degree of temperature at which this change takes place is known as the coagulation-point. It has been shown by Pauli and others that various salts have the effect of raising or lowering this coagulation-point, and that the effect is due to the combination of ions of neutral salts with the colloid.

Colloids unite with water and with salt in about the same way; and the presence of water and salt in an organism mutually affect each other. If a swollen colloid-that is, one which has taken up water-is submitted to dry air it will lose water; but there is the greatest difficulty in removing the

* Pauli's "Physical Chemistry in the Service of Medicine," p. $130^{\circ}$

† Ibid., p. 14. 
whole of the water. In like manner, the salt may be removed from a protein-salt mixture by dialysis, but all the salt cannot be removed; the protein-ion combination is therefore very stable. This again is of importance in the living organism. Through the decomposition of large molecules of protein or carbohydrate during metabolism, there are produced certain substances, e.g. urea, sugar, etc., which are of a low molecular weight, readily diffuse, and have other characteristics in common with the electrolytes. But fortunately such substances are nonelectrolytes, they are only ionised very slightly or not at all, and they have no power to displace the electrolytes from the ion-protein combination. The ions, and not the salts, are therefore essential to the organism, and the stability of the ion-protein compounds has a protective influence upon its well-being.

That it is the combination of ions with the protein which gives an electrical reaction; and that it is the metallic ion which has the power of precipitating protein has been proved by experiment.

When protein has been rendered as free as possible from salts by dialysis against running water, thereby rendering it practically ion-free, it is found to have no electrical charge whatever. But native protein, i.e. protein of living organisms, has a recognisable negative electric charge. When positively charged metallic ions (cations) are added to such a protein they cause precipitation by neutralising its electrical charge-that is, by converting its kinetic into potential energy, so that aggregates of sufficient size are formed to fall to the bottom.

If an electric current is sent through a solution of 


\section{IONS GIVE THE ELECTRICAL CHARGE 93}

electrolytes (crystalloids) the substance dissociates into ions which wander to the positive or negative pole as they are negatively or positively charged. But if a similar current is sent through a colloidal solution the particles all move in one direction and accumulate upon the positive or negative electrode according to the charge they have. This is conclusive that such particles have an electric charge. The native protein has a negative charge, and its particles collect about the cations or metallic ions, which are miniature positive electrodes, and they accumulate thereon until aggregates of sufficient size are produced to cause precipitation.

It has been shown, by Biltz and others, that there is further a connexion between the electrical charge and the precipitation. Oppositely charged colloids mutually precipitate each other, and such precipitated colloid has no electrical charge, i.e. it does not move with the electric current. Pauli and Hoffmeister demonstrated that the electrical charge possessed by proteins is entirely due to their association with ions. Hardy and Bredig endeavoured to show that the electrical phenomena of colloidal particles were dependent upon an antagonism between the surface tension and the electrical charge of the colloidal particles. But Billitzer does not consider that surface tension plays the part attributed to it by the former. If oppositely charged ions are added to a colloid, the colloidal particles collect about those ions through electro-static attraction, the ions acting as electrodes, and aggregates are formed which are precipitated or go into solution according to the nature of the ion. Pauli performed a number 
of experiments which show that the conductivity of protein through the presence of ions is very great; and that the electrical charge is entirely due to the associated ion. In these experiments he tested the behaviour of dissolved proteins with many salts, and the results are summarised as follows :*

1. Protein which has been carefully freed from electrolytes shows no electrical charge.

2. None of the albuminous constituents of blood serum show any electric charge in the absence of electrolytes.

3. Neutral salts of alkalies or alkaline earths do not impart an electrical charge to uncharged protein.

4. A trace of acid imparts a positive electrical charge through the positive $\mathrm{H}$ ions, and alkalies a negative charge through the $\mathrm{OH}$ ions.

5. Alkaline salts (e.g. carbonates and phosphates of alkali metals) render protein electro-negative; acid salts give a positive charge.

The native proteins of the blood and tissues carry a negative electrical charge which is derived from $\mathrm{OH}$ ions split off from the salts of the serum and lymph. $\uparrow$ When bicarbonate of sodium is added to fresh non-charged protein it assumes a strong negative electric charge and becomes sodiumbicarbonate-protein.

As the electrical conditions of the proteins of the body are determined through the salts of the fluids, so are those of the cells ; which again shows how im-

* Pauli's "Physical Chemistry in the Service of Medicine," p. 143.

$\dagger$ Loc. cit., p. 145. 
portant is a proper balance of the salts in the organism. Höber has found by experiment that the red blood corpuscles, under normal conditions, are negatively charged; but that they are susceptible to changes which depend upon variations in the environment, especially changes in the ionic constitution and concentration. For example, in an isotonic sugar-sodium-chloride mixture the red blood corpuscles become electro-positive under the influence of $\mathrm{CO}_{2}$, and regain their normal reaction when the $\mathrm{CO}_{2}$ is withdrawn.* The inference is that red blood corpuscles suffer a complete change in their electrical reaction during their passage through the pulmonary circulation. Many other cells likewise show this variability in electrical reaction. According to modern investigations the fluids of the body are neutral ; the free $\mathrm{H}$ and $\mathrm{OH}$ ions exist in them in the same proportion as in the molecule of water. How then is the variability in the reaction of cells to be explained? Why for instance do the red blood cells change their reaction when their environment is changed ? or why does a protein assume a positive electrical charge when it is exposed to the presence of an equal number of $\mathrm{H}$ and $\mathrm{Cl}$ ions ? It is because the colloid is semi-permeable to ions; the protein takes up more $\mathrm{H}$ than $\mathrm{Cl}$ ions ; and the same holds good for $\mathrm{OH}$ ions when it is submitted to the influence of alkalies. The red blood corpuscle becomes positive when exposed to the presence of $\mathrm{CO}_{2}$ because it is permeable for some of the negative $\mathrm{O}$ ions which it contains and which leave it, whereby an excess of the positive ions remains.

$$
\text { * Loc. cit., p. } 150 .
$$


Ostwald was the first to discover, in this semipermeability for ions, the cause of the electrical phenomena observed in cells. Pauli admits it as a very probable explanation; and Bernstein has applied the same idea to muscle and nerve. "If we imagine the surface of the muscle fibril to be more permeable for positive ions than for the negative ions contained within the muscle, then the muscle must carry a positive charge externally and a negative charge within." Stimulation of the nerve brings about the well-known phenomena of negative variation by altering the permeability for ions ; and Bernstein's experiments have shown that the muscle current follows very accurately the laws governing ionic concentration chains. "The current of rest is due to the semi-permeability of the membranes for ions; and when the permeability of the membrane is altered through some agency which precipitates protein or causes it to go into solution, we get variations in the current of rest."*

The two chief laws of protein precipitation hold good for the physiological effects of ions. We have seen that protein forms the point of attack of many salts in the organism, and that by them a change in state is produced. This change of state consists of precipitation or solution, and frequently a coincident alteration in the state of the energy associated with the molecule. In the case of salts of the alkali metals and magnesium precipitation does not occur until a fairly high concentration has been reached;

* Pauli's 'Physical Chemistry in the Service of Medicine,' p. 150. 
and the precipitate redissolves when the mixture is diluted. In other words, the action is reversible. Certain laws govern these reactions. As already shown, the effect of the salt is the algebraical sum of the effects of its individual ions. Anions and cations antagonise one another; cations precipitate, anions inhibit the precipitation* in proportion to their power.

All cations have certain physiological characters in common. They precipitate protein. They more or less increase the irritability of muscle and nerve ; they excite intestinal activity and increase the blood pressure.

The anions have a solvent action on protein, or, to speak more correctly, they inhibit the action of cations in general. The physiological effect of the anions and their solvent action upon proteins increases through the scale, from sulphate to sulphocyanate. The sulphates, citrates and tartrates are protein-precipitators, because the anion is associated with the over-balancing properties of the metallic ions; they are therefore cathartics. But in the nitrates, bromides, iodides and sulphocyanates the anion has the predominating influence, the characteristic effect of which is sedative attended by a decrease of blood pressure.

The ions of salts of the alkaline earths and the heavy metals have likewise been studied, and have been shown to obey the above broad general rule, although their action is attended by complicating circumstances.

It has long been recognised that there was a certain * Brit. Med. Jour., 1896, ii., 837. 
relation between the cathartic effect of a salt and the metallic portion of it. It is now known that their effect in producing catharsis and diuresis is due in part to the increased blood pressure they cause and in part to their action upon the protein. The cathartic and precipitating power parallel one another in all of them. The heavy metals cause precipitation in any concentration.

The sulphocyanates are the last of the anion series, and possess the properties of the group in the highest degree. The $\mathrm{Br}$ ion has a well-marked sedative effect; the I ion has a multiplicity of effects such as lowering of blood pressure, influencing the metabolism of the thyroid gland, and the resolution of various inflammatory exudative products. Williamson has shown that under the influence of potassium iodide changes occur in the structure of leucocytes; in the small oxyphile leucocytes the granules become gradually less distinct, and eventually the protoplasm appears perfectly homogeneous and stains with eosin very feebly ; the larger eosinophile cells show no change whatever.* This effect was also observed under the influence of pilocarpin nitrate, sodium salicylate, carbolic acid, turpentine and camphor.

The sulphocyanates have been specially studied by Pauli and Bruylants. The latter showed that there is a relationship between the metabolism of the sulphocyanates and the purin-bodies. Edinger has shown that iodine and sulphocyanates exist in the same places in the organism; and that sulphocyanates do not pass through the body even in the

* Brit. Med. Jour., 1896, ii., 837. 
smallest doses without influencing metabolism. The . excretion of sulphocyanate is decreased when iodine is taken, and is completely stopped when iodine is produced; under such circumstances no sulphocyanate is found in the saliva.

Another factor is the relation between the effects of iodides or sulphocyanates and the effects of salts of the heavy metals or alkaline earths. "It has been definitely established through exact observation and experiment, that the iodides favour and bring about the excretion of ions of the heavy metals, e.g. lead and mercury, in cases of chronic intoxication. The explanation of this fact which has long been known therapeutically, has been sought in the formation of soluble albuminates which the iodides have been supposed to bring about."* In fact, the iodides not only inhibit the precipitation of protein by the metallic ion, but they dissolve already existing precipitates.

The heavy metals $\mathrm{Pb}, \mathrm{Zn}, \mathrm{Hg}$, etc., coagulate proteins even in the weakest concentration. There is at first a rapid increase in the power of precipitation with an increase in the concentration, but this falls to zero as concentration goes on. Still further concentration will cause a second precipitate, which is very heavy and again soluble. But the precipitating power of these metals suffers a great change in presence of the anions such as iodide and sulphocyanate. "If the ions of the metal are present in a low concentration the precipitation of protein is prevented altogether ; if present in larger amount the

* Pauli's "Physical Chemistry in the Service of Medicine," p. 84 . 
protein precipitation is markedly increased."* In the case of living animals only the former possibility, that of the presence of a low concentration of ions, comes into consideration. The iodides and still more sulphocyanates "act under these circumstances as substances which favour the formation of readily soluble ion-protein compounds through which the elimination of the heavy metals is greatly aided." $\dagger$

The relationship between the salts and esters was studied by Pauli through the sulphocyanates. Esters are combinations of an alcohol and an acid; they are scarcely dissociable into ions in aqueous solutions, and there is a wide difference between their power of entering the cells of an organism and that of the ionisable salts. Overton has shown that esters readily enter the cells because they are soluble in the lipoids-lecithin, cerebrin, cholesterin -of the cells. Salts on the other, hand enter the protoplasm with difficulty because of its comparative impermeability to them. The ester enters the cell and becomes saponified by union with the lipoids, whereby the anion of the acid is set free, and a physiological anion effect follows. Pauli found for instance that if an experiment be made with sodium sulphocyanate and the amyl-ester of sulphocyanic acid, a characteristic sulphocyanate effect will follow in both cases, but while 2 or 3 drops of the ester will cause a fatal intoxication in an animal, from 8 to 10 grains of the salt must be injected subcutaneously to produce the same effect. The ester enters the cell readily, and the anion is not set free until it is within it; but the p. 85 .

* Pauli's "Physical Chemistry in the Service of Medicine,"

$\dagger$ Loc. cit. 
salt is dissociable into ions before it reaches the cells, and the protoplasm is not so permeable to the ions as to the ester. There are numerous drugs having an ester-like construction. Cocaine is the methylester of benzoyle-ecgonin; eucaine is an ester; the orthoforms and anæsthesin are likewise esters. It is the presence of the alcohol radical which renders this effect possible; and the saponification of the ester by union with the lipoids of the protoplasm liberates the anion and permits it to become effective. Cocaine is twenty times more effective as an anæsthetic than benzoyle-ecgonin; nevertheless the latter is the active principle of cocaine and is dissociated from it by union with the lipoids of the cell. "Existence in the form of an ester is a sine qua non of a useful local anæsthetic whose active anions must enter the endings of the sensory nerves."* A consideration of the subject of narcosis was made by Meyer. When a substance is put into a vessel with two unmixable fluids such as oil and water, the amount of the substance which is dissolved in the oil and in the water was found by him to bear a definite proportion or relationship to each other. This observation led him to form a theory of narcosis which was based upon the distribution of the active substance between the watery fluids of the tissues and the fat-like constituents of the nerve cells.

The activity of metallic ions can also be increased by combination with an alcohol-radical or transformation into an ester; and most acute metallic intoxication can be brought about in animals by

* Pauli's "Physical Chemistry in the Service of Medicine,". p. 95. 
ethylic compounds of lead, zinc or mercury. Even in therapeutics advantage is sometimes taken of such ester-like combinations.

There is still another way in which the specific effects of many ions can be increased or decreased, viz. through the combination of one ion with another. This occurs when ions of the alkaline earths act upon protein in the presence of alkali metals. The precipitation of protein which can be brought about by the alkaline earths may be inhibited through the addition of alkali metals, or hastened through addition of the anions, the most powerful of which are the sulphocyanates. Indeed there seems to be a physiological antagonism between the monovalent cations $\mathrm{Na}, \mathrm{K}, \mathrm{NH}_{4}, \mathrm{Li}$, and the divalent cations $\mathrm{Ca}, \mathrm{Ba}, \mathrm{Sr}$, etc.; as well as a synergistic increased effect of the anions in the presence of calcium, barium and strontium. This physiological antagonism has already been noted in Loeb's experiments with ions upon the development of the eggs of Fundulus magellus, a small bony fish, upon the contraction of the swimming bell of medusæ and upon ciliary movement. There is a marked difference in the electrical charge carried by the monovalent and divalent ions, and this may be taken in part as explanatory of the antagonism between them.

The relationship of calcium, barium and strontium to the proteins is important, because of the position occupied by calcium in physiology and pathology. They occupy a position between the alkali metals and the true heavy metals. In common with the former they have a high precipitating power; in common with the latter they form a firm bond 
between the ion and the protein. This is important because of their affinity for the musculature of the heart and bloodvessels, and the processes of calcification, atheroma and arterio-sclerosis which depend upon such affinity. The firm union of the ion and protein takes place even before the precipitation limit is reached. But the precipitating power of the metallic ion is markedly depressed by the anion $\mathrm{Br}$, still more by $\mathrm{I}$, and most of all by the sulphocyanate anion, which also has a strong affinity for the protein. A firm bond can be formed by $\mathrm{Ca}$ even in the presence of iodide or sulphocyanate anions. The calcium-iodide-protein is however much more soluble than calcium-carbonate or phosphate-protein. The I ion not only forms a soluble proteincalcium combination, but by its presence inhibits or prevents the formation of insoluble calciumprotein combinations and favours the excretion of the metallic ion. This is the basis for the clinical observation that the eontinued use of iodides is useful in the treatment of arterio-sclerosis and will retard its course.

It has thus been established by experiment and clinical observation that the iodides and sulphocyanates bring about the excretion of lime, lead and mercury from the human system by forming ionprotein compounds which readily go into solution. Therapeutics may therefore continue to speak of the alterative and resolvent effect of drugs, and is presumably correct in speaking of such actions as the effects of ions upon the colloids. Indeed the action of all salts is the effect of its ions upon the colloids or crystalloids in the organism. Most of the alka- 
loids are also ionisable and have a similar mode of action. Many of the non-ionisable therapeutic agents, as narcotics, sedatives and bactericides, have, through their ester-like structure, an intimate relation with the lipoids of the cells and become ionised by combining with them. In this way an anion is liberated by which the pharmacological effect is produced. Just as the non-ionised compound finds its selective point in the lipoids, so the ionised ones find their point of attack in the proteins, "and a difference in the distribution or a replacement of the normal ions of the cell would be connected with changes in the state of the colloids and consequently of their functions."*

"The influence of ions upon physiological functions such as growth, irritability and life itself, is of importance not only to the biologist but to the pathologist, especially in connexion with the subject of disinfection. The experiments of Loeb have been already referred to; it was he who first observed that certain ions were toxic and others antitoxic to living tissues. The fertilised eggs of - Fundulus magellus develop equally well in distilled water or in sea-water. If however the eggs were put into a solution of $\mathrm{NaCl}$ of the same strength as sea-water they all died in a few hours. But if a small amount of calcium chloride, a constant constituent of seawater, be added, the development proceeds and normal embryos are produced. The sodium is toxic and the calcium ion antitoxic. This is an instance p. 86.

* Pauli's "Physical Chemistry in the Service of Medicine," 
not only of the toxicity of one of the ions, but of antagonism between a monovalent and a divalent metallic ion. An opposite effect of these ions upon medusæ was observed; the bell continuing to contract in a pure solution of $\mathrm{NaCl}$ after removal of the nervous system, and ceasing to contract when calcium or strontium was added; again, however, witnessing to the antagonism between the ions. Ciliary action is also stimulated by one and depressed by the other. The excised gastrocnemius of the frog is stimulated to contract by pure sodium chloride solution and checked by calcium or strontium; while, on the other hand, pure solution of sodium chloride is toxic to heart muscle, and calcium or strontium is antitoxic.

Extended observations of the effects of ions on heart tissue were made by Knight.* The experiments were upon the embryos of perch and Fundulus. The general result of the observations was that chlorides of the metals depress the heart beat; but the degree of the depression depends upon the kind of metallic ion. Heavy metals like $\mathrm{Cu}$ and $\mathrm{Au}$ caused the beat of the heart to fall gradually until it ceased beating, the ventricle ceasing first. Lighter metals such as $\mathrm{K}, \mathrm{Na}, \mathrm{Li}, \mathrm{Cs}$ were also used. Potassium and cæsium chlorides acted as heart depressants, the cation $K$ being more energetic, and the auricle continued to beat a few times after the ventricle ceased to contract. Calcium and strontium stimulated the contractile efforts of the heart; while $\mathrm{Mg}, \mathrm{Ba}, \mathrm{Be}, \mathrm{Zn}$, and $\mathrm{Cd}$ acted as depressants. The addition of calcium chloride to the solution always * Brit. Med. Jour., 1897, ii., 1484. 
inhibited the depressant effect of $\mathrm{K}$ and $\mathrm{Ba}$. In these observations we see the effect of cation and anion. The positive electrical charge of the metallic ion counterbalances the negative electrical charge of the native protein. Many of the cations increase the irritability of both muscle and nerve. The ions of $\mathrm{Ba}, \mathrm{Ca}$, and $\mathrm{Sr}$ stand between the alkali metals and the heavy metals as regards protein precipitation, but they stimulate irritability. The anion effect is seen in the depression which follows the ions of the halogen compounds, unless it is overbalanced by the metallic ion.

Experiments showing the influence of ions upon growth were made by Moore, Roaf and Whitley on the tadpole of Rana temporaria and other cellular structures.* Living cells are very susceptible to a change in the proportion of $\mathrm{H}$ and $\mathrm{OH}$ ions, both of which are toxic when the concentration exceeds a certain degree. The toxicity of acid salts is due to the $\mathrm{H}$ ion, of alkaline salts to the $\mathrm{OH}$ ion. An increase of alkalinity tends to an increased cell division or growth of parts; but cell division becomes irregular or ceases if the $\mathrm{OH}$ ions exceed a certain concentration. Acids and acid-salts, on the other hand, exhibit a retarding influence on growth, cell development being arrested. Neutral salts do not show much toxicity; they have very little effect until the osmotic pressure rises above that of the body-fluids of the organism. When the isotonic point is reached there is a short range at which these salts are toxic, dependent upon the effects of the metallic ion. Barium and ammonium are toxic

* Brit. Med. Jour., 1906, ii., 1788. 
before the isotonic point is reached. Ions of the phosphates favour cell development when the ionic concentration is low, but retard it when the concentration is high.

Upon micro-organisms their influence was studied by Krönig and Paul*, who used specially the spores of anthrax and Staphylococcus pyogenes aureus for their experiments. These are of importance in connexion with the subject of disinfection, and the reader is referred to the original paper for a fuller account of the observations of which a mere outline can be given :

1. The ions of $\mathrm{Hg}, \mathrm{Cu}, \mathrm{Ag}, \mathrm{Zn}, \mathrm{Cd}, \mathrm{Pb}$, and $\mathrm{Au}$, are all toxic. They are protein precipitators even in the lowest concentration. The observers found that the toxic action of salts of these metals upon living vegetable cells stands in a definite relation to the electrolytic dissociation. The action of the metallic ion depended not only upon the specific effect of the cation, but upon the ionic concentration and association with an anion. The halogens $\mathrm{Cl}, \mathrm{Br}$ and $\mathrm{I}$, have a destructive effect which decreases as their atomic weight increases. Not only the halogen, but the cyanogen compounds of $\mathrm{Hg}$ disinfect in proportion to their dissociation. The disinfecting power of an aqueous solution of mercuric chloride is diminished by addition of $\mathrm{HCl}$ or another halogen compound, probably through the recombination of ions. (An instance of the dissociation of one substance into ions and their recombination to form another substance is observed after testing diabetic urine with Fehling's solution. If

* Zeit.f. Hyg. und Infectionsk., 1897, xxv., 112. 
the contents of the test-tube are allowed to stand for a few days, the decolorised fluid gradually regains its blue colour from a recombination of $\mathrm{Cu}$ and $\mathrm{SO}_{4}$ ions.) Neutral salts have an extremely feeble power of destruction over the bacteria. But the disinfecting power of nitrate, sulphate or acetate of $\mathrm{Hg}$ in aqueous solution is increased by the addition of a halogen compound. This clearly shows the association between certain metallic ions and anions.

2. The acids, both inorganic and organic, have a destructive effect upon the bacteria which is proportionate to the concentration of $\mathrm{H}$ ions in the solution. Oxidising agents, e.g. nitric, chloric, permanganic acids, have their power increased by addition of a halogen acid, as $\mathrm{HCl}$ to permanganic acid.

3. The alkaline salts of $\mathrm{K}, \mathrm{Na}, \mathrm{Li}$ and $\mathrm{NH}_{4}$ in solution were also destructive to the bacteria in proportion to the concentration of $\mathrm{OH}$ ions. $\mathrm{H}$ ions are more destructive to anthrax spores and staphylococcus than $\mathrm{OH}$ ions in equal concentrations.

The direct application of ions as a therapeutical agent has been put to practical use. In a paper read by Professor Stéphane Leduc an account was given of such a mode of application. The facility of introducing electrolytic substances through the skin or surface of a wound increases the power of medicine. The knowledge that the electric current provokes an exchange of contents between the constituents of two different electrolytes or between two different cells has been taken advantage of in therapeutics. Such an interchange can take place at the surface between the skin and the electrodes. 
"As the cations go down the electric current and the anions go up, so under the anode the cations will penetrate through the skin, while the anions will penetrate under the cathode."* This is a regular effect, and by taking advantage of it many electrolytic substances can be introduced through the skin under the impulse of the electric current. The coagulation of plasma forms no obstacle to the entrance of such ions, and their action will be in proportion to the permeability of the proteins to the ions.

In the direct ionic application the electrodes are covered by fifteen to twenty layers of absorbent lint or other tissue and well soaked in the solution to be ionised. Fresh tissue must be used at each sitting. The solution must be made with pure distilled water, otherwise the introduction of undesired ions may result. Iodine ions can be introduced into the thorax by this method. The solution of sodium or potassium iodide is applied on absorbent tissue to the eathode and this to the affected part, and a current of 60 to 100 milliampères is sent through it. The ions have a great speed, for they are driven not only by the electro-motive force, but by the high osmotic pressure; and in ten to fifteen minutes iodine appears in the saliva and can be detected by starch. The solution must be applied by the cathode, for if it be applied at the anode no iodine will be found in the saliva. $f$ This mode of treatment may be used in thoracic diseases, in ankylosis, scoliosis, old neuralgias, and other ailments. Ions

* Brit. Med. Jour., 1907, ii., 631.

$\dagger$ Loc. cit. 
other than iodine can be used. Care must be taken in carrying out the application, for a caustic effect is apt to be produced. It is necessary to use a current of strong intensity and density to produce the therapeutic effect. "If the application is defective the proper intensity cannot be reached, the skin being burnt. This burning of the skin is the main obstacle to electro-ionic medication; but it is in a large measure avoidable."* It is caused by the $H$ and $\mathrm{OH}$ ions produced at the electrodes, both of which enter the skin and are destructive to the cells in such a high ionic concentration. But with proper precautions as to the covering of the electrodes, their cleanliness, and careful application to the skin, the caustic ions may be prevented from destroying or even damaging its cells.

This treatment opens up a new path in therapeutics, and by following it a new mode of medication may be devised for many ailments.

* Leduc : loc. cit. 


\section{VI.-OXIDATION AND IMMUNITY}

According to the view which was formerly generally accepted, animal oxidations occurred in the fluids of the organism. To-day, led by Pflüger and other investigators, we believe that oxidation occurs in the tissues, and with formed elements. How oxidation occurs is not a settled point, but it may be viewed from the ionic standpoint.

A body which is oxidised by neutral oxygen at the temperature of that body is said to be easily oxidisable or auto-oxidisable. On the other hand, bodies which are indifferent or nearly indifferent to neutral oxygen, as the proteids, fats, and carbohydrates, are not auto-oxidisable, but are said to be dys-oxidisable or brad-oxidisable substances. How do such oxidations take place? In auto-oxidation a cleavage of the neutral oxygen into ions occurs. The auto-oxidisable substance combines with one of the oxygen ions, while the other is free to oxidise dys- or brad-oxidisable substances which may be present at the same time. The latter is called a secondary oxidation.

Living protoplasm has a peculiar construction dependent upon the special construction of its proteins. These are called living or active proteids or biogens; and they differ from non-living proteid, such as is 
seen in the serum and tissue fluids, in being more unstable or having a greater tendency to intramolecular change. We have already seen that this instability is ascribed by Pflüger to the presence of cyanogen, and by Latham to cyanhydrines in the molecule. But it is claimed by Verworn that the changes are due to the introduction of oxygen into the biogen molecule, which he considers has a sidechain of an aldehyde character to act as an oxygen receptor. Loew considers that instability to be due to the simultaneous presence of an aldehyde and amino-acid groups in the molecule. He believes that in the living proteid they are separate, and that when they combine the protoplasm dies or is changed into a stable, non-living proteid.

The oxidations which occur in living protoplasm are explained differently. If the protoplasmic proteid is not indifferent to neutral oxygen, there may be a cleavage of the oxygen molecule whereby the living proteid is oxidised by one of the ions, the other ion being free to act upon more difficultly oxidisable substances by a secondary operation. Another widely different theory is that reducing substances are formed by the protoplasm, which split the neutral oxygen molecule, uniting with one and setting the other free. The cells of animal tissues and organs have the property, like the cells of lower organisms, of splitting dys-oxidisable substances into such as are more easily oxidisable, perhaps with the production of nascent hydrogen. The oxidation of the readily oxidisable substances as produced by ionisation of oxygen leads to the secondary oxidation of the less oxidisable ones; and the products undergo further 
cleavage and oxidation until they arrive at the final stage of metabolism.

According to Traube,* we have to deal in the first place with the splitting of water into $\mathrm{H}$ and $\mathrm{OH}$ ions. The $\mathrm{OH}$ ion combines with and oxidises the oxidisable substance; while the $\mathrm{H}$ ion combines with neutral oxygen to form peroxide of hydrogen; the latter again having an oxidising action. It is known that $\mathrm{H}$ and $\mathrm{OH}$ ions are toxic to cellular tissues, and it is affirmed by Loew that certain cellular enzymes which he calls catalases protect the cell from the effects of these ions.

The above supposes a direct oxidation of the primary active substance. Animal oxidations may however be brought about by oxygen-carriers, or bodies which, without being oxidised themselves, alternately take up and introduce oxygen into substances which are oxidised with difficulty or dysoxidisable. These were called by Traube oxidation ferments and later oxidases. Little is known about the nature or action of ferments. Some however are nucleo-proteids, others, like the catalases, are proteoses, while, on the contrary, liver-aldehyde and laccase are not of a proteid nature. Some are direct oxidases, others are indirect or peri-oxidases. They seem to have a pronounced specific action, or as Ehrlich calls it monotropism, that is to say, they oxidise certain substances and not others. Their action is not well understood, but it is a catalysis, produced by intermediate reactions. Some of these oxidases contain iron or manganese, and as these salts are

* Hammarsten's "Physiological Chemistry," p. 6 (American Edition). 
known to be catalysers, so the important rôle of oxygen-carrying by the oxidases has been ascribed to these salts.

In animal organisms, oxidation has been looked upon as a combustion of material. This comparison may still be considered to hold good. In the combustion of devitalised organic products, such as wood, coal or oil, there is first a decomposition into other substances before the phenomenon of light is produced. In the living organism, chemical energy is transformed into heat and work by various oxidations, whereby there is a cleavage of complex substances into simpler and more stable compounds. Such a decomposition results from the preliminary dissociation of water into $\mathrm{H}$ and $\mathrm{OH}$ ions, which react upon the substance to be decomposed; it is called a hydrolytic cleavage, e.g.-

$$
\begin{gathered}
\text { Tristearin } \\
\mathrm{C}_{3} \mathrm{H}_{5}\left(\mathrm{C}_{18} \mathrm{H}_{35} \mathrm{O}_{2}\right)_{3}+3 \mathrm{H}_{2} \mathrm{O}=\mathrm{C}_{3} \mathrm{H}_{5}(\mathrm{OH})_{3}+3 \mathrm{C}_{18} \mathrm{H}_{36} \mathrm{O}_{2} \text {. }
\end{gathered}
$$

Such cleavages can be produced outside the body by means of acids and alkalies. But the animal organism has a better way of producing the cleavage, and that is by means of the enzymes; such as the proteolytic, amylolytic and lipolytic enzymes of the alimentary canal.

The action of the enzymes seems to depend upon the stereometric construction of the molecules acted upon. Each acts upon a special kind of substance or is monotropic ; thus, the enzymes of yeast act only upon $a$-glucosides, while emulsin will only act upon $b$-glucosides. But the manner of their action is still unknown. Certain work done by Ikeda, Bredig and 
Reinders upon lipase, invertase, diastase and emulsin, shows that there is a marked correspondence between catalysis and enzyme action. By working with inorganic colloidal solutions, such as platinum and gold, Bredig was able to show that they had such a strong resemblance to the action of enzymes that he called them inorganic ferments. This correspondence has led to the idea that ferment action is due to the play of electricity which comes with the metallic ions in colloidal solutions. We have seen that a colloidal solution consists of very fine particles which have assumed an electrical charge through giving off ions, just as have electrodes. In consequence the enzymes act pretty much like electrodes. Some of these ferments, called catalysers, determine the direction of a reaction, whether it shall be oxidation and reduction or hydration and splitting off of water. Such catalysers can act in two directions, depending on the relationship between the original substance and those to be formed. Amygdalin can be split into amygdalic nitril glucoside and glucose under the influence of yeastmaltose; it can also be rebuilt from these constituents by help of the same enzyme. In the living organism many antagonistic reactions take place under the influence of such catalysers. The synthesis of glycogen from dextrose, and the splitting of glycogen into dextrose, represents such an antagonistic reaction, in which the dextrose becomes polymerised into glycogen, with loss by the molecules of $\mathrm{H}$ and $\mathrm{OH}$ ions ; "while the synthesis of starch in plants and its diastatic splitting into glucose or maltose represents a heterodome antagonistic reac- 
tion in which the synthesis has the upper hand by day and the analysis by night."*

The colloidal constitution of living matter is intimately connected with the most important problems of biological chemistry. Chemical reactions of the most different character are simultaneously possible in the colloidal ground substance of the cell. Antagonistic reactions such as oxidation and reduction, hydration and dehydration, condensation and polymerisation, synthesis and analysis, go on almost side by side. "Just as the chemist allows different chemical reactions to take place in different vessels, the cell is believed to utilise the different chambers of its honeycomb structure, and, with the aid of colloidal ferments, allows the necessary reactions to go on independently of each other." $\dagger$ The laws of colloid chemistry govern the changes that go on in the cells, but these laws are modified by the processes of metabolism and their variations are not clearly understood. In the cells the colloids are more or less jelly-like or in the condition of gels; but in the tissue juices they are in the fluid condition and are called sols.

In intra-cellular substances there is a certain parallelism between the changes in colloids and the cellular manifestations, such as in swelling, absorption, movement, and the effects of various stimuli. But the extra-cellular substances of living organisms are subject to direct control by the laws of colloidal chemistry, as investigations have shown. A study of the phenomena exhibited by extra-cellular col-

* Pauli's "Physical Chemistry in the Service of Medicine," p. 64 .

† Loc. cit., p. 58. 
loids is therefore of importance in view of the modern teachings respecting immunity.

The living organism produces curative or protective agents in the blood, antigens and antibodies. The antigens are substances which give rise to the antibodies. Their chemical composition is unknown, but they have a colloidal constitution. The study of these substances was begun with the discovery of antitoxins by von Behring.

The antibodies, such as antitoxin and antibacterial substances, are monotropic, i.e. "they are so to speak charmed bullets which strike only those objects for whose destruction they have been produced by the organism, and they are directed against bacteria or against the products of their metabolism (toxins) which cause disease."* The cause of this specificity is in Ehrlich's opinion the effect of the chemical relation which exists between the infective body and the antibody. They fit one another as a key fits a lock. The colloid nature and chemical reactive power of the immune substance do not exclude one another ; $\uparrow$ for colloids possess certain groups of atoms which render them capable of reactions of a synthetic nature. "The condition for this action is the presence of two groups, whose chemical relationship is of the closest and whose interaction is therefore a condition of their union. This action as to union is the basis of my side-chain theory." $\ddagger$

* Ehrlich: "The Harben Lectures," Jour. Roy. Inst. Pub. Health, 1907, p. 323.

$\dagger$ Loc. cit.

+ Ehrlich: "The Harben Lectures," Jour. Roy. Inst. Pub. Health, p. 324. 
In the case of toxins, there must be a connexion between their chemical constitution and action, just as there is in well-known poisons. In cocaine the anæsthetic effect is due to the benzoyl-radical, which in consequence Ehrlich calls the anosthesiophore; the soporific effect of sulphonal and other disulphons is due entirely to the ethyl-radical; and so on. Similarly there is in the toxin a group which causes the peculiar effect of the toxin, and this is called by Ehrlich the toxophore group.

But the toxophore group is not of itself sufficient to bring about the poisonous action. There must be some peculiarity of the toxin which causes its distribution, and this action he attributes to a haptophore group. Similarly there must be a corresponding chemical group in the cellular protoplasm which reacts with them, and this is called the receptor. The toxin action can only occur when there are present such receptors fitted to anchor the toxins. "We can prove the existence of receptors,"* and the binding action or anchoring of toxins by such receptors plays a great part in immunity.

In order that the poisonous action of the toxin may take place, we must presume not only the presence of fitting receptors, but that they are present in a position favourable for the toxic action to be brought about. When the receptor and the organs sensitive to the action of the toxin are present, the conditions for infection are most favourable; distribution takes place at once, and the poison

* Ehrlich: "The Harben Lectures," Jour. Roy. Inst. Pub. Health, p. 326. 
circulates until it reaches the sensitive cells. When receptors are not present the animal possesses natural immunity; when they are present the organ or body is more or less sensitive to the poison, and antibodies are formed.*

According to the views of Ehrlich, antibodies are purely and simply receptors fitted for union with the poison ; that when antitoxin is used therapeutically we are merely injecting a number of receptors which will reinforce those of the organism. The toxins are anchored to such receptors by the haptophore group; and when they have anchored the toxin, the work of the receptors, as such, is done.

All antibodies act in a similar way. But they have another action upon the anchored substance. This action may be direct, as in the case of the precipitins and agglutinins. It may, however, be indirect, as in the case of the opsonins, which render the bacterial cells assimilable by phagocytes.

There is another class of antibodies called by Ehrlich the amboceptors. They are present in the blood serum of normal animals, and are of various kinds. They are considered by Ehrlich to play an important rôle even in the normal condition. "I hold that this function in physiological life is that of seizing upon and elaborating nutritive substances." $\dagger$ They also arise as a new formation during the process of immunisation.t They are characterised by monotropism, and their presence renders the cell liable to the action of a toxin-like

* Ehrlich: "The Harben Lectures," Jour. Roy. Inst. Pub. Health, p. 326.

$\dagger$ Loc. cit.

$\ddagger$ Loc. cit. 
constituent said by him to be present in the blood serum, and called the complement. The complement is also a normal constituent of the blood serum, but has no direct relation to the cell. It is harmless by itself, but, like toxin, has a toxophore and a haptophore group. The amboceptor-laden cell is exposed to the action of the complement of the serum, and the latter acts upon the cell through the influence of the amboceptor. Complement and amboceptor stand in a direct relation to one another, and become anchored together. This is not a relationship due to a maximum chemical affinity; but rather a loose relationship with perhaps a reversible action.

The amboceptor is able to combine with substances of the most varied kind, providing they possess fitting receptors. The peculiar power of the amboceptor to fix a large number of complements is, therefore, not to be wondered at. But if the entire mass of amboceptors reacted in an active manner upon the entire mass of the complement, the latter would all be anchored to the complementophile group of the amboceptors, and there would be no free complement in the living body. This would produce a grave condition of affairs. For as soon as there arose occasion for the action of complements with any special kind of amboceptor there would be no complement available, all being used up by the action of indifferent amboceptors. It is owing to the fact that the complements are free or only loosely joined to amboceptors that they are ready for use at any given moment. The maximum stimulus to action is made possible by anchoring the amboceptor to the erythrocyte, the avidity of 
which for the complement is carried to the maximum. The amboceptor exercises the function of bringing about a modification of the conditions which determine the distribution of the complement. It causes the complements to become monotropic by union with its substance; and the complements are localised by amboceptors which are united with some other substance such as the cells. Such is the amboceptor theory of Ehrlich.

That the proteid substances are able to act upon one another is undoubted. But all authorities are notagreed upon the foregoing explanation. Ehrlich's theories are not accepted without an attempt being made to render the subject somewhat clearer. This attempt is made through the study of the action of ions upon colloids and by the laws of colloidal chemistry; to which we must now return.

"Let us suppose that a sufficient number of ions are introduced into a colloidal solution of a metal, which represents a suspension of weakly charged electro-negative particles. In consequence of electrical attraction, the negative colloidal particles will collect about the electro-positive ions, until, through the heaping up of a sufficient number of such particles, the collecting ions will be electrically neutralised. When the aggregates thus formed have reached a sufficient size, the solution becomes turbid and finally a precipitate drops to the bottom."* According to the ionic theory a similar process takes place in the reactions of precipitins, agglutinins, and probably the antitoxins.

* Pauli's "Physical Chemistry in the Service of Medicine," p. 109. 
Just as there are colloids which carry an electronegative charge, so there are others which carry a positive charge ; and each kind will be precipitated by an oppositely charged ion or colloid. Oppositely charged colloids will precipitate one another, just as the ions of salts precipitate colloids ; and, owing to the greater size of the meres or colloidal particles, the conditions for the formation of large aggregates are very favourable. In this again we see the importance of the ionic theory. A study of the phenomena exhibited by the extra-cellular colloids in the light of this theory will, it is hoped, throw more light upon the immunity reactions. How these are brought about is by no means yet clear to us. But colloids undergo changes, not only by reacting upon one another, but by giving off ions, as we have already seen. Indeed, colloidal particles become remarkably changed by the loss of a side-chain or a few atoms from the molecule. As the colloidal particles grow smaller by this loss of side-chains or ions, their electrical charge grows, and they approximate more and more to the nature of ions, until, finally, the colloid may pass over by dissociation in the solution into strongly charged ions.* The converse of this is possible and probably takes place in the reconstruction of the digested and assimilated nutritive particles into the colloidal material of proteids, carbohydrates and fats.

An important point in connexion with the precipitins is that the precipitation of colloids is only possible in the presence of salts. If for instance the

* Pauli's "Physical Chemistry in the Service of Medicine," p. 120. 
proteins or bacteria under investigation are mixed with the specific substance under consideration in a salt-free condition no reaction occurs. The specific substances may therefore be looked upon as giving to the colloidal protein the properties of sensitive colloids, and of being precipitated through the presence of a small amount of salt-ions.*

Again : two reacting colloids show an optimum for precipitation, and an inhibition of the precipitating process when one is in excess. This is a generalised phenomenon of colloids in agglutination, and, according to Biltz, is observed in nearly all immune-body reactions. The bacterial antitoxin sera show a maximum effect when they contain a medium amount of the immunising substance.

The proteins, including the antibodies, according to Landsteiner, represent amphoteric substances; that is, substances which assume basic properties in acid substances and acid properties in alkaline solutions ; they change the sign of their electrical charge with a change in their reaction. "But there exists a zone between the extreme changes of their electrical charges when these hermaphrodite-like substances respond to the slightest change in their surroundings." That these normally sensitive colloids have at one time a positive and at another time a negative kind of electricity is evident from facts; and Landsteiner's attempt to explain the specificity of antibodies is based upon his conception of the rôle played by these amphoteric substances.

The side-chain theory of Ehrlich, developed by

* Pauli's "Physical Chemistry in the Service of Medicine," p. 123. 
him to explain his views of immunity, does not satisfy all the conditions. He has utilised the fact that the affinity of toxin for antitoxin, and the toxicity of toxins, vary independently of each other to support the idea that each contains a toxophore and a haptophore group, which supply the materials for the reaction. But Arrhenius, Gruber, Pauli, and others, who seek for an explanation of the facts by the light of the ionic theory, consider that toxin and antitoxin consist of a mixture of compounds which have a weak affinity for each other; and that Ehrlich's assumptions are not supported by the facts of colloidal chemistry.

It is through a study of colloidal chemistry that we may also expect to find an explanation of extracellular phenomena such as the development of cartilage and bone, and the precipitation of crystalline substances in these and other tissues. The nucleus of the question consists of the fact that we are dealing on the one hand with the simple process of crystallisation, and on the other with the formative influence of the cells and forces destined to act upon them. The colloids constitute an excellent means of keeping slightly soluble salts in solution, under certain circumstances, by uniting with the ions of the salts to form aggregates which in the case of protein are not necessarily precipitated (vide ante). If however through some influence, such as metabolism, the dissolving protein is destroyed, a precipitation of the colloidal material may occur. Crystals being once formed may serve for centres of continued crystallisation. It is in such a conception of the vital activities of the cell and cystallisation 
that we may expect to find an explanation of the pathological processes of calcification and deposition of uric acid, or on the other hand the physiological calcification and ossification which occur as a result of the metabolism of the tissues.

The theory of ions, nascent or unattached meres of substances having an electrical reaction and arising from molecular forms of matter by dissociation, is, from the view taken in the foregoing pages, extremely important. Whether it is possible to construct a working hypothesis of life upon-it appears quite probable in the light of recent progress in electro-biology and bio-chemistry. The time has not yet arrived when we can say exactly what life is or what constitutes the difference between dead and living matter, although the question has been considered philosophically for centuries. Important as ionisation is in constructive and destructive processes there must be something which initiates those processes, some at present unknown cause of their continuance. The riddle of contractility still remains unsolved. What is defined as life is the product of all the forces acting in an organism, but the fons et origo from which these forces are initiated is still an unknown quantity. When a child is fed on milk, the proteins are first split up by the alimentary enzymes into ions or some analogous forms of matter in an active state which may be called meres. While in this active condition they are ready for union with other ions, meres, or analogous forms of matter, to construct new protein molecules or to be reduced to a lower grade of chemical constitution on their way to urea. When a cell makes 
use of serum-protein for the formation of its own special proteins, the serum-protein is first broken down into fragments which consist mainly of amino-acids. How is protein reconstructed? We must either admit that matter may be in two forms -active and passive - or we must assume that a distinct vital principle is involved in the process of reconstruction. If we admit that matter about to undergo construction into molecules of something else is in an active form, such as ions, or meres analogous to them, it would be difficult to draw a line between the activity of ions in electrolytic conduction and such matter in the course of construction into fat or cellular protein. It is the old question of a vital principle as distinct from chemical force or physical energy. What is it renders the matter active, which enables ions or meres to form organic substances, which produces will and reason? The vitalist argues that it is a vital force which mysteriously moulds the elements into organic tissues, the tissues into organs, and the organs into an organism. The physicist says life is the sum of the particular vital activities exhibited by an organism. According to the first theory it is antecedent to and the source of all vital phenomena; according to the latter it is the result of the numerous activities exhibited by an organism and dependent upon various forces. Life is the result of the communication of motion to previously inert matter, a transformation from passivity to activity, and the conversion of that activity to a particular mode of action, whether it be dominated by blind energy or a purposive and intelligent force. 
In writing Finis to this little work I gratefully acknowledge the amount of information derived from the many sources quoted. Especially do I acknowledge the free use I have made of Pauli's valuable "Physical Chemistry in the Service of Medicine," of Hammarsten's "Physiological Chemistry," Newth's "Inorganic Chemistry," Möller's "Chemistry," Morgan's " Physical Chemistry," and several other works. According to the conception of natural phenomena in these works, transformation of energy forms the kernel of all phenomena in Nature. This principle however has not yet solved the problem of life phenomena and has merely touched the fringe of that subject, great as must be acknowledged is the progress that has been made in manydepartments. While physicists alone have been unable to exhaust the problem of life, the teaching of a vital force is again to the fore; and the neovitalists, tracing back their theory to the anima of Georg Ernst Stahl, urge that vital force alone can account for the phenomena of vitality. It requires care in the employment of the ionic theory to the explanation of vital phenomena not to mistake "the death-dance of the molecules" for living vitality. The assertion of Ostwald that we react only in proportion to differences in energy also requires limitation; for there is little doubt that at different times we react differently to the same degree and kind of stimulus. The quality of the stimulus is as important as its quantity; noise is not music necessarily, although the same amount of energy may be exhausted in producing the vibration.

It may be that belief in a vital force will continue. 
It will only bow to the laws of energy, and cease to exist when our knowledge of natural phenomena has reached a higher level than at present. This knowledge can only be gained through more exhaustive research in organic domains by the aid of biochemistry, and further dynamical research into the relations of matter and force. There are forces at present only vaguely understood, forms of matter so subtle that it is almost impossible to say they are material. There are forms of matter, like radium, from which inconceivably minute particles radiate at a velocity of two thousand miles a second, and the exhaustion of a minute grain of which would occupy millions of years. The energy radiating from such matters is exceedingly great; and our knowledge of such substances is very recent. As knowledge progresses other forms of force not yet known or understood may come within our cognisance and help to make clear the subject of vitality. It is conceivable that matter is energy in another form. That the energy which renders matter active and capable of uniting into organic molecules arises by the transformation of energy possessed by infinitesimal particles radiating throughout the universe. If energy is not matter in another form, it is so closely associated with it that one might almost say that force is indissoluble from matter; that where matter is, there also is energy ; and that the more complex the molecules become the higher is the form of force associated with the material forming them, and so from ions which convey electricity matter passes through various stages of activity, until it reaches the highest form in the cells of the nervous system. 


\section{INDEX}

ABEGG on formation of ions, 16 Absorption of ions, 21, 32 Acids, 59

Affinity of matter, 48

Amboceptor theory, 117

Amides, 68

Amines, 66

Amino-acids, 42, 67

Emmerling on the, 41

Amphoteric substances, 123

Anæsthetic ions, 101

Anions, 17, 49

Antagonism of ions, 97, 102

Antibodies, 117

Application of ions, direct, 108

Atom as a system, the, 6

Atomic theory, 1

Atoms, chain theory of, 52

vortex theory of, 46

Bacteria, effects of ions upon, 107

Barker on amino-acids, 42

Bein, influence of septa on ions, 20

Biogens, 76

Calcification, 124

Carbohydrates, evolution of, 53

Catalases, 113

Cations, 17, 49 ,

Cells, electric reaction due to ions, 95 axi

Chain theory, 52

Cholin, 69

Colloidal constitution of living matter, 85

Colloids, 83
Colloids, action of ions on, 88 animals dependent on, 88

Condensation theory, 2

Contractility influenced by ions, 23,29

Constructive processes in plants, 34

Cyanhydrines, 77

Cyanogen compounds, 77

Cyanogen theory of living matter, 77

Dissociation, 12

Diurëides, 72

Electrical potential due to ions, 81,92

Electricity conveyed by ions, 17

Electrolytes, 13

Electrons, 5

Enzymes, 88, 114

Erhlich on immunity, 117

Esters and ions, 100

Evolution of organic matter, 46

Excretion of metals, 99

Fats, evolution of, 59

Fischer on proteins, 40

Functions influenced by ions, 21, 29

Globulins, solution of, due to ions, 81,88

Glucosamine, 55

Graham on colloids, 83

Growth influenced by ions, 24, 104 
Halogens, the, 61

Heart, effect of ions upon the, 28 Heat due to ionisation, 26, 36

Howell on the heart, 29

Hydrocarbons, evolution of, 57

Hydroxyl, effect on growth, 106 Hydroxylamine, 39,66

Imides, 68

Immunity and oxidation, 111

Ions, the, 12

absorption of, 21

and esters, 100

and lipoids, 100

and oxidation, 111

antagonism of, 90, 97, 102

anions, 17

applied in therapeutics, 108 conduct electricity, 17

effect on contractility, 23,29

on growth, 24, 104

on the heart, 28,105

on micro-organisms, 107

on the organism, 80

on proteins, 85,94

on taste, 22

physiological, of, 96

essential to the organism, 90,92

give the electrical charge, 92 how formed, 12

hydroxyl, effect on growth, 106

in biology, 30

in immunity, 111, 121

in pharmacology, 96

in plants, 31

their electric charge, 17

their reaction, 17

their valency, 49

their velocity, 18

Ion-protein compounds, 89

Kalenberg on taste due to ions, 22

Kinetic theory, 1

Lecithin, formation of, 51

Lipoids and ions, 100
Living matter, 30,73 characters of, 7 evolution of, 46 instability of, 76 Pflüger's theory of, 77

Loeb on contractility, 27

Matter, affinity of, 46

polarity of, 47

theories of, 2

valency of, 49

IrcKendrick on life, 30

Meres, 12, 84

Metabolons, 5

Metals, excretion of, 98

Micro-organisms, effect of ions on, 107

Millikin and Stiles on action of ions, 27

Mineral constituents of body are ions, 81

Muscular activity and ions, 25

Nägeli on living substance, 30

Nitrogen compounds, 64

Non-electrolytes, 13

cannot displace ions, 92

Osmotic pressure due to ions, 19

Ostwald on reaction, 127

on permeability of cells, 96

Oxidases, 113

Oxidation and ions, 111

Pauli on electrical charge of proteins, 94

on ions and lipoids, 100 in immunity, 121

on living matter, 86

on physiological effects of ions, 96

on sulphocyanates, 100

Permeability of cells to ions, 95

Pflüger's theory of living matter, 77

Phosphorus compounds, 61

Physiological effect of ions, 96

Polarity of matter, 47

Proteids, evolution of, 43 


\section{INDEX}

Protein-ion compounds, 89,92 Proteins, 39 construction of, 42 electrical charge due to ions, 92

kept in solution by ions, 81 , 88

Pauli on, 85, 89, 94 synthesis of, 64

Protoplasm, effect of ions on, 23

Radio-active bodies, 5

Receptors, 117

Richards on taste, 22

Sugar formation, 54

Sulphur compounds, 63

Synthetic processes in plants, 41 , 53

Taste due to ions, 22

Therapeutics, ions in, 96, 108
Theory of amboceptors, 117

of atoms, 1

chain, the, 52

condensation, 2

kinetic, 2

Pflüger's, 77

vortex-atom, 46

Toxicity of ions, 23, 104

Traube on oxidation in the tissues, 113

Urea, 70

Uric acid, 72

Valency of the atoms, 49

Variability of electric reaction, 95

Verworn on living matter, 76

Vital force, 10, 126

Vitalism, 125

Vogt's theory of matter, 2

Vortex-atom theory, 46 


\section{A SELECTION FROI MESSRS. REBMAN'S LIST.}

VITALITY FASTING AND NUTRITION. A Physiological Stady of the Curative Power of Fasting, together with a New Theory of the Relation of Food to Human Vitality. By Hereward Carrington, Member of the Society for Psychical Research, etc., etc.; with an Introduction by A. Rabagliati, M.A., M.D., F.R.C.S. (Bradford).

This book presents a mass of entirely new material to the scientific world as a whole on a great variety of subjects. New theories are advanced as to the nature of disease, the action of drugs and stimulants, the germ theory, the quantity of food necessary to sustain life, of cancer, insanity, pain, fatigue, sleep, death, the causation and maintenance of bodily heat and of human vitality. Altogether one of the most remarkable books of recent years.

Just Ready. One Royal 8vo. volume of about 700 pp., cloth, price 21s. net.

\section{ARCHIVES OF THE ROENTGEN RAY. A Review of Physical Therapentics.}

Published Monthly. Price 1s. 6d. net (postage 2d. extra). Annual Subscription, payable in advance, $16 \mathrm{~s}$.

THE PRINCIPLES OF QUALITATIVE ANALYSIS, From the Standpoint of the Theory of Electrolytic Dissociation and the Law of Mass Action. By WhHelu Böttger, Privat docent in the University of Leipzig. Translated, with the Author's sanction and revised with his co-operation, by W. G. Smeaton, Instructor in General Chemistry in the University of Michigan.

The Chemical Neros says: "Prof. Böttger's book is well adapted to aid the teacher to expound the subject in a thoroughly scientific manner and in accordance with modern conceptions. There can be no question that it is a particularly valuable treatiso on the general principles and methods."

The Lancet states: "The publication of such a work bids fair to displace entirely the commonplace text-book of analysis, of which there is, or was, no end."

Royal 8vo., $316 \mathrm{pp}$., with a Coloured Plate and 10 other Mlustrations, cloth, price 9s. net.

\section{ELECTRIC IONS AND THEIR USE IN MEDICINE. BY} Professor Stephane Leduc, Professor at the School of Medicine at Nantes. Translated by R. W. Mackenna, M.A., M.B., Ch.B. Edin., Physician to the Liverpool Skin Hospital. With an Appendix by the Translator. Only authorized translation from the French Edition.

EXTRACT FROM THE TRANSLATOR'S PREFACB.

"The present seems an opportune moment for presenting this monograph in an English dress. The subject of treatment with Ions is one which Professor Leduc has made peculiarly his own. He is a distinguished pioneer in an unexplored country, and in this little book are presented the results of many of his investigations."

Large Crown 8vo., 80 pp., cloth. 
ENTOMOLOGY. With Special Reference to its Biological and Economic Aspects. By Justus Watson Folsom, D.Sc. (Harvard), Instructor in Entomology in the University of Illinois.

"On the whole we have nothing but praise for this book."-Professor CARPENTER in the Irish Naturalist.

“. . Fills a place in entomological literature which has not previously been occupied. . This is one of the most interesting books on Entomology in general which has been published for some years."-Journal of the Royal Horticultural Society.

One Demy 8vo. volume of 490 pp., with 5 Plates (1 coloured) and 300 Figures in the Text, cloth, price 14s. net.

\section{A MANUAL OF CLINICAL CHEMISTRY, MICROSCOPY,} AND BACTERIOLOGY. By Dr. M. KLopstock and Dr. A. Kowarsky. Only authorized translation by Thew Wright, M.D., Buffalo, N.Y.

This manual is used by those who take part in the course of Clinical Chemiatry, Microscopy, and Bacteriology held in the "Institut für Medizinische Diagnostik" in Berlin.

As the book is intended especially for practitioners, it has been assumed that the reader has an elementary, chemical, and bacteriological education. The needs of daily practice have been especially considered in the choice of the methods of examination. Wherever it has bcen possible, the simplest and quickest methods have been chosen.

Size, $7 \frac{1}{3}$ in. by $5 \frac{1}{2}$ in. Over 300 pp., bound in flexible cloth, with 70 Ilustrations, 30 of which are printed in several colours, price $8 \mathrm{~s}$. net.

\section{ELECTRICITY IN MEDICINE. By Dr. W. H. GuILlEMINoT,} Paris. A Text-Book for Students and Medical Practitioners. Only authorized translation by W. Deane Butcher, M.R.C.S., Surgeon to the London Skin Hospital.

"A work which is at once a model of exposition and a storehouse of information, useful alike to the student and practitioner."-Treatment.

"Among recent text-books on this subject, none can be recommended with greater confidence than that of Dr. Guilleminot."-Scottish Medical and Surgical Journal.

One Demy 8vo. volume, of over $600 \mathrm{pp}$., with 79 Illustrations in the Text and 8 Plates in Colours, price 17s. net.

HYPNOTISM, OR SUGGESTION AND PSYCHOTHERAPY. A Study of the Psychological, Psycho-physiological, and Therapeutic Aspects of Hypnotism. By Dr. (Med.) August Forel, Dr. Phil. (h.c.) et Jur. (h.c.), Chigny, Switzerland; formerly Professor of Psychiatry and Director of the Provincial Lunatic Asylum, Ziirich. Translated by H. W. Armit, M.R.C.S., L.R.C.P., from the fifth (German) Edition.

"It is undeniable that study of hypnotic phenomena has added very greatly to our knowledge of morbid mentality, and that as a guide to the student of this branch of investigation no more fitting book could be chosen than this of the distinguished exponent of the Nancy School. Dr. Armit is therefore ... to be thanked for his able and painstaking translation."-British Medical Journal.

One Large Crown 8vo. volume of 382 pp., cloth, price 7s. 6d. net. 


\section{THE EFFECTS OF TROPICAL LIGHT ON WHITE MEN.}

By Major Chas. E. Woodruff, A.M., M.D., Surgeon United States Army.

"The book is one specially for anthropologists, but it will interest all those who are living in the tropics, where it will be welcomed."-Lancet.

"Major Woodruff's book deserves the attention of all who are interested in questions of tropical hygiene."-Le Radium.

One Demy 8vo. volume of 358 pp., cloth, price 10s. 6d. net.

\section{RADIOTHERAPY AND ITS APPLICATION TO SKIN DIS-}

EASES. By J. Belot, M.D. Paris, with a Preface by L. Broce, M.D., of Paris. Only authorized translation into the English Language by W. Deane Butcher, M.R.C.S. Eng., etc.

"In reviewing the first French edition of this work, we had great pleasure in recording our unqualified appreciation of its high scientific merits. A closer and more detailed study of the English translation has only tended to confirm us in our good opinion of its practical importance to all engaged or interested in the subject of radiutherapy."

"... It is without exception the best work on Radiotherapy in any language."Archives of the Roentgen Ray.

One Royal 8vo. volume, with 13 Plates and 28 Illustrations in the Text, 464 pp., cloth, price 178. net.

LIGHT ENERGY. Its Physics, Physiological Action, and Therapeutic Applications. By M. A. Cleaves, M.D., Fellow of the New York Academy of Medicine; Fellow of the American Electro-Therapentic Association.

"As a work of reference it should prove useful. ... There is a remarkably gond index to the book, which certainly is a mine of information."-Bvitish Medical Journal.

"This treatise on Light Energy, its physics, physiologicul action, and therapeutic applications, is the first systematic text-book on the subject which has yet been pub. lished. The work should prove of great value to all those specially interested in photo. t],erapy." - British Journal of Dermatology.

In one Royal $8 \mathrm{vo}$. volume of $827 \mathrm{pp}$., with numerous Illustrations in the Text and a Frontispiece in Colours. Price, cloth, 21s. net; or in Half Leather, 25s. net.

\section{ELEMENTS OF GENERAL RADIOTHERAPY FOR PRAC-}

TITIONERS. By Dr. Leopold Freund, Vienna. Unly authorized English translation by G. H. Lancashrre, M.D. Brux., M.R.C.S. Eng., and L.R.C.P. Lond., Assistant Physician to the Manchester and Salford Hospital for Skin Diseases. Including "Notes on Instrumentation" (with numerous Illustrations). By CLARence A. Wright, F.R.C.S.E., F.F.P.S.G., etc.

The work contains 834 References, a feature which renders it of the utmost usefulness to all interested in the subject of Radiotherapy.

In one Royal 8vo. volume of $597 \mathrm{pp}$., profusely Illustrated. Price in Cloth binding 21s. net; in Half Leather, 25s. net.

- Descriptive Catalogues sent on application. 

UNIVERSITY OF CALIFORNIA MEDICAL SCHOOL LIBRARY

THIS BOOK IS DUE ON THE LAST DATE STAMPED BELOW 


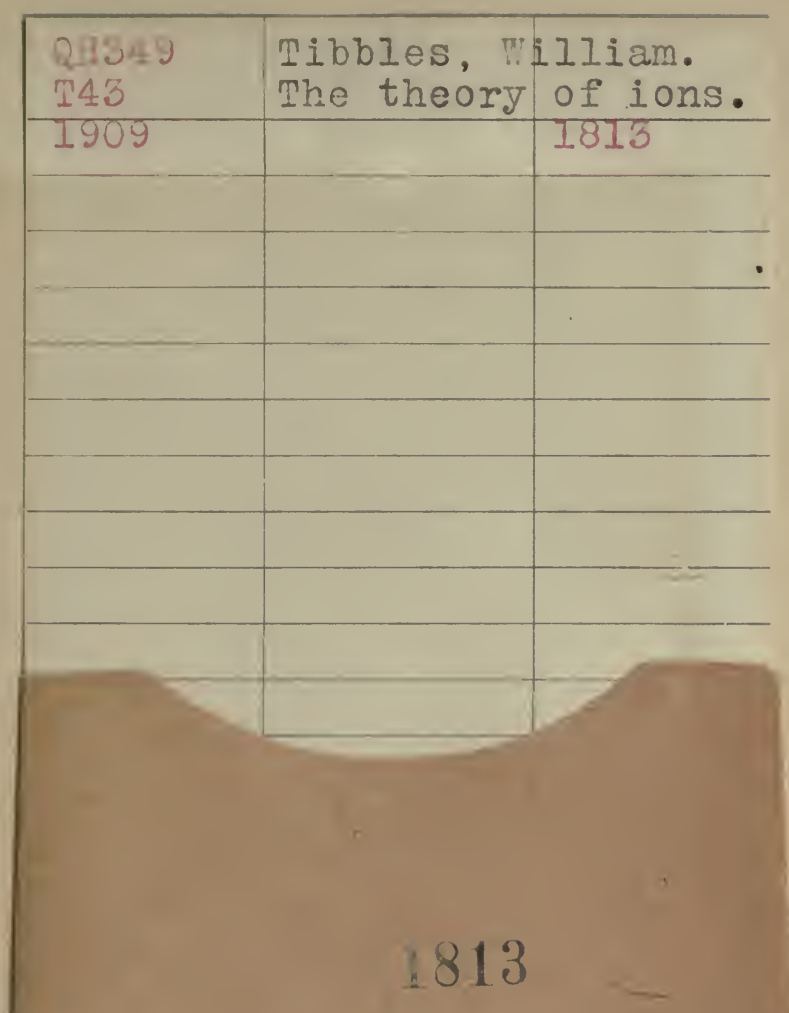

University of California Medical School Library 
4.

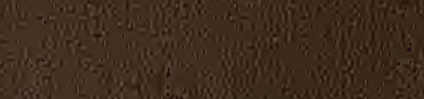
Shond

s. 